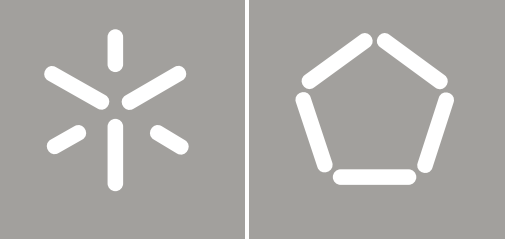

Universidade do Minho

Escola de Engenharia

Hugo Daniel Abreu Peixoto

Steps towards Interoperability in Healthcare Environment

PhD Thesis

PhD program in Biomedical Engineering / Medical Informatics

Work developed under the supervision of Professor Doctor António Carlos Abelha

Professor Doctor Manuel Filipe Santos 


\section{Declaração}

Nome: Hugo Daniel Abreu Peixoto

Endereço electrónico: hpeixoto@di.uminho.pt Telefone: 255714001

Número do Bilhete de Identidade: 12802839

Título da Tese de Doutoramento :

Steps towards Interoperability in Healthcare Environment

Orientador(es):

Professor Doutor António Carlos Abelha

Professor Doutor Manuel Filipe Santos

Ano de conclusão:

Ramo de Conhecimento do Doutoramento:

Programa Doutoral em Engenharia Biomédica, Informática Médica.

DE ACORDO COM A LEGISLAÇÃO EM VIGOR, NÃO É PERMITIDA A REPRODUÇÃO DE QUALQUER PARTE DESTA TESE/TRABALHO.

Universidade do Minho, /----

Assinatura: 
'A person who never made a mistake never tried anything new.'

Albert Einstein (1879-1955). German theoretical physicist, mathematical and humanist that formulated the Theory of Relativity. 



\section{Acknowledgements}

Over the last few years during the development of this work I had the pleasure and opportunity to establish contact with several persons from distinct areas such as Healthcare and Informatics.

It would be a delicate task to enumerate all those friends that helped me and contributed to the conclusion of this work, although and taking the risk to miss someone really important I would like to dedicate the next lines to special persons that I really need to thank. My first words go to my two supervisors, for all their patience and dedication to my work and problems, Professor António Abelha and Professor Filipe Santos, without their time and advices this work would not be possible. Alongside, I would also like to express my best regards to Professor José Machado and Professor José Neves for all their work during my University trainning and for granting me an one life opportunity working at Centro Hospitalar do Tâmega e Sousa. This opportunity would also not be possible without the help of two great persons that lead me through the hard task of the first job and all its difficulties, namely Dra. Lúcia Cerqueira and António Correia. To the second one I would also like to thank for all the good advices and ideas that contributed to the work presented. For Eng. Jorge Branco, Eng. Bruno Marinho and Fernando Coelho I would like to thank the technical knowledge and friendship.

To my second family, Luís, Marcos, Márcio and Rui, you have made the last few years easier with your friendship and love. For all the plays and laughs that made my bad moments a lot better.

I would also like to point out my parents strength, Manuela and Carlos, and sister, Cláudia, without their support this work was impossible to achieve. My family was an important help and an inexhaustible support when the thoughts were negative.

Finally a word to my life companion, Ana, for all the time I did not dedicate to her, for all the love, support and knowledge provided along the pathway. 



\title{
Steps towards Interoperability in Healthcare Environment
}

\begin{abstract}
Healthcare units have complex Information Systems (IS) made up from heterogeneous data sources, which speak different languages and with different objectives. Nevertheless, all these sources have indeed important information that can contribute in an active way to provide a healthcare system of excellence. The evolution that has been noticed in Health IS has promoted the development of new methodologies and tools that are intended to solve this complicated problem. In this manner, one of the main paradigms that arises is the interoperability among systems and its capability to allow a general and simplified access to relevant information. Another aspect that should be kept in mind, given the constrains of the global economic situation, is the reduction in the investment in national healthcare systems. This thesis is based on a set of studies performed at the Centro Hospitalar do Tâmega e Sousa (CHTS) in which the main goals are promoting an improvement in the relation patient-hospital, having in consideration the reduction of implementation costs, but preserving the quality of information. The last one should be accessible everywhere and at anytime to help with clinical decision and, in the future, be available for clinical studies through data computationally interpretable. To do so, an Electronic Semantic Health Record was formalized and implemented, with the help of the clinical staff, which collects all the information considered important and relevant. This Health Record was delivered through a platform for the distribution and archive of clinical information, named Agency for the Integration, Diffusion and Archive (AIDA), which is supported by intelligent agents that treat data in an ex-
\end{abstract}


haustive and structured way. To test the proposed model and system and in order to strengthen the relation between the patient and the hospital, an appointment alert system based on SMS and electronic mail was developed, which allowed the reduction of non-programmed misses and that provided a decrease of costs by better re-distributed appointment schedules, and allocate human resources and physical spaces in a more effective manner. Finally, to reduce stopping periods of systems and to promote the user's confidence on Information Systems, an open-source tool was developed that enables the scheduling of preventive actions according to a mathematical model. These tools allowed for a continuous improvement of systems and are currently well accepted by clinicians and Information Technologies (IT) specialists inside the healthcare unit, proving in real clinical situation the effectiveness and usability of the model. 


\section{Caminhos para a Interoperabilidade em Cuidados de Saúde}

\section{Resumo}

As unidades de saúde possuem Sistemas de Informação (SI) complexos, compostos por fontes de dados heterógeneas com objectivos distintos. Porém, toda a informação é importante e pode contribuir de forma ativa para a prestação de cuidados de saúde de excelência. Com a evolução dos SI na Saúde novas metodologias têm sido desenvolvidas com o intuito de solucionar este problema complicado. Nesta perspectiva, um dos principais paradigmas que se coloca é a interoperabilidade entre sistemas e a sua capacidade para permitir um acesso simples a informação relevante. Outro factor relevante relaciona-se com os constrangimentos financeiros que toda a economia global atravessa e que se reflete numa diminuição no investimento nos serviços nacionais de saúde. Esta tese tem como base um conjunto de estudos realizados no Centro Hospitalar do Tâmega e Sousa cujos principais objetivos se prendem com um esforço orientado para a melhoria da relação paciente-hospital, tendo em conta a redução de custos de implementação, mas garantindo sobretudo a qualidade de informação. Esta deverá estar disponível em qualquer lugar e a qualquer altura para o auxílio à decisão clínica e, em última instância, disponível para estudos clínicos através de dados interpretáveis computacionalmente. Para tal, recorreu-se à ajuda de pessoal clínico para a implementação de um Processo Clínico Electrónico Semântico que recolhe toda a informação considerada relevante. Este Processo Clínico foi potenciado através de uma plataforma para a distribuição e arquivo de informação clínica, denominada de Agência para a Interoperação, Difusão e Arquivo (AIDA), baseada em agentes inteligentes que tratam os dados de forma 
estruturada. Para testar o modelo e de forma a fortalecer a relação paciente-hospital foi desenvolvido um sistema de alertas para consulta via mensagens escritas e e-mail, que diminuiu o número de faltas não programadas, proporcionando uma redução de custos através de uma redistribuição dos tempos de consulta alocando recursos humanos e físicos de forma mais eficaz. Por fim, com vista à redução dos tempos de paragem de sistemas, e potenciar a confiança dos utilizadores nos mesmos, foi desenvolvida uma ferramenta baseada em tecnologia open-source que permite o agendamento de intervenções preventivas de acordo com um modelo matemático. Esta ferramenta proporcionou uma melhoria contínua dos sistemas e está globalmente aceite por clínicos e especialistas de Tecnologias de Informação (TI), provando em situações clínicas reais a usabilidade e eficácia do modelo. 


\section{Contents}

Abstract

Resumo

IX

Acronyms

XVII

List of Tables

XXI

List of Figures

XXIII

1 Introduction 1

1.1 Health Information Systems . . . . . . . . . . . . . . . . . 4

1.2 Information Systems vs Economic Crises . . . . . . . . . . . . . . 8

1.3 Motivation and Objectives . . . . . . . . . . . . . . . 9

1.4 Thesis Organization . . . . . . . . . . . . . . . . . . . . . . . 11

1.5 Publications . . . . . . . . . . . . . . . . . . 12

2 Background

2.1 Healthcare Information Systems . . . . . . . . . . . . . . . . 17 
2.1.1 HIS Projects. . . . . . . . . . . . . . 25

2.2 Interoperability . . . . . . . . . . . . . . . . . . . . . 30

2.2.1 Technical Standards for Interoberability . . . . . . . . . . . 34

2.2 .2 Interoperability Impact . . . . . . . . . . . . . . 43

2.2 .3 Interoperability Levels . . . . . . . . . . . . . . . . . 45

2.2.4 Interoperability Costs . . . . . . . . . . . . . . . . 46

2.2.5 Semantic Interoperability . . . . . . . . . . . . . . . 47

2.3 Electronic Health Record . . . . . . . . . . . . . . . . . . . . . . . . . 49

2.3.1 Electronic Health Record Pros and Cons . . . . . . . . . . . . 50

2.4 Interoperability and Electronic Health Record Projects . . . . . . . . 52

2.4 .1 openEHR . . . . . . . . . . . . . . . . 52

2.4 .2 Linked2Safety . . . . . . . . . . . . . . 55

2.4.3 MobiGuide ....................... 58

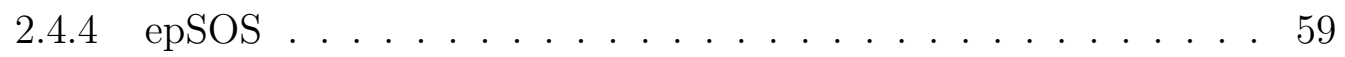

2.4.5 SemanticHealthNet . . . . . . . . . . . . . 62

2.4 .6 CDA HL7 . . . . . . . . . . . . . . . . . . 64

2.5 Open-Source Software in Healthcare . . . . . . . . . . . . . 66

$\begin{array}{lll}3 & \text { Results } & 71\end{array}$

3.1 Study I - Semantic Interoperability and Health Records . . . . . . . . 75

$3.1 .1 \quad$ Abstract . . . . . . . . . . . . . . 77

3.1 .2 Introduction . . . . . . . . . . . . . 77

3.1 .3 Implementation . . . . . . . . . . . . . . . 78 
3.1.4 Conclusions . . . . . . . . . . . . . . . . . . 78

3.1.5 References ....................... . . 79

3.2 Study II - AASYS - Appointment Alert System . . . . . . . . . . . . 81

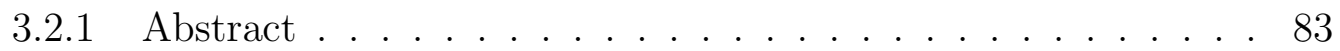

3.2 .2 Introduction . . . . . . . . . . . . . . . 83

3.2 .3 Information Systems . . . . . . . . . . . . . 85

3.2 .4 Open Source Software . . . . . . . . . . . . . 87

3.2.5 AASYS Overview . . . . . . . . . . . . . . . . 88

3.2.6 Results and Discussion . . . . . . . . . . . . . . . 91

3.2.7 Conclusions . . . . . . . . . . . . . . . . . . . 93

3.2.8 References . . . . . . . . . . . . . . . . . . 93

3.3 Study III - ScheduleIT . . . . . . . . . . . . . . . . . . . . 97

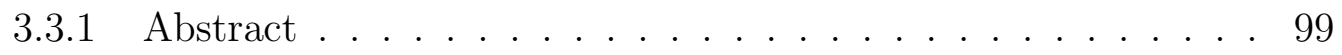

3.3.2 Introduction . . . . . . . . . . . . . . . . 99

3.3.3 Open-Source Software in Healthcare . . . . . . . . . . . . . . . 101

3.3.4 Preventive Actions . . . . . . . . . . . . . . . . . 103

3.3.5 ScheduleIT . . . . . . . . . . . . . 107

3.3.6 Conclusions . . . . . . . . . . . . . . . . . . 109

3.3.7 References . . . . . . . . . . . . . . . . 110

3.4 Study IV - Intelligence in Interoperability with AIDA . . . . . . . . . 113

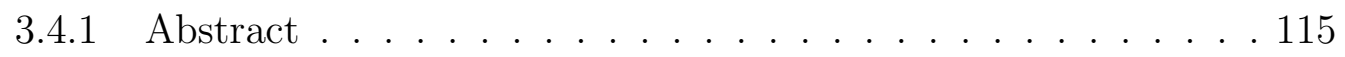

3.4 .2 Introduction . . . . . . . . . . . . . . . . . 115 
3.4 .3 Interoperability . . . . . . . . . . . . . . . 117

3.4.4 Semantic Interoperability . . . . . . . . . . . . . . . . 119

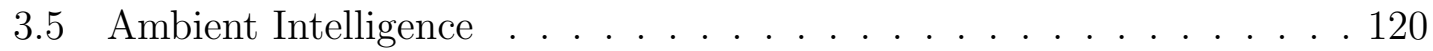

3.6 Implementation . . . . . . . . . . . . . . . . . . . . . . 121

3.6.1 AIDA framework . . . . . . . . . . . . . . . 121

3.6.2 Electronic Semantic Health Record . . . . . . . . . . . . . . 125

3.6.3 Conclusions . . . . . . . . . . . . . . . . . . . . . 128

3.6.4 References . . . . . . . . . . . . . . . . 128

4 Discussion, Conclusions and Future Work 131

4.1 Discussion . . . . . . . . . . . . . . . . . . . 133

4.2 Conclusions . . . . . . . . . . . . . . . . . . . . . . . . 138

4.3 Summary of Thesis Achievements . . . . . . . . . . . . . . . . . 140

4.4 Future Work . . . . . . . . . . . . . . . . . . . . . . . . . 141

$\begin{array}{ll}\text { Bibliography } & 143\end{array}$

$\begin{array}{ll}\text { Appendices } & 151\end{array}$

A Interoperability and the Semantic Health Record (in Portuguese) 153

A.1 Abstract (in Portuguese) . . . . . . . . . . . . . . . 155

A.2 Keywords (in Portuguese) . . . . . . . . . . . . . . 155

A.3 Introduction (in Portuguese) . . . . . . . . . . . . . . 155

A.4 Semantic Web vs Medical Semantic (in Portuguese) . . . . . . . . . 157 
A.5 Health Record (in Portuguese) . . . . . . . . . . . . . . . . . . 158

A.6 Electronic Health Record (in Portuguese) . . . . . . . . . . . . . . . . 159

A.6.1 EHR features (in Portuguese) . . . . . . . . . . . . 159

A.6.2 EHR requirements (in Portuguese) . . . . . . . . . . 160

A.6.3 EHR advantages (in Portuguese) . . . . . . . . . . . 161

A.7 Agency for Interoperation, Diffusion and Archive (in Portuguese) . . 162

A.7.1 AIDA-PCE (in Portuguese) . . . . . . . . . . . . 163

A.8 Goals (in Portuguese) . . . . . . . . . . . . . . . 164

A.9 Methodologies (in Portuguese) . . . . . . . . . . . . . . 165

A.9.1 XML construction (in Portuguese) . . . . . . . . . 165

A.9.2 Semantic Health Record (in Portuguese) . . . . . . . . . . . 167

A.10 Results (in Portuguese) . . . . . . . . . . . . . . . . . . 169

A.11 Conclusions (in Portuguese) . . . . . . . . . . . . . . 170

A.12 Acknowledgements (in Portuguese) . . . . . . . . . . . . . . 170

A.13 References (in Portuguese) . . . . . . . . . . . . . . . . . 171

B Modelling intelligent behaviours in multi-agent based HL7 services 175

B.1 Abstract . . . . . . . . . . . . . . . . 177

B.2 Introduction . . . . . . . . . . . . . . . . . . 177

B.3 Health Level Seven Protocol . . . . . . . . . . . . . . . . . . . . . 179

B.4 AIDA Platform and HL7 Services . . . . . . . . . . . . 180

B.5 HL7 Activity study . . . . . . . . . . . . . . . . . . . . 184

B.6 Modelling approaches . . . . . . . . . . . . . . . . 186 
B.7 Embedding adaptive learning behaviours . . . . . . . . . . . . . . 189

B.8 Conclusion . . . . . . . . . . . . . . . . . . . . . . . . . 190

B.9 Acknowledgements . . . . . . . . . . . . . . . . . . . . . . 192

B.10 References . . . . . . . . . . . . . . . . . . . 192 


\section{Acronyms}

AASYS Appointment Alert System

AIDA Agency for Integration, Diffusion and Archive

AIM Association pour les Applications de l'Informatique en Médecine

AKMI Austrian Working Group in Medical Informatics

CDA Clinical Document Architecture

CHTS Centro Hospitalar Tâmega e Sousa

CITL Center for Information Technology and Leadership

CS Computer Science

DCMI Dublin Core Metadata Initiative

DSS Decision Support Systems

EFMI European Federation for Medical Informatics

EHR Electronic Health Record

ESHR Electronic Semantic Health Record

GIA Grupo de Inteligência Artificial

GMDS German Society Medical Computer Science, Biometry and Epidemiology

HDF HL7 Development Framework

HIPF Health Informatics Profiling Framework 
HIS Health Information Systems

HIT Health Information Technologies

HL7 Health Level Seven

HPA Hospital Padre Américo

HS Health System

ICNP International Classification for Nursing Practice

ICT Information and Communication Technologies

IEEE Institute of Electrical and Electronics Engineers

IS Information Systems

IT Information Technologies

JCI Join Commission International

MIM Belgium Society for Medical Informatics

MIS Management Information System

NHS National Health Service

NLM National Library of Medicine

OCG Austrian Computer Society

OECD Organization for Economic Cooperation and Development

OGBMT Austrian Society for Biomedical Engineering

PACS Picture Archive and Communication System

PAQC Patient Access to Quality Care

PCR Patient Clinical Record

PN Participating Nation 
PR Patient Record

RDF Resource Description Framework

RIM HL7 Reference Information Model

RPO Recovery Point Objective

RTO Recovery Time Objective

SBIS Sociedade Brasileira de Informática em Saúde

SHARP Strategic Health IT Advanced Research Projects

SI Sistemas de Informação

SMS Short Message Service

SOA Service-Oriented Architectures

UMLS Unified Medical Language System

WHO World Health Organization

XML eXtende Markup Language 



\section{List of Tables}

2.1 The seven interoperability levels, designation and meaning (adapted from [Mykkanen and Tuomainen, 2008]). . . . . . . . . . . . . 45

2.2 Health Information and Interoperability Taxonomy (adapted from $[$ Middleton, 2004]) . . . . . . . . . . . . . . 4 46

3.1 Total of schedule periods . . . . . . . . . . . . . . . . . . . 91

3.2 Criticality level applied to Information Systems. . . . . . . . . . . . . 105

3.3 RTO and RPO levels applied to Information Systems. . . . . . . . . . 105

3.4 Week interval determination according to threshold level. . . . . . . . 107

A.1 Acesso a relatórios. . . . . . . . . . . . . . . . . . . . 169

B.1 K-Means Clustering Centres - RIS Timespan Between HL7 Messages - Study A. . . . . . . . . . . . . . . . . . 187

B.2 Number of Cases in each Cluster - Study A . . . . . . . . . . . . . . 188

B.3 K-Means Clustering Centres - RIS Timespan Between HL7 Messages Between 8 A.M. and 8 P.M - Study B . . . . . . . . . . . . 188

B.4 Number of Cases in each Cluster - Study B . . . . . . . . . . . . . . 188

B.5 K-Means Clustering Centres - RIS Timespan Between HL7 Messages Between 21 P.M. and 7 A.M - Study C . . . . . . . . . . . . . . 189 
B.6 Number of Cases in each Cluster - Study C . . . . . . . . . . . . . . 189 


\section{List of Figures}

1.1 Interdisciplinary fields of Medical Informatics (adapted from [Yu, 2003]). 3

1.2 Centro Hospitalar do Tâmega e Sousa E.P.E.. . . . . . . . . . . . 8

1.3 Opportunities and implementations for ten year time period (adapted from $[$ Sullivan, 2009]). . . . . . . . . . . . . . . . . . 9

2.1 The Information Process in Health Information Systems (adapted from $[W H O, 1988]) \ldots \ldots \ldots \ldots \ldots$

2.2 The Information Systems workflow and model for success (adapted from $[$ Delone and Mclean, 2003]). . . . . . . . . . . . . . . 19

2.3 The query-translation strategy for heterogeneous data- base integration (adapted from $[$ Sujansky, 2001]) . . . . . . . . . . . 33

2.4 Operation report on XML (adapted from $[$ Seals, 2000]). . . . . . . . . 40

2.5 The OSI Model (adapted from $[$ HL7, 2010]). . . . . . . . . . . . . 42

2.6 The relationship of the formal artefacts of openEHR (adapted from $[$ openEHR, 2007]). . . . . . . . . . . . . . . . 5 54

2.7 EHR4CR conceptual overview (adapted from [EHR4CR, 2011]). . . . 57

2.8 epSOS Basic Architecture (adapted from $[\mathrm{epSoS}, 2012 \mathrm{~b}]$ ). . . . . . . . 60

2.9 European Countries in Pilot phase I (adapted from [epSoS, 2012a]). . 62 
2.10 Infostructure for semantic interoperability resources (adapted from $[$ SemanticHealthNet, 2011]). . . . . . . . . . . . 63

2.11 Major components of a Clinical Document Architecture document (adapted from [Dolin et al., 2006]). . . . . . . . . . . 65

2.12 CDA - An example of allergies and adverse reaction (adapted from [Dolin et al., 2006]) . . . . . . . . . . . . . . . 66

3.1 Overview of the integration schema. . . . . . . . . . . . 86

3.2 Global Workflow. . . . . . . . . . . . . . . . . . . 90

3.3 Number of canceled (a) and missed (b) appointments. . . . . . . . . . 92

3.4 ScheduleIT web interface for programed actions for the selected day. . 108

3.5 AIDA- Agency for Integration Diffusion and Archive. . . . . . . . . . 124

A.1 AIDA. . . . . . . . . . . . . . . . . . 162

A.2 Ficheiro XML. . . . . . . . . . . . . . . . 166

A.3 Workflow. . . . . . . . . . . . . . . . . 166

A.4 Processo Clínico Semântico. . . . . . . . . . . . . . . . . 168

B.1 Study of HL7 communications sent to the RIS service depending the time of the day. . . . . . . . . . . . . . . . . . . 185

B.2 Study of HL7 communications received by the WAP service depending the time of the day. . . . . . . . . . . . . . . . . 185 
Chapter 1

\section{Introduction}



Medical Informatics has become an emergent field over the last decades and consequently, new technologies have been build in order to support its developments on the improvement of care giving [Wolfram, 1995]. Medical informatics can even be considered as an interdisciplinary research field that is uniquely placed at the intersection of several fields:

- Computer Science;

- Biology;

- Physics;

- Mathematics;

- Engineering;

- Medical Sciences and Healthcare.

Figure 1.1 shows a graphical representation of cited fields provided by the European Medical Informatics Association [Yu, 2003].

Medical Informatics provides new methodologies for global cooperation, network computing, share and access to clinical information. Information Systems ensure physicians, not only the opportunity to have access to medical resources widely

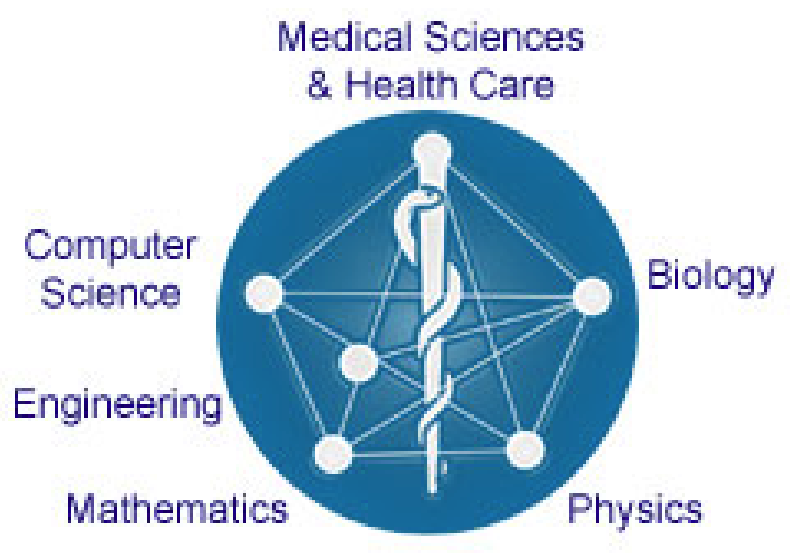

Figure 1.1: Interdisciplinary fields of Medical Informatics (adapted from [Yu, 2003]). 
spread, but also the chance to be part of their construction [Bodenreider, 1998, Neves et al., 1999].

\section{$1.1 \quad$ Health Information Systems}

Nowadays, exchange and share of clinical information among Information Systems (IS) is becoming one of the main ways to improve the quality in the services provided to patients. Nevertheless, one of the principal obstacles to accomplish this goal is the high number of heterogeneous information sources arising inside a healthcare facility, such as medical applications and software, medical equipment and even clinical staff self-knowledge introduced as needed in the Patient Clinical Record (PCR).

Definition 1.1 (Information systems) A technologically implemented medium for recording, storing, and disseminating linguistic expressions, as well as for drawing conclusions from such expressions [Langefors and Sundgren, 1975].

In a healthcare unit it is easy to step into proprietary applications from a wide range of providers, each one talking its own language and its own philosophy and implementation method, treating information according their own thoughts and workflows. This increases complexity to Health Information Systems (HIS), which depends not only on the number of systems but also on the number of providers. Building up all the information and make it readable by physicians has become a high important task.

Definition 1.2 (Health Information Systems) Integrated computer-assisted systems to store, manipulate, and retrieve healthcare administrative and clinical data [MeSH, 1987]. 
Definition 1.3 (Information Systems Applications) Integrated group of computer programs and associated data that support end-users in carrying out one or more of their business functions [Ferrand and Lay, 1994].

Every day in clinical practice, decisions are made that can save human lives. Clinical decisions are taken based on medical records made electronically or by hand in paper, medical examinations, and physical evaluations having the close contact with the patient. Not only the clinical diagnostic is produced taking in consideration all the information available and considered useful by physicians, but also the drug prescription or pathology identification.

Information is spread through healthcare units and it is almost impossible to avoid the creation of information silos. These silos can lead to data loss or even worst can restrict access to important information that could change or interpose clinical diagnosis. Drug allergies or examination reports that the doctor could not have access to may lead to bad patient treatment and medical errors based on incomplete or mistaken information. Interoperability is one of the keys to overlap these constraints and promotes better and easier access to information [Peixoto et al., 2010].

Definition 1.4 (Interoperability) Interoperability is not a closed concept for which a line can be drawn. Instead, interoperability is a mean to achieve a goal, in the case of our industry, to advance the effective delivery of healthcare. For this to be achieved, systems must work together so that the distinctiveness of each system is apparent and can be harnessed by end users [HIMSS, 2005].

On one hand, Interoperability among systems is one common interest within scientific community and several works are being published every day, about the methodologies of implementation and the ways to achieve it. On the other hand, accomplishing such task requires hard work and it is not yet established the best or only way to reach full interoperability. 
Healthcare facilities can take advantages from Interoperability, and homogeneity among Information Systems can lead to time reduction in diagnostic and appointments, since physicians have access to relevant information when and where they need it the most. In addition, it also provides better information quality by single patient identification and correct association between all the information systems. In the end interoperability may help decreasing medical errors on treatments based on reliable information and results [Miranda et al., 2009].

Over the last decade, the Artificial Intelligence Group, in the Informatics Department at the University of Minho, has dedicated their studies into building a platform for Interoperability, Diffusion and Archive called AIDA [Abelha et al., 2002]. Their efforts allowed that four major healthcare facilities in Portugal could benefit from an interoperability platform that covers all the main areas and it is becoming an emergent tool in Healthcare Information Systems in Portugal, such as:

- Centro Hospitalar do Tâmega e Sousa - E.P.E.;

- Centro Hospitalar do Porto;

- Centro Hospitalar do Alto Ave;

- Unidade Local de Saúde do Norte Alentejano - E.P.E.;

- Hospital da Santa Casa da Misericórdia de Vila Verde.

The team involved in this work is developing scientific procedures in distinct areas such as [Miranda et al., 2009], [Peixoto et al., 2012c], [Abelha et al., 2002], [Abelha, 2004] :

- Electronic Health Record (EHR); 
- Information Quality;

- Knowledge Representation;

- Decision Support Systems (DSS);

- Artificial Intelligence and Ambient Intelligence; and

- Interoperability.

Some of these projects and implementations have been hosted by the Centro Hospitalar Tâmega e Sousa E.P.E. (CHTS) and took benefit from the cooperation and help provided by all the collaborators. CHTS is a major hospital build up by two facilities (Figure 1.2): the larger one is Hospital Padre Américo located in the city of Penafiel, built in 2001 and that hosts most of the patients; the second one, Hospital de São Gonçalo is located in Amarante and is a small and older building that fills the basic needs of the city and rounding localities population. Both buildings are located in the north of Portugal and together they cover over 500.000 patients from several regions near Vale do Sousa. Indeed, the overall population led to 247.003 appointments in 2010 at a pace of almost 1.000 every day, over 70 physicians per day as well as 30 administrative helpers [Peixoto et al., 2012b]. All these numbers show that CHTS is a good test-tube for this project, and having users to test all the systems along the way made things easier to develop and deploy.

The main difference between this work and others in this area is to use present Interoperability levels to provide an Electronic Semantic Health Record (ESHR), in order to improve healthcare treatments and patient communication, and last but not least important a workflow to ensure reliability, scalability, security and performance over Information Systems. All the frameworks built during this project considered AIDA as the main base, but several implementation tasks were performed along the way to allow correct project flow. 


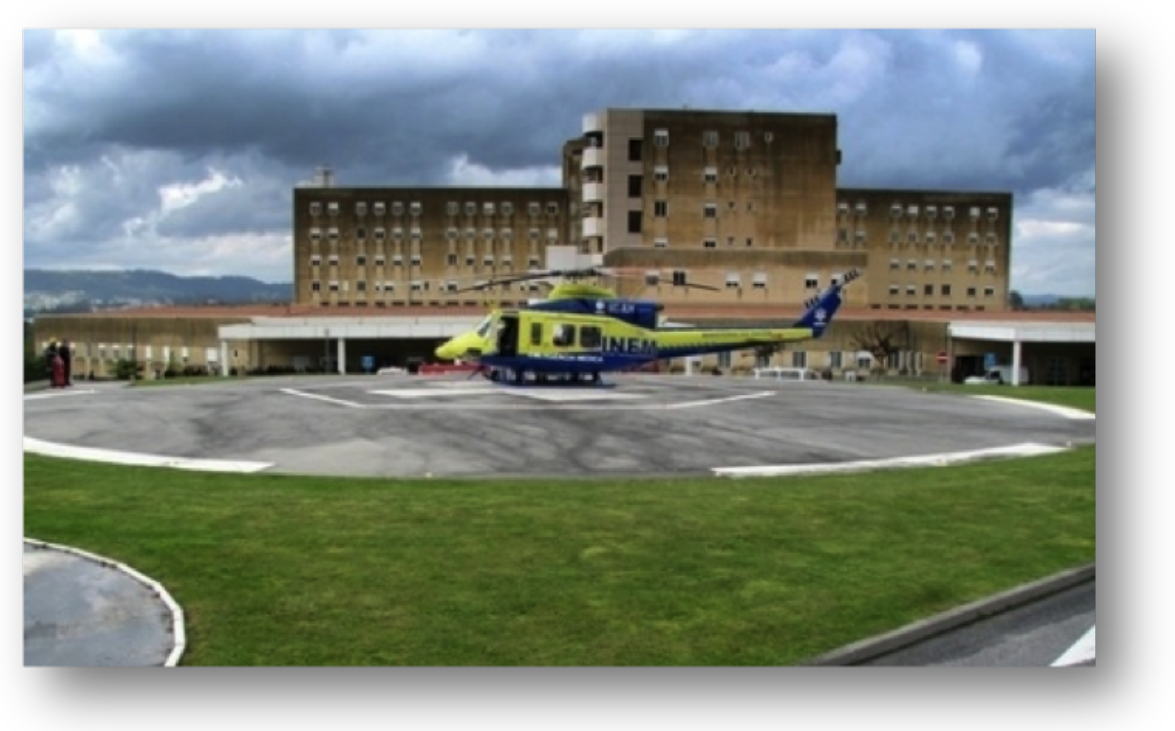

Figure 1.2: Centro Hospitalar do Tâmega e Sousa E.P.E..

\subsection{Information Systems vs Economic Crises}

The adoption of Information and Communication Technologies (ICT) is essential for modern healthcare delivery systems if they are to gain greater efficiency, reduce overall healthcare costs and improve patient safety. In recent years, the acquisition of computer technologies by healthcare organizations has increased substantially with the spending showing upward tendency placing the industry as one of the major consumer of ICT products and services [Sullivan, 2009].

The Health Information Technologies (HIT) adoption trend by healthcare organizations is unstoppable, however it is expected to be a backlash in view of the current financial crisis. Negative impact on the growth of the HIT industry is currently underway as hospitals and health systems are taking measured but deliberate action by delaying capital projects, cutting capital and operating budgets, and laying off workers [Sullivan, 2009].

Figure 1.3 shows the opportunities for a 10 years period of time of , considering pre 2005 until 2015. Initially, Information Technologies focused theirs goals on administrative systems; nowadays we are evolving from patient-centered systems to 


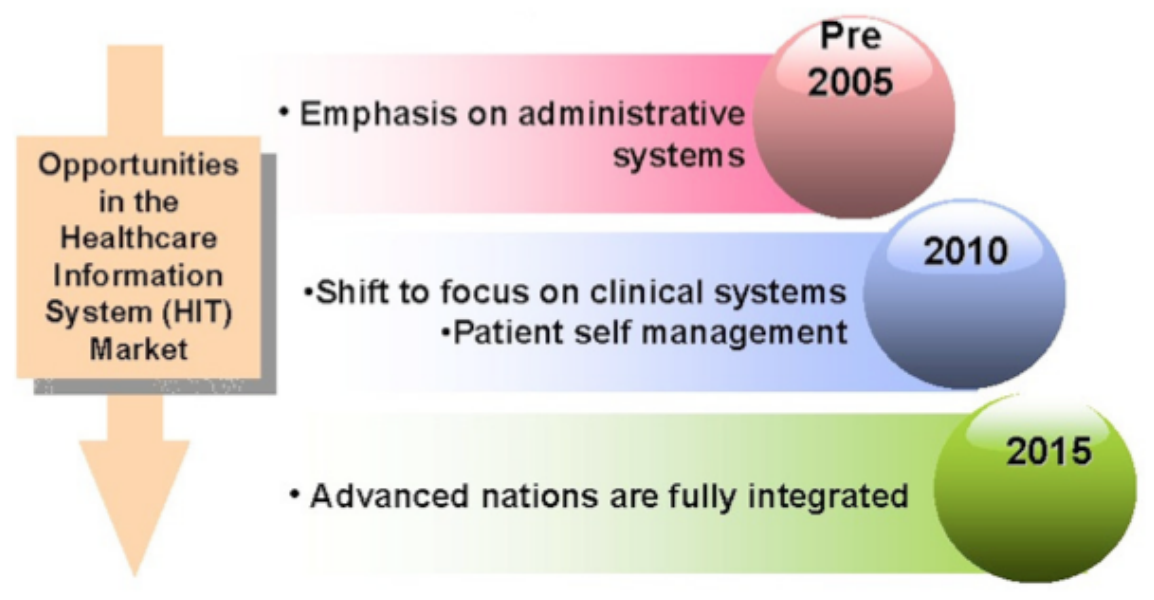

Figure 1.3: Opportunities and implementations for ten year time period (adapted from [Sullivan, 2009]).

advanced integration between nations, for example, European guidelines for interoperability [Sullivan, 2009].

Information technology in the healthcare industry is evolving from an administrative tool for billing and bookkeeping to a clinical tool for improving the quality and efficiency of healthcare, and the scope of information sharing is expanding beyond the walls of individual institutions.

Many of the European guidelines are sustained by Open-source software, which first perceived advantage is the fact that they are made available free or at a low cost, where developers should focus on sharing and complete systems in an open, widely spread and accessible way. Taken globally, several healthcare facilities with the same goals can share information and aims and fight together to improve sustainability for Health Information Systems in the Global Economic Crises [Sullivan, 2009].

\subsection{Motivation and Objectives}

Currently information exchange among people, companies and systems plays an essential role in society. In this paradigm, the organization of society depends 
upon a method of social and economic development where information, as a means of creating knowledge, plays a fundamental role in the production of wealth and contributes to the well being and quality of life of citizens. A Healthcare facility is not exception and has to adapt to constant advances in technologies and systems in order to produce knowledge by data and ensure quality treatment to patient. Over the last years HIS have become an important matter for government and boards of director through all facilities due not only to global economic crises but also to patient right to better health assistance.

This work results from four years of experiences lived inside a healthcare facility and all the outcomes were produced accordingly to goals and workflows established through meetings and brainstorms of a heterogeneous team composed by physicians, nurses, administrative crew, quality technicians and Information Technology (IT) specialists.

Since 2008, CHTS has been being evaluated in order to ensure International Accreditation from the Join Commission International (JCI). During these years Informatics Department has been called in order to provide specific changes, on one hand to the assess changes in the Patient Records (PR) namely to provide electronic support, and on the other hand to improve the relationship with the patient himself.

One of the major motivations was to mark CHTS as a leading innovation center where patients are treated with quality of information and physicians can perform their work without being concerned with technical and electronic concepts, spending more time on what is more important, the patient. One of the main purposes of this work is the analysis and development of Systems based on the Healthcare Information System of the CHTS and the main needs of its users. These systems should be interactive and user-friendly, and should become the basis for Decision Support Systems (DSS). Providing data source not only to physicians but also to computers and make spread data interpretable by machines and in the near future DSS it is also an important task to accomplish during this work [Peixoto et al., 2010]. 
The main questions behind this work are:

- Is it possible to improve Healthcare Information Systems in order to improve patient-unity relationship?

- Can Electronic Semantic Health Record overwhelm the current Electronic Health Record?

- Uptimes from servers can provide better or even reliable systems. How can Information Systems help improving uptimes according scalable, secure and performance of each institution needs?

- Can Open-source software provide an alternative to proprietary software?

\subsection{Thesis Organization}

The present thesis is divided in four chapters. Chapter 1 is a global introduction to the thesis in which the reader can find the most relevant subjects being studied and applied in the further chapters. Furthermore, the reader can also find in this first chapter the guidelines, motivation and main goals expected to be achieved.

The second chapter, Chapter 2, provides an extensive Literature Review over the related systems and technologies used to produce this work. Information Systems, Open-source software, Electronic Health Records and Interoperation frameworks are presented. Leading advantages and disadvantages of the systems are also exposed and studied in order to conduct the reader to the next chapter, where the main results from this work are presented. Therefore, Chapter 3 is divided in four parts called studies, each one representing an article presented to scientific approval whether in journals, book chapters or conference proceedings. An important part of this thesis relies on this chapter, where practical results, software and frameworks are presented. The first article presents the Electronic Semantic Health Record 
edited by Springer Boston in 2010 [Peixoto et al., 2010]. The next article refers to AASYS, an Appointment Alert System presented at the European Simulation and Modeling Conference in Guimarães, Portugal [Peixoto et al., 2012b]. Study number three presents a framework for scheduling preventive actions according all the needs called ScheduleIT. This study, edited by Elsevier was presented at the International Conference on Health and Social Care Information Systems and Technologies in Algarve Portugal in October 2012 [Peixoto et al., 2012a]. Finally the last study, study number four presents AIDA as an Agency for Interoperability and Artificial Intelligence [Peixoto et al., 2012c].

The last chapter, i.e. Chapter 4, is where a global discussion and main conclusions are presented, in order to assess whether the goals proposed in the first chapter were achieved. In this part, some reflections concerning the key topics of the research will be taken: exploiting the benefits provided by the interoperation and semantization of the EHR; how Open-source software can, in the current global economic situation, help healthcare providers to overcome financial issues; how Information Systems can help hospital-patient relationship; among others. This chapter will end with some final remarks and future directions.

\subsection{Publications}

During the reported work several outcomes were published and submitted to scientific evaluation with success.

- Three book chapters publications in Springer:

- Semantic Interoperability and Health Records - Hugo Peixoto, José Machado, José Neves and António Abelha, E-Health. In Hiroshi Takeda (Ed.), (Vol. 335, pp. 236-237): Springer Boston - 201, IFIP Advances in Information and Communication Technology, 2010. In ISI Web of Science; 
- Modelling Intelligent Behaviours in Multi-agent Based HL7 Services. Miguel Miranda, Gabriel Pontes, Pedro Gonçalves, Hugo Peixoto, Manuel Santos, António Abelha and José Machado, Computer and Information Science. In Roger Lee (Ed.), (Vol. 317, pp. 95-106): Springer Berlin / Heidelberg, Studies in Computational Intelligence, 2010. In ISI Web of Science, SCOPUS and DBLP - Appendice B; and

- Intelligence in Interoperability with AIDA - Hugo Peixoto, José Machado, António Abelha and Manuel Santos, 20th International Symposium on Methodologies for Intelligent Systems, 2012 World Intelligence Congress, Macau, Volume: 7661 (to be published by LNCS Springer).

- One Journal publication in Elsevier:

- ScheduleIT - Open-Source Preventive Actions Management Platform in Healthcare Information Systems - Hugo Peixoto, António Abelha, Manuel Santos and José Machado, Conference on ENTERprise Information Systems, International Conference on Health and Social Care Information Systems and Technologies, Portugal - 2012. Procedia Technology, Volume 5, Elsevier, 2012.

- Two International Conference Proceedings publications:

- Interoperabilidade e o Processo Clínico Semântico - Hugo Peixoto, José Machado and António Abelha, First European Workshop on Computing and ICT Professionalism (EWCIP), Santiago de Compostela, Spain, in ISI Web of Science, 2010. In ISI Web of Science - Appendice A; and

- AASYS - Appointment Alert System: An open-source-based software to improve show rates in a health care unity - Hugo Peixoto, José Machado , António Abelha, José Neves, Manuel Santos and António Correia, European Simulation and Modelling Conference, Guimarães, Portugal - 2011. In ISI Web of Science (To be indexed). 
- Previous publications on Decision Support Systems from the author:

- Computer-Aided Diagnosis in Brain Computed Tomography Screening Hugo Peixoto and Victor Alves, Advances in Data Mining. Applications and Theoretical Aspects. In Petra Perner (Ed.), LNCS, Vol. 5633, pp. 62-72: Springer Berlin / Heidelberg - 2009. In ISI Web of Science, SCOPUS and DBLP. 
Chapter 2

\section{Background}





\subsection{Healthcare Information Systems}

Early in 1984 Hurtubise defined Management Information System (MIS) as "a system that provides specific information support to the decision making process at each level on an organization" [Hurtubise, 1984]. MIS were defined and studied first than HIS; afterwards Heldenbein came up with a global approach for HIS which he defined as a "system" [Helfenbein, 1987]. Hence, like every other system, HIS has its own agents with organization and structure. Figure 2.1 presents the information workflow with data flows through six stages from raw inputs to information that can be used for decision making. HIS are part of a more global framework called the Health System (HS) which offers curative care, rehabilitative care, disease prevention, and health promotion services. HIS should allow the generation of the necessary information to every level of the organization.

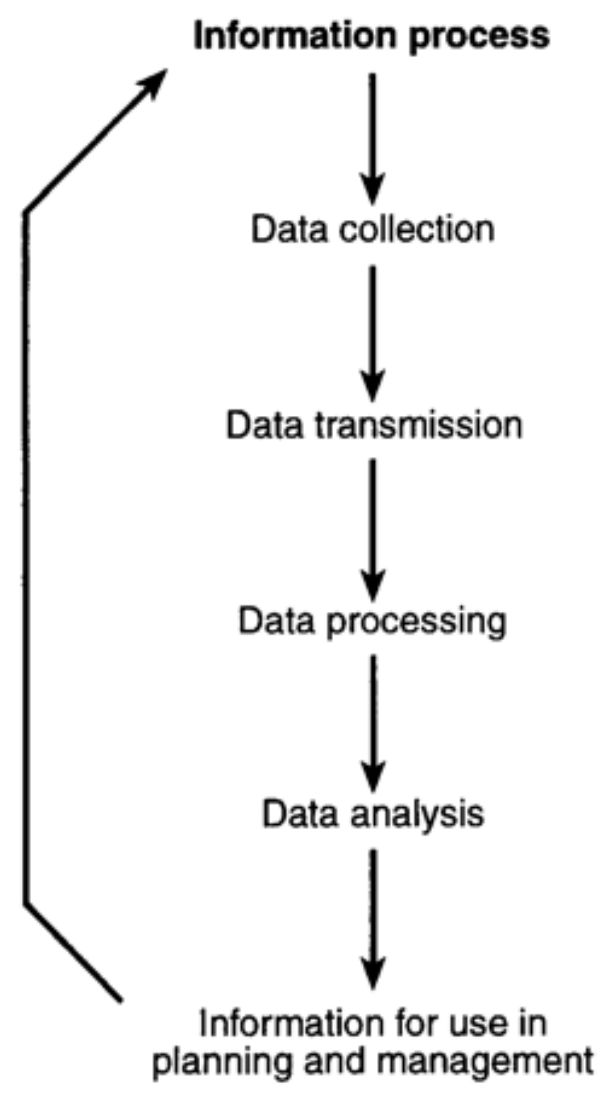

Figure 2.1: The Information Process in Health Information Systems (adapted from [WHO, 1988]). 
From Figure 2.1 it is easy to understand that HIS orientation is to combine and use common elements within an healthcare facility in order to produce real resources and ensure information to users when and where they need it the most. A HIS was also defined as the socio-technical subsystem of a hospital, which comprises all information processing as well as the associated human or technical actors in their respective information processing roles. One of the main goals of HIS is to contribute to a high-quality and efficient patient treatment. Another of its aims is to simplify administrative workflows, processing of the centralized and distributed healthcare data, and the development of effective system networking. From that moment HIS started to develop from administrative software to cover departments, clinics, and hospitals [Berger and Ciotti, 1993].

Delone and Maclean in 2003 have presented six success dimensions for Information Systems namely [Delone and Mclean, 2003]:

- System quality;

- Information quality;

- Usage;

- User satisfation;

- Indivual impact; and

- Organizational impact.

Figure 2.2 presents the organization of these six success dimensions. For system quality, attributes like system flexibility and accuracy, response time, easy of use and convenience of access should be considered. Information quality can be measured by information system output, meaning information quality, accuracy and usefulness, among others. System and information quality are closely linked and influence each 


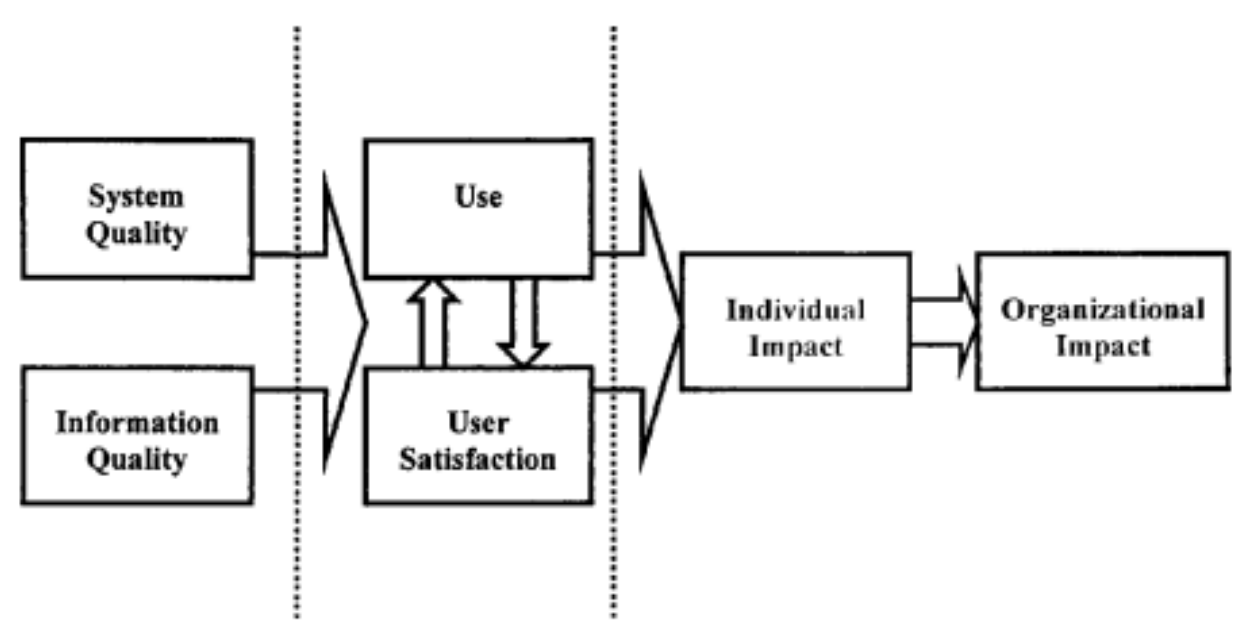

Figure 2.2: The Information Systems workflow and model for success (adapted from [Delone and Mclean, 2003]).

other; but either together or separated both influence use and user satisfaction. Usage refers to the interaction between information products with the user and system and information use. Time, frequency and regularity are examples of attributes to measure this element. User satisfaction can be influenced by the extent of use which leads to a positive or negative effect. Information product on management work and manager's behavior, such as quality of decisions, constitutes the dimension of individual impact [Currie and Procter, 2002]. Finally, organizational impact refers to the global impact of HIS on organization performance, e.g. process collaboration, quality or costs [Kivinen and Lammintakanen, 2012]. Overall, Kivenen and Lammintakanen enhance that success is a dynamic process and different dimensions relate to it temporally and causally [Kivinen and Lammintakanen, 2012].

Early in the 90's a group of clinical, technical and research entities started working together towards a common goal: define, develop, experiment and promote an advanced healthcare system based on standards totally open and vendorindependent. Such system should be capable of interact with older applications and new ones allowing information to flow without boundaries. This project was called EDITH Initiative [Fedele, 1995].

The EDITH Initiative intended to operate directly with national and inter- 
national organizations in order to establish standards for healthcare informatics. Furthermore, EDITH Initiative enabled the cooperation between individuals, industries and healthcare organizations, complying with the common architectural principles [Fedele, 1995]. The main results from this initiative were [Fedele, 1995]:

- An organizational model of the hospital structure, representing the fundamental background for identifying strategies and planning the introduction of information systems in the organization;

- The kernel of the architectural specification of the hospital information system, whose fundamental principles and criteria have also been approved and accepted by the Italian UNI-CNR Commission for standards in healthcare informatics;

- The principal software components of the architecture, providing any generic application with a common technological platform and a set of services specific for the hospital domain to facilitate the consistency and inter-working of heterogeneous, distributed applications; and

- The development of a set of applications, capable of providing an advanced support to the main requirements of any hospital, both from the clinical (e.g. admission, wards, laboratories, patient dossier, radiology) and from the managerial viewpoints (in terms of indicators on the cost and the quality of the services delivered to patients).

Bakker and Leguit presented a study in 2009 that reports the evolution of HIS in the Netherlands. This study emerged from a governmental project in the Leiden University Hospital which started in 1972 and evolved for a global implementation all over the country [Bakker and Leguit, 1999]. A special agency called NOBIN was created and the main contributions expected were:

- Better quality of patient care; 
- More efficient utilization;

- Support of research; and

- Support of education.

The philosophy from the proposed system followed one of the first definitions for HIS provided by Collen in 1988:

Definition 2.1 "The goal of a hospital information system is to use computers and communication equipment to collect, store, process, retrieve and communicate patient care and administrative information for all hospital affiliated activities, and satisfying the functional requirements of all authorized users" [Collen, 1988].

The system proposed by Bakker and Leguit was one of the first projects where the main emphasis was not on finance and administration but on patient care instead [Bakker and Leguit, 1999].

In 2010 the reliability of HIS was put under a great stress test in Kazakhstan [WHO, 2010]. A task force, which combined a multidisciplinary team from several governmental entities was formed in order to evaluate the arrangements in place to deal with crises. Regardless of the cause, this task force examined initiatives taken to prevent and mitigate risk, and provide recommendations on strengthening the overall preparedness capacity of the health system [WHO, 2010].

In this national project the coordination of multi sectoral surveillance and early warning was the responsibility of the Ministry for Emergency Situations that houses a fully equipped $24 / 7$ crisis center [WHO, 2010]. The crisis center hosts and provides the facilities for the national multi sectoral emergency committee in times of a large-scale crisis. It also receives information from a variety of sources within the country, therefore a good organization and information share system was necessary [WHO, 2010]. 
Information Systems support the transition between institution-centralized applications to patient-centered applications, meaning that all the National Health Service (NHS) faces a series of new challenges, namely quality of information and cost-effectiveness on its global process. Information infrastructure inside a healthcare unit should reflect the vision of the NHS and it should travel between organizational and professional boundaries. Information not only should be accessible inside the institution but also beyond it, and be accessible to its users and other institutions that share the same kind of data [Marques et al., 2010]. Several perspectives and frameworks have been presented over the last years in order to examine HIS integrity and quality. Indeed, one of the turning points in HIS was the transition from fee-for-service to the managed healthcare systems with a goal of cost minimization and quality improvement [Kongstvedt et al., 2000].

Mykkanen and Tuomainen in 2008 summed up the priorities, barriers and strategies to effective implementation of Information Technology in evidence-based practice environments such as healthcare. The next paragraphs represent the global proposal from Mykkanen and Tuomainen work [Mykkanen and Tuomainen, 2008]:

- First of all, priority number one goes to support knowledge and based decisions. For this priority three barriers were identified: (i) information and provider overload; (ii) lack of information; (iii) operationalize evidence. The main strategies to face these barriers are:

- Research on prioritize;

- Research to include data on added value in terms of mortality and morbidity;

- National patient data record;

- Patient ownership of patient data, guidelines, and reminders;

- Common patient identifier; 
- Common provider identifier;

- Integration across systems;

- Research on what information users need;

- Basic research in managing information complexity;

- Alignment of research priorities with clinical management;

- Performance measures focused on how much evidence informs practice;

- Regular presentation of significant translation research findings to senior; and

- Leadership.

- Priority number two goes to reporting and evaluation functions where the main barriers are: (i) threats to provider autonomy; (ii) data issues; (iii) report complexity; (iv) system resources. In order to overcome these barriers the strategies proposed are:

- Flexibility in decision support with required feedback about reasons for non-compliance and arriers to compliance;

- Local review of compliance with local solutions (tailored training);

- Add autonomy in other areas: e.g., guideline input, self-review, link to reference;

- Materials;

- More data automation (e.g., link diagnosis to test);

- Review and monitoring of data quality;

- Linkages to other information in electronic health record to eliminate duplicate entry;

- Move reports off system put analytical tools on a system separate from patient care system; and 
- Simplify user generation of report.

- Finally the last priority focus on evolution of health information systems, so healthcare systems needs are suppressed. The main barriers to achieve this goal are: (i) emphasis on provider level activities and provider entered data; (ii) emphasis on workload rather than care received by patient. The strategies proposed are:

- Develop patient-centered data collection methods, core data elements, and system capacity for patient-based health data sets;

- Focus on outcomes (maintaining/improving functional status of the patient), not workload; and

- Encourage just in time rather than just in case visits, collect interim data remotely.

The study taken by Kivenen and Lammintakanen in 2012 also provides perspectives on information availability and information use among users, in a Finish healthcare institution. They followed an interview approach, on confidential and relaxed ambient, in order to ensure less external influence and better results. The results refer only to a single institution therefore no extrapolation can be considered [Kivinen and Lammintakanen, 2012]. They concluded that there is still plenty of integration constrains. Knowledge and background of managers take a considerable impact on HIS implementations and success. The most relevant conclusion from this work are that HIS and MIS implementations are not always well planned and are not being considered as an essential tool in strategic information management [Kivinen and Lammintakanen, 2012].

HIS today suffer from a number of key problems, namely; (i) lack of interoperability and vendor lock-in; (ii) cost and difficulty of maintenance, given the rate of change and sheer size of the information in the health domain; (iii) lack of support 
for security, privacy and consent [openEHR, 2007]. These constraints are widely recognized, but there are no global accepted way to solve them, because of the sheer volume of health data being produced, and the number and complexity of systems. Indeed, there is no silver bullet fix, of course. However, several works propose their solutions based on personal knowledge and experience, but also in years of studies from governments and scientists around the world [openEHR, 2007].

\subsubsection{HIS Projects}

Over the last decades several countries have created task forces and assembled teams in order to provide help and guidelines for institutions and users. Several examples can be found in countries over the Americas like Brazil, Canada and United States. Other projects are taking place in Europe in countries like Belgium, Austria, France, Germany. Asia also have a global planning institution for supporting Medical Informatics. Medical Informatics is the science and art of modeling and recording real-world clinical concepts and events into computable data used to derive actionable information, based on expertise in medicine, information science, information technology, and the scholarly study of issues that impact upon the productive use of information systems by clinical personne [Silverstein, 1999]. Though, Medical Informatics has evolved and in the last years a new definition started to be a global accepted concept, Health Informatics. Health Informatics relies not only on information systems but most of all in clinical guidelines, which countries start to follow and adopt. Elderly population and health concerns are becoming even more important to governments and the next implementations, prove all these concerns.

Brazil has the Brazilian Society of Medical Informatics known as the Sociedade Brasileira de Informática em Saúde (SBIS) which has projects undergoing since 2002. In the first year, for example, some documents were published in several areas like global health information systems, drug prescription and interactions and also 
telemedicine and wireless applications which were already being studied. Several approaches to HIS were presented: for instance Campos and Pires presented works on this area. Pires published a work on a global billing system which has certain rules to be applied, like wages for workers, price tables for interventions and extra work payments [Pires, 2002]. Campos proposed and presented a portal in behalf of the patient where users could have access to on-line forms, on-line laws and other relevant information [Campos, 2002]. In drug prescription and interactions, Mahmud, Lopes and Kalva, among others, presented their work. Mahmud published a work about $C O M E D I$, a commission which regulates and promotes educational prescription methods based on informatics statistics [Mahmud, 2002]. On his work, Lopes presented a system that aids physicians in drug prescription for diabetes and hypertension. The system was based on eXtended Markup Language (XML) and uses an web interface to interact with users, aiding with drug interactions and could be extended, as stated by the author, to several other drugs [Lopes, 2002b]. Finally, Kalva presented $A L I A N C A$, a knowledge based system for alert in prescription moment [Kalva, 2002]. Already in 2002 and during the SBIS conference, telemedicine and wireless application played their role and several studies were published on this theme. Santos, Figueiredo and Lopes presented an on-line chat for medical discussion, wireless medical knowledge sharing and on-line oncological pediatric training, respectively [Santos, 2002, Figueiredo, 2002, Lopes, 2002a]. In the last years the number submited papers for publication has grown.

Canada Health Infoway is up since 2001 and has several projects in numerous areas such as Diagnostic Imaging Systems, Drug Information Systems, Infostructure, Innovation and Adoption, Interoperable EHR, Laboratory Information Systems, Patient Access to Quality Care (PAQC), Public Health Surveillance, Registries and Telehealth [CHI, 2001]. Gen 2 DIS is a Drug Information System which provides drug interactions alert to physicians and is also a governmental approach in order to reduce costs and increase quality of services [CHI, 2010]. One of the PAQC 
projects selected can demonstrate the potential to accelerate transformation initiatives that reduce wait times. Technology deployments from this project include consumer health solutions such as chronic disease management tools and patient portals and scheduling [CHI, 2001]. This program provided self-care portals, online tools to access and update personal health information. Tools such as chronic disease management solutions increased patient participation in their care resulting in the improved management of their conditions and reduced use of healthcare resources. PAQC projects provided by the Canadian Health Infoway were aligned to jurisdictional and national healthcare priorities and support the national wait time agenda [CHI, 2001].

United States was always a pioneer in HIS and in 2004 created the Office of the National Coordinator for Health Information Technology, which is a staff division of the Office of the Secretary, within the U.S. Department of Health and Human Services. The main operation focus is on coordination of nationwide efforts to implement and use health information technology and the electronic exchange of health information [HITECH, 2004]. The Strategic Health IT Advanced Research Projects (SHARP) are a set of implementations and projects ran by this Office [SHARPS, 2010]. This program started in 2010 and several areas are divided in smaller but non less important projects. The first project refers to Security and Health Information Technology where the main goals were to reduce privacy and security risks [SHARPS, 2010]. Other important project is Patient-Centered Cognitive Support in order to improve the power of health IT to integrate and support physician reasoning and decision-making as providers care for patients [SHARPS, 2010]. Health Care Application and Network Design project improved system designs that facilitate information exchange while ensuring the accuracy, privacy, and security of electronic health information [SHARPS, 2010]. Finally, Secondary Use of EHR Information, which intends to promote a higher quality patient data by enabling medical device manufacturers to create products that will interoperate with other 
manufacturers devices, EHRs, and Health IT systems [SHARPS, 2010].

Some European institutions try to provide instructions for Europe as an unified entity. For instance, the European Federation For Medical Informatics (EFMI) has several projects ongoing. The EFMI was created at a meeting, assisted by the Regional Office for Europe of the World Health Organization (WHO), in Copenhagen in September 1976 [EFMI, 1976]. The representatives of national Health/Medical Informatics societies from ten European countries signed a declaration of intent stating:

"The Federation shall be constituted as a nonprofit organization concerned with the theory and practice of Information Science and Technology within Health and Health Science in a European context. We declare that the ten delegates here today from the ten national societies shall constitute the preliminary Council of the Federation which thus hereby exists." Copenhagen, 11 September 1976 [EFMI, 1976].

This global project involves several countries such as Austria, Belgium, France and Germany among others. Each country has its own national framework and institution in order to provide cooperation and collaboration between healthcare institutions inside each country.

In Austria the Working Group in Medical Informatics (AKMI) of the Austrian Society for Biomedical Engineering (OGBMT) and of the Austrian Computer Society (OCG) focus their work on several topics that comprehend: Health Information Systems; Human-Computer Interaction; Information Systems; Internet and Intranet; Knowledge Management; Knowledge Technology; Clinical Bioinformatics; Biomedical Signal and Image Processing; Multimedia and e-Learning in Health Education; Quality Management; Standards; and Telemedicine [AKMI, 2011].

The Belgian Society for Medical Informatics (MIM) was founded in 1974 to promote and develop medical information science and technology in Belgium. The administrative board includes 15 members (physicians, engineers and computers 
specialists) from academic institutions, hospitals, computers and the software industry. The MIM is a scientific society and its major activities focus on improving communication among researchers and developers in the field of medical computing and telematics. It is also the place of choice where problems related to the role of medical informatics in society and its ethical aspects are discussed [MIM, 1974].

The French Association for the applications of medical informatics also known as Association pour les Applications de l'Informatique en Médecine (AIM), was created in 1968 and is a scholarly society, mainly composed of researchers and university teachers [AMI, 1968]. AIM goals are the following:

- Promote computer applications, scientific researches and corresponding technical developments within the healthcare system;

- Introduce HIS healthcare professionals, interested administrations and concerned industrial actors;

- Simplify exchanges between healthcare professionals (physicians, biologists, administrators, nurses, researchers), and scientists specialized in computer science, as well as research organizations and concerned associations representatives or agencies;

- Contribute to healthcare professionals, researchers and engineers education to medical informatics;

- Collaborate with groups and scientific associations sharing synergetic goals; and

- To participate to the professional thinking that should precede or give rise to the update of official texts that regulate the automatic processing of medical data [AMI, 1968]. 
German Society for Medical computer science, Biometry and Epidemiology (GMDS) presented itself on the web in 2006 and has set the goal of the medical computer science, including medical documentation in theory and practice to promote research and teaching [GMDS, 2006].

With the pervasive influence of IT, many countries are now aggressively applying this technology to the management of health data and patient care. In view of the strong progress that has been made in this field among countries in the Asia Pacific in recent years, and recognizing the importance of the Asia Pacific as a region in the forefront global scientific, economic and cultural growth and development, the International Medical Informatics Association launched the Asia Pacific initiative at its General Assembly in October 1993 [APAMI, 1993].

As proven before, associations around the world have similar focus and goals namely:

- Health Information Systems consolidation;

- Collaboration with groups and scientific associations;

- Knowledge management;

- Standards; and

- Information Quality.

\section{$2.2 \quad$ Interoperability}

Healthcare is a knowledge intensive activity and every department has its own specific language and needs generating a complex web of data spread through the institutions. In the last decades healthcare unities have gain their own independence 
and even inside healthcare institutions, departments had their own financial independence therefore whenever a new need was pointed from users, administrators and managers easily could buy the appropriate solution. Each service started to have as small database with specific patient data and where users registered pathologies or specific interests. This creates a computational issue that generates development problems. However, these applications are used by people with good satisfaction despite they do not allow a transversal vision of the patient data along different services or specialties, they can not grow easily and sometimes they do not attend secure and confident procedures. Running applications in distributed environment is a huge problem when applications have not been developed to share knowledge and actions [Peixoto et al., 2012c]. Creation of silos of information is easy and access to information is hard and a major concern.

Every day new applications, are developed by proprietary companies, in order to assist physicians on their work. Every of these applications is responsible for generating data knowledge and turning healthcare into a science based on information and reputation [Hersh, 2002]. Each of these applications has its own language and workflow, besides, together with users known needs have created several boundaries hard to transpose meaning that there is still lack in information quality and easy information access. Actually, the increase number of heterogeneous applications promotes the creation of silos of information, which are constraints to the easy flow of information within a healthcare institution. Interoperability is a key property in enterprise applications, which is hard to achieve due to the large number of interoperating components and semantic heterogeneity [Ralyte et al., 2008].

Demands of information handling within the healthcare sector range from clinically valuable patient-specific information to a variety of aggregation levels for follow-up and statistical and/or quantifiable reporting [Peixoto et al., 2010].

Furthermore, patients visit several hospital over their life, and every time they are admitted a new episode is registered. Therefore patients have multiple 
episodes in multiple healthcare units, and this number increases along the time [Orgun and $\mathrm{Vu}, 2006]$. Most of the times information present in previous episodes is lost and fragmentation occurs. Since healthcare is a science based on information, access to previous data is of extreme need. The need to access patient information grows in parallel with the need to consolidate the patient information across the numerous systems in a healthcare organization.

IS have their capabilities widely exposed and explored. Tough, software developers and users should create their own challenges. Sujansky tries to understand if the total integration of databases is possible and for that he prepared an extent research [Sujansky, 2001].

Figure 2.3 illustrates Sujansky vision of the flow of information which should be in a heterogeneous database information system. In order to transform and translate data, it is necessary to transform data from the native formats in which they are collected and stored to a common shared format in which they can be uniformly accessed. When storing the transformed data homogeneity is being performed and Sujansky defines this as the implementation of a query model, enabling users and applications to ignore the specifications of the constituent query models. Data warehouses for diverse bioinformatics data and clinical data repositories are examples of this integration strategy. Data translation may take place manually or automatically.

Despite all the efforts being made, full interoperability is still to come. Therefore, until that point is reached there is a lot to be done and a long road to travel [Peixoto et al., 2012b]. The lack of integration between the different HIS is not only an obstacle for a more effective clinical practice, but it may lead to a suboptimal care for the patient [Peixoto et al., 2012b]. Over the last decades a methodology for solving data share and access has become one of the main concerns of governments throughout the world. Several projects from European countries and even European projects in general have tried to support and define Interoperability. Orgun 


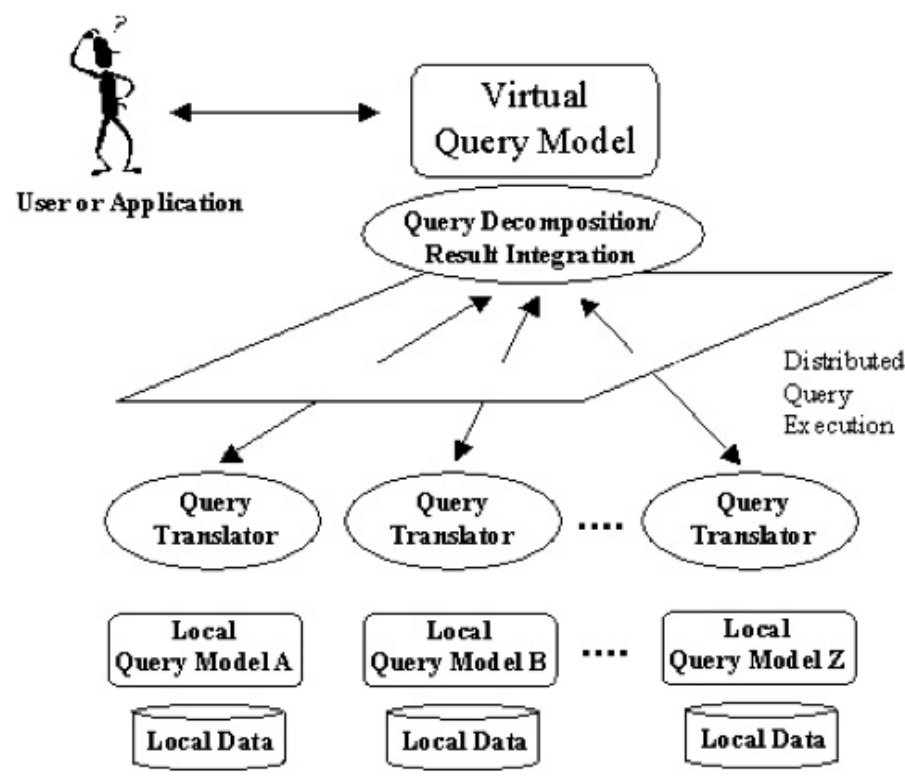

Figure 2.3: The query-translation strategy for heterogeneous data- base integration (adapted from [Sujansky, 2001]).

in 2005 defined one of the problems of interoperability which is the extraction from heterogeneous sources [Orgun and Vu, 2006].

An interoperability problem appears when two or more systems are put in relation and cannot communicate without external interaction [Chen et al., 2010]. Interoperability paradigm is considered when an interoperability problem occurs [Chen et al., 2010].

Certainly, HIS need to communicate and share data, so that information must be available anywhere, for anyone who needs it, at any time. Hence, interoperability can be defined as a state created between two or more applications or entities when, in the need to perform a given task, data have to be accessed and understood between both, and that task is succeeded without the need for extra operator intervention [Aguilar, 2005]. The Institute of Electrical and Electronics Engineers (IEEE) proposed a similar approach and defines interoperability as the ability of a system or a product to work with other systems or products without special effort on the part of the customer [IEEE, 1991]. Though, to accomplish interoperability is still a complex task and there is no conceptual or predetermined method for such 
assignment, meaning several models are available through studies throughout the world each one trying to present its own methodology. Although interoperability had been studied and its implications to care delivery had been considered, the level of interoperability among systems in most healthcare institutions remains frustratingly low [S.M. and Moore, 2003]. In Healthcare it is globally accepted that technology can achieve needed information sharing across disciplines and venues; however, the lack of well-defined and broadly accepted guidelines prevents the interoperability of HIS.

Ralyte in 2008 have stated that the basic infrastructure is put in place although institutions and applications have not yet achieved the sufficient interoperability levels [Ralyte et al., 2008]. For the author the main reason for this it is that the problem is not only technological but it also resides in organizational and business domains [Ralyte et al., 2008]. Indeed, interoperability is a multidimensional problem that concerns different layers of the healthcare infrastructure. Interoperability is not a problem concerning only software and technologies. Several technologies are already available in order to enhance interoperability. These technologies include TCP/IP, XML, SOAP, HL7 and BPEL.

\subsubsection{Technical Standards for Interoberability}

Over the last years the needs for improvals in HIS have become more and more evident. There are several needs that must be fulfilled and are well known among IT tecnichians and health staff:

- The need for long term EHR, oriented for a bigger average life expectancy of 100 years;

- Concepts dimension variability brings the need for dynamic EHR and adaptable technologies; 
- Patients travel more therefore the need to share clinical information through healthcare providers;

- The need for DSS, and statistical studies of the population, where HIS can provide quality information to perform such operations, and standards can provide a wide range of sources; and

- The costs of the HIS should decrease according the global crises.

There is still a lack of information sharing among IT providers for healthcare, and the idea of creating a single statistical query for example, that can cover all the data sources inside a healthcare unit is still utopic, since data structures are different from data source to data source. It is necessary to centralize the information on the patient and integrate data from external sources and avoid centralization on a datastructure or application or even healthcare institution.

The main advantagens of implementing IT standards in the health domain are:

- Stimulate competition and cost reduction;

- Open systems at reasonable implementation costs;

- Compatibility improval and interoperability between different vendors; and

- Growing from small scale to bigger scale with full integration.

Definition 2.2 Neither an isolated company or an isolated information system can by itself meet all the management requirements of an healthcare institution, even more it can not work in order to provide a national or international electronic health record complete and distributed.

Therefore, it is necessary to have systems that communicate between each other in a quick and easy way to address the all complexity of a HIS. 
Health data management requires interoperability of all applications within a hospital and across groups of hospitals and primary care centers that work together or are in the same region. As of yet, no single integration strategy achieves this goal, and the three most common approaches have not succeeded, despite many attempts:

- The single supplier solution gives the entire organization a common data base with no duplicate data elements. Yet, no user gets exactly what he needs, and everyone within the organization has to compromise. This type of system has to be proved unsuitable for groups and regions because of high cost and long lead times.

- Although multi-vendor, best of breed systems are easier to adapt and grow, and the investment is spread over a longer period, they present data integration problems that require complicated architectural fixes. The traditional method of linking systems through point-to-point proprietary interfaces can be very costly. Interfaces may need to be amended if changes are made in the connected systems, potentially costing more than the individual applications. Attempts to overcome these problems by using generic interfacing tools, the so called interface engines, have had limited success.

- In 1997, the Organization for Economic Cooperation and Development (OECD) recommended open modular solutions based on standards. This approach calls upon healthcare to adopt common architectures and interfaces based on standards, making specific applications or software products and linkages available to both users and vendors. It is important to distinguish clearly between the quasi openness vendors claim for their proprietary systems and real openness of systems based on public standards.

This last item is proving to be the best approach to healthcare systems and nowadays several working groups have focus their work on this approach. Not only 
groups have focused on following standards and try to interoperate systems but before and more important several governmental and non governmental organizations started to build standards and publishing them.

The Dublin Core Metadata Initiative (DCMI) is a global framework which main goal is to provide standards to enhance the finding, sharing and management of information. DCMI created an interoperable framework at the system level, which is mainly based on the abstraction level of the exchangeable data or records, which is to be understood in terms of four tiers, namely [DCMI, 1995]:

- Tier 1 - Shared Terms Definitions - data components with shared natural language definitions;

- Tier 2 - Formal Semantics of Interoperability - data is based on formal semantics;

- Tier 3 - Description Set of Syntactic Interoperability - data is structured according to shared formal vocabularies in exchangeable records;

- Tier 4 - Description Set Profile Interoperability - data content is structured according to shared formal vocabularies, being bounded by a set of invariants on the exchangeable data or records.

These levels are oriented to the Dublin Core environment and its reference model, but can be extrapolated to other metadata models [DCMI, 1995]. The Health Informatics Profiling Framework (HIPF) was designed in 2004 to bring order to the description of health informatics standards artifacts [ISO, 2004]. A common means of description is necessary to facilitate the co-ordination, communication and comparability of health informatics standards across and between disciplines and jurisdictions. The HIPF is an approach and tool to describe the variety of artifacts within the domain of health informatics standards. 
Regardless the field of study, interoperability can be classified in three distinct ways:

- Technical interoperability - This is a domain independent approach where the aspect concerning is moving the data from system A to system B, neutralizing the effects of distance. In this transport layer there is no need to know about meaning of what is exchanged.

- Semantic interoperability - In this approach it is necessary to specify to domain and context. Usually it involves the use of codes and identifiers to ensure that system A and system B understand the set of information without ambiguity. It enables two cooperating systems or components to use and interpret the data in the same way.

- Process interoperability - Coordination of work processes that enables the business processes at organization that house system A and system B to work together.

In the last decades, users have understood that the quality of information inside a healthcare institution relies on data interoperability, thus, the enrolling of all the players is extremely necessary. Studies to determine the impact: financial and social, the benefits and constraints and the levels of interoperability are needed and institutions should focus their efforts on this matter in search for the best patient treatment possible.

\section{XML}

Extensible Markup Language (XML) is an emerging Internet standard that is growing in many industries, including healthcare. XML was intended to replace HTML as the standard on the Internet for the interchange of documents and data. 
XML is finding a niche in augmenting unstructured HTML documents with structures serving as the data-exchange mechanism for transaction-based systems, and serving as a data-exchange mechanism between disparate systems [Seals, 2000].

XML may prove to be of value in avoiding the need to consolidate data into a single system by providing a standard means of communicating data between and among systems at the presentation layer instead of at the data layer. In the healthcare field, much of the data of an enterprise are necessarily in an unstructured form. A patients description of his symptoms falls under this category as other text related documents and diagrams. Document archival and retrieval systems have been used effectively to index, archive, and allow the retrieval of unstructured documents. With the advent of XML, documents and data can reside together [Seals, 2000]. Figure 2.4 represents the codification of a surgery report on an individual in XML.

XML is proven to be an excellent tool since:

- Widely implemented with excellent open-source tools;

- Life of data is longer than life of application;

- Data driven, platform independent; and

- Formal schema and query models.

XML structure are growing fast in the healthcare domain, and are taking advantages from the global web to structure health data. Web ontologies allow the creation of linked data were data are stored over XML files and new query languages are being developed. Therefore, with the usage of linked data, XML does not make only readable to humans through interface classes, but makes also readable to machines in Resource Description Framework (RDF). RDF is a standard syntax to represent directed graphs in XML. It consists in: (i) subject; (ii) predicate; (iii) object. Therefore, using ontologies, such as SNOMED, it is possible to enable 


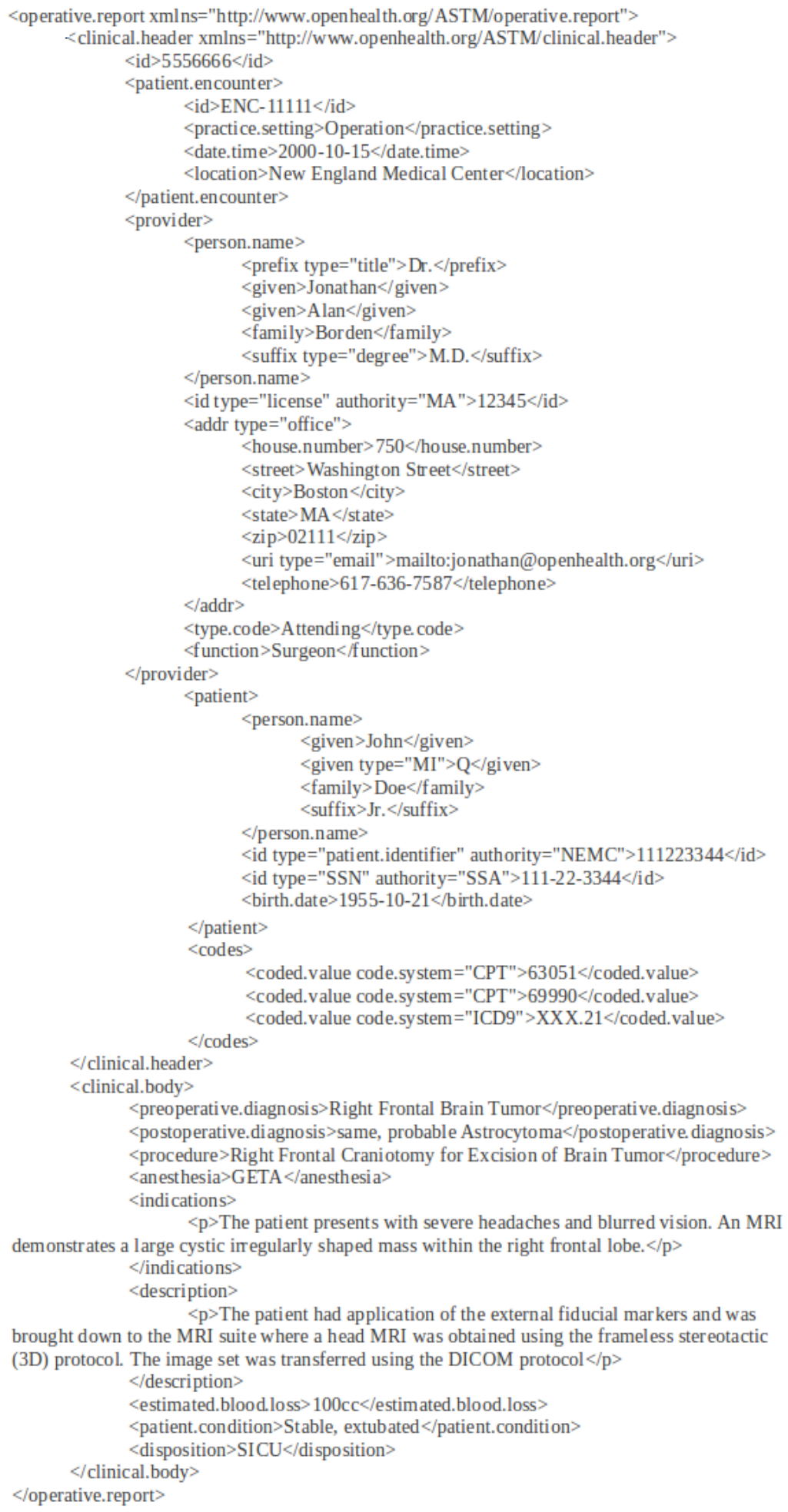

Figure 2.4: Operation report on XML (adapted from [Seals, 2000]).

the creation of standard documents that compose an individual Health Record, for example w3C.

A case-study published in W3C consortium in 2009 by Jentzsch shows the use 
of $\mathrm{RDF}$ in order to deal with data from prescriptions and the integration through web systems [Jentzsch et al., 2009]. Their main goal was to ensure the hole study of the individual and not only a DSS to provide the adequate drug for the treatment. Gene studies, as well as potential collateral effects, active components can interfere in patients well being, therefore this study provides an extent reflection over all these variables [Jentzsch et al., 2009].

Also Clark presented a work in the Semantic Web in Health Care and Life Sciences Interest Group, which main goal was to provide user the potential cure to complex diseases such as Alzheimer [Clark and Ocana, 2009]. This study integrated the SWAN Alzheimer Knowledge Base, and it is fully integrated in the Massachusetts Hospital providing quick access to relevant information, and better diagnosis and treatment for patients [Clark and Ocana, 2009].

\section{HL7}

HL7 also known as Health Level Seven is a standard protocol for information exchange between medical devices. Indeed, it is used to enable communication from application to application, and is independent from the hardware layer of the chosen network. HL7 corresponds to a conceptual definition of an application to application interface placed in the seventh layer of the OSI model [HL7, 2010]. Figure 2.5 shows how the OSI model is distributed [HL7, 2010].

HL7 can handle all the important communication tasks in the hospital:

- Admission, Discharge, Transfer;

- Order Management;

- Finance;

- Observation; etc. 
HL7 is a set of messages that are passed between applications. Each of these messages has its own structure and is build up by several segments that represent a logical grouping of data fields. Also different message structures are presented between different situations like admissions and discharge [HL7, 2010].

This tool provides a secure, standard for information sharing between entities allowing information quality to remain untouched and in a high level. HL7 is the most common standard used among healthcare units and proprietary software is usually capable of transmit and receive information through this method [HL7, 2010].

HL7 is now on its third version, which has the global aim to support all healthcare workflows. Development of this third version has started in 1995, and resulted in an initial standard publication in 2005. The v3 standard, as opposed to version 2, is based on a formal methodology and object-oriented principles [HL7, 2010].

HL7 Version 3 Development Framework (HDF) is a continuous process based in XML, that tries to develop specifications in order to enhance interoperability between healthcare systems. The HL7 Reference Information Model (RIM), vo-

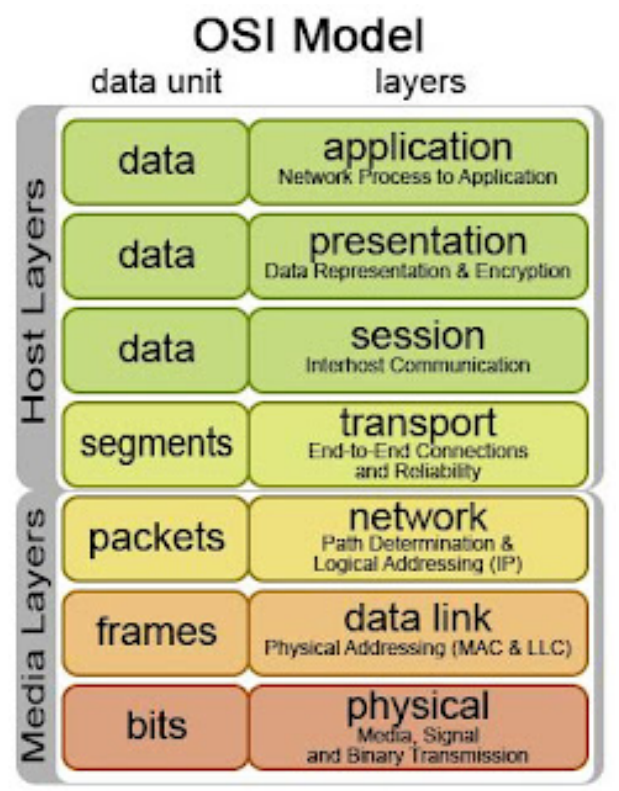

Figure 2.5: The OSI Model (adapted from [HL7, 2010]). 
cabulary specifications, and model-driven process of analysis and design combine to make HL7 Version 3 one methodology for development of consensus-based standards for healthcare information system interoperability. HDF is the most current edition of the HL7 V3 development methodology [HL7, 2010].

HDF not only allows to document the messaging, but also the processes, tools, actors, rules, and artifacts relevant to development of all HL7 standard specifications. Eventually, the HDF will encompass all of the HL7 standard specifications, including any new standards resulting from the analysis of electronic health record architectures and requirements [HL7, 2010].

HL7 specifications draw upon codes and vocabularies from a variety of sources. The V3 vocabulary work ensures that the systems implementing HL7 specifications have an unambiguous understanding of the code sources and code value domains they are using [HL7, 2010].

Appendix B is a paper on multi-agent base HL7 services published in the 9th ACIS/IEEE International Conference on Computer Science and Information Science, COMPUTER AND INFORMATION SCIENCE 2010, Studies in Computational Intelligence, Volume: 317, Springer, 2010. Appendix B details the architecture and methodologies of a multi-agent based HL7 interoperation service. The mentioned system is incorporated in an integration platform, which is implemented in several healthcare institutions and uses Multi-Agent Systems to control and enable the how of data and information within them.

\subsubsection{Interoperability Impact}

Healthcare is an agglomerate of various players that are directly or indirectly involved [Aguilar, 2005]. Each one has its role and when the goal is interoperability every player has to be heard and their the needs and ideas have to be taken in 
consideration [Aguilar, 2005]. Aguilar in 2005 presented the four major players in this definition:

- Healthcare Providers: Physicians, nurses, technicians belong to this group. It is necessary to understand the level of knowledge of this actors since the final usage of systems will be held by them. Day-to-day practice hints to new problems and facing these problems can also create solutions and adaptations that can and should be shared;

- Information Technology and Administrative Staff: This group can take a key role in implementing, deploying and developing standards according to their own knowledge;

- Healthcare Companies: All the companies that develop does not only software products, but also medical devices such as imaging and laboratories for example. For this item, all vendors should be considered, namely global companies that work in several countries and small business companies that sell small solutions for hospitals and clinics; and

- Health Authorities and Government: Ultimate laws and definitions are held by this actor. Laws and regulations are an important mean to achieve the global goal, interoperability.

Indeed, when driving towards interoperability and to maximize all the benefits, the needs of a variety of players have to be taken into consideration. It includes healthcare professionals, whose work environment will be directly affected by the way standards and technologies are used to support the workflow in their daily practice. It is recommended that before considering mandating the use of a particular technology or standards through any official body, global consent has been achieved through a collaboration process [Aguilar, 2005]. 


\subsubsection{Interoperability Levels}

In order to promote interoperability between systems it is necessary to truly understand the levels and meanings of such levels. In 2008 Mykkanen promoted a study where a table similar to Table 2.1 was designed, interoperability is dived in seven distinct levels [Mykkanen and Tuomainen, 2008].

Table 2.1: The seven interoperability levels, designation and meaning (adapted from [Mykkanen and Tuomainen, 2008]).

\begin{tabular}{|c|c|c|}
\hline Level & Designation & Meaning \\
\hline 7 & $\begin{array}{l}\text { Application life } \\
\text { cycle interfaces }\end{array}$ & $\begin{array}{l}\text { The life cycle of the application, including } \\
\text { integration and development methods }\end{array}$ \\
\hline 6 & $\begin{array}{l}\text { Functional refer- } \\
\text { ence model }\end{array}$ & $\begin{array}{l}\text { The domain-specific information or func- } \\
\text { tional model or assumptions about the used } \\
\text { methods }\end{array}$ \\
\hline 5 & Semantics & $\begin{array}{l}\text { The meaning of the defined interface ele- } \\
\text { ments }\end{array}$ \\
\hline 4 & $\begin{array}{l}\text { Functional inter- } \\
\text { faces }\end{array}$ & The defined functionality and information \\
\hline 3 & $\begin{array}{l}\text { Application in- } \\
\text { frastructure }\end{array}$ & $\begin{array}{l}\text { The integration points in the distribution ar- } \\
\text { chitecture of the participating applications }\end{array}$ \\
\hline 2 & $\begin{array}{l}\text { Technical infras- } \\
\text { tructure }\end{array}$ & $\begin{array}{l}\text { The infrastructure for supporting the inter- } \\
\text { face and communication technologies }\end{array}$ \\
\hline 1 & $\begin{array}{l}\text { Technical inter- } \\
\text { faces }\end{array}$ & $\begin{array}{l}\text { The technologies used in the interfaces and } \\
\text { implementations }\end{array}$ \\
\hline
\end{tabular}

These levels can be useful to locate the primary focus of an interoperability standard and for identifying which interoperability aspects are not covered by the given standard and must be solved and coordinated using other standards or project-specific conventions [Mykkanen and Tuomainen, 2008]. From level 1 to level 6 , every time a new system is added to the global architecture needs to be checked and studied, since protocols, interfaces, infrastructures are different from vendor to vendor.

On the other hand the Center for Information Technology and Leadership (CITL) divided interoperability levels where a system can be fit in four. This is a more global approach when compared to Mykkanen definition but it can be 
a more simpler and a good starting point for a healthcare unit to commit with [Middleton, 2004]. This approach is presented on Table 2.2.

Table 2.2: Health Information and Interoperability Taxonomy (adapted from [Middleton, 2004]).

\begin{tabular}{cll}
\hline Level & Description & Examples \\
\hline 1 & Non-electronic data & Mail, phone \\
2 & Machine trans- & PC-based and manual fax, email, or scanned \\
& portable data & documents \\
3 & Machine-organizable & Secure e-mail of free text and incompati- \\
& data & ble/proprietary structured messages, HL-7 \\
& & msgs \\
4 & Machine-interpretable & EDI of structured messages with controlled \\
& data & terminology; No PC/information technol- \\
& & ogy Fax/Email Structured messages, non- \\
& & standard content/data Structured messages, \\
& & standardized content/data \\
\hline
\end{tabular}

\subsubsection{Interoperability Costs}

In 2004, a study taken in the US by Blackford Middleton "shows conclusively that there are strong financial reasons for the nation to invest in standardized healthcare information exchange". According to Middleton team, it would be possible to save nearly $\$ 86.6$ billion dollars every year and the only way to do it was to perform healthcare information exchange and interoperability [Middleton, 2004].

In this study, according to the author, health information exchange and interoperability could reduce costs by:

- Reducing healthcare information management labor costs;

- Reducing duplicative tests and procedures;

- Reducing fraud and abuse;

- Improving service delivery efficiency; 
- Improving patient convenience; and

- Reducing medical error.

\subsubsection{Semantic Interoperability}

One of the main challenges for HIS is to represent the semantics of the sector, which are far more complex than in other industries. In order to perform such task, a knowledge-oriented computing framework that includes ontologies, terminology and a semantically enabled health computing platform is needed, in which complex meaning can be represented and shared. At the same time it must support the economically viable construction of maintainable and adaptable health computing systems and patient-centric EHR [openEHR, 2007].

Definition 2.3 The Semantic Web provides a common framework that allows data to be shared and reused across applications, enterprises, and community boundaries. It is a collaborative effort led by W3C with participation from a large number of researchers and industrial partners [W3C, 2010].

Semantic interoperability exists when different systems like computer systems, interacting with each other or with people can cooperate and make effective use of the terms that are used in the interaction [Graybeal, 2009]. When two people try to communicate, a lot of redundant information is available for confirming assumptions and refining understanding. Facial expressions, tone of voice, repetition using different words, gestures, actions, and physical objects themselves guide the participants understanding. Also, many terms can be, and really are approximately translated for many purposes, 'friend' and 'colleague', for example, can substitute for each other.

The first steps towards semantic interoperability rely on good practices and data management, principally defining data and metadata structure. The appropri- 
ate time to execute this is on data creation point, since it is where it is more possible and easy to understand how data are organized [Graybeal, 2009].

Once data and metadata structures have been defined, usually by using a content standard to organize metadata, and metadata to describe data structure, it is possible to focus on describing the data in a semantically interoperable way. Where the structural information might recognize the existence of 3 variables in ASCII format separated by tabs, semantic interoperability demands that those variables to be named, and that some correspondence exists between variable names and the names be in a way that other people and computers can recognize them. Making names understandable it can take several forms and be achieved by several means. The easiest in some situations is to choose a vocabulary that can describe all the variables - for example, the SNOMED is one with extensive coverage in the healthcare scenario and declare that all your names will be specified using that vocabulary standards [CT, 2002, Graybeal, 2009].

Local mapping is available too, in order to do so it is necessary to establish a comparison and mapping between local naming and global defined and accepted standards [Graybeal, 2009]. Therefore a vocabulary mapping is needed and other organizations should have access to it [Graybeal, 2009]. Not all of these solutions are totally in place for every scenario, but most of the pieces are in place. As more projects need semantic interoperability, and implement the approaches that have been created, the initial cost is considered an increment above the work needed for every institution, and by adapting organizations to this paradigm early results and overcomes are expected [Graybeal, 2009].

Appendix A presents a work published in the First European Workshop on Computing and ICT Professionalism based on an Electronic Semantic Health Record in Santiago de Compostela, Spain in 2010. This work gathers all the knowledge from semantic interoperability and the next information on Electronic Health Records. 


\section{$2.3 \quad$ Electronic Health Record}

The EHR begins to attract IT technicians, scientists and physicians interest due to the constant need of information and its quality and the necessity for a structured data support that follows the advances in IT. The first EHR did not focus on clinical information but in demographic and financial data. During the following years, areas like drug prescription, clinical and cost management were on focus and only a few years late the first clinical approaches came to public. The first known were [Duarte, 2008]:

- 1969 - Problem-Oriented Medical Record;

- 1972 - The National Center for Health Services Research and Development together with the National Center for Health Statistics promoted a conference in order to define a structure for clinical registry of clinical data; and

- 1991 - The Report called The Computer-based Patient Record - An Essential Technology for Health Care.

Due to the constraints of implementation, like hardware restrictions, records synchronization and initial costs, the settle of the EHR was a hard task and took long time to be established.

According to Pereira, in 2003, an Electronic Health Record can contain data from [Pereira, 2003]:

- Clinical History;

- Physical Examinations;

- Admission Evolution;

- Diagnostics; 
- Cirurgical Interventions; and

- Complementary examination results.

Therefore, the main aims of an EHR are [CPSA, 2004, Dick and Steen, 1991, Erstad, 2003, Hayrinen et al., 2008, Kukafka et al., 2007, Ovretveit et al., 2007, Abelha, 2004]:

- Keep the clinical history of the patient, providing information to support decisions for all the physicians and other healthcare professionals like nurses;

- Reduce the loss of clinical registry or data in order to reduce medical errors;

- Help the communication between the healthcare facility with other external information sources like primary healthcare facilities or external labs and clinics; and

- Management and planning aid in order to improve cost-effectiveness relationship.

\subsubsection{Electronic Health Record Pros and Cons}

According to Abelha in 2004 and Coiera in 2003 the EHR presents more advantages when structure and content are taken into consideration [Abelha, 2004, Pereira, 2003] :

- Interface can be user-oriented, allowing several different layouts according to information needs and taking into consideration user role; for instance and doctors have different needs of information;

- Data is readable no matter what user typed the information, since no hand writing is promoted. Less errors due to misunderstandings will occur; 
- Continuous data feed can enhance alert and alarm events in abnormal situations; and

- Automatic data collection from external data sources such as imaging equipments and laboratory devices.

Definition 2.4 Electronic Health Record EHR means a repository of patient data in digital form, stored and exchanged securely, and accessible by multiple authorized users. It contains retrospective, concurrent, and prospective information and its primary purpose is to support continuing, efficient and quality integrated health care [Ovretveit et al., 2007].

In practical terms, this means that an EHR has the following characteristics [openEHR, 2007]:

- Patient-centred: one EHR relates to one subject of care, not to an episode of care at an institution;

- Longitudinal: it is a long-term record of care, possibly birth to death;

- Comprehensive: it includes a record of care events from all types of carers and provider institutions tending to a patient, not just one speciality; in other words there are no important care events of any kind not in the EHR; and

- Prospective: not only are previous events recorded, so is decisional and prospective information such as plans, goals, orders and evaluations.

According to Duarte in 2008 the main disadvantage that prevented EHR to assume more quickly an important role in healthcare units was the physicians resistance to change their habits. Old workflows were consolidated over the last decades and paper health record was established and worked according to the user needs [Duarte, 2008]. Transition to new technologies is always an hard process but with 
adequate training users could benefit from EHR advantages and even more participate in future evolutions [Gurley, 2004].

\subsection{Interoperability and Electronic Health Record Projects}

In Europe and all over the world, several projects are ongoing in the field of Interoperability for Healthcare; where the EHR plays an important role, and over the last years the number of projects have increased significantly. In this section several projects spread through the globe are presented in detail. The main goals and definitions, institutions and partners as well as start and end dates are also presented. The projects main focus is interoperability and Electronic Heath Records, data collection and quality of information.

\subsection{1 openEHR}

The openEHR Foundation is an international not-for-profit Foundation; and its founding shareholders were the University College London, in the United Kingdom and Ocean Informatics, in Australia; working towards [openEHR, 2007]:

- Making the interoperable, life-long EHR a reality; and

- Improving healthcare in the information society.

In order to achieve these goal the openEHR foundation will try to:

- Develop open specifications, open-source software and knowledge resources;

- Engage in clinical implementation projects; 
- Participating in international standards development; and

- Supporting health informatics education.

Having established a solid set of baseline specifications, the openEHR Foundation and community aims to build on these in order to provide more direct value to implementers, clinicians and users of HIS. Community and vendor involvement is encouraged in all the activities described below.

openEHR formalises the Electronic Health Record in terms of:

- Reference model (RM) - This is the model that describes the health record itself - not the clinical data that is contained within it. The reference model deals with containers such as Folders and Compositions. Compositions are a broader concept than documents - but include documents. Examples of Compositions are an ECG report, a progress note, a laboratory report and a referral. The Composition is the minimum unit of communication and committal to the EHR. The openEHR Reference Model specifications are available from the specification page; online UML.

- Archetype Model (AM) - Archetypes are descriptions of valid Entries, Sections and Compositions. These are expressed in a formal manner which enables them to be shared between systems. A blood pressure archetype represents a description of all the information a clinician might want to report about a blood pressure measurement, and may include some aspects which are mandatory. A 'SOAP' archetype describes the sections of a problem oriented health note and which entries are valid under each section - for example only diagnoses may be allowed under the 'A' section. Templates are logical models of user forms - and are described in terms of choices of archetypes whose data are captured on a particular form. See the Archetypes and Templates FAQ. The 
openEHR Archetype Model specifications are available from the specification page; online UML.

- Service Model (SM) - This is the computational viewpoint of the openEHR architecture. The service model consists of service definitions for the major services in the EHR computing environment. These are largely derived from existing work in OMG Corbamed, CEN HISA and implementation experience.

- Terminology and other Ontologies - Underpinning archetype-enabled health record systems are knowledge resources such as vocabularies, terminologies and ontologies, which define the semantics of terms and concepts referenced in the health record. Archetypes enable multiple terminologies to be used, and in any natural language in which they are available.

Figure 2.6 presents the relationship of the formal artefacts of openEHR.

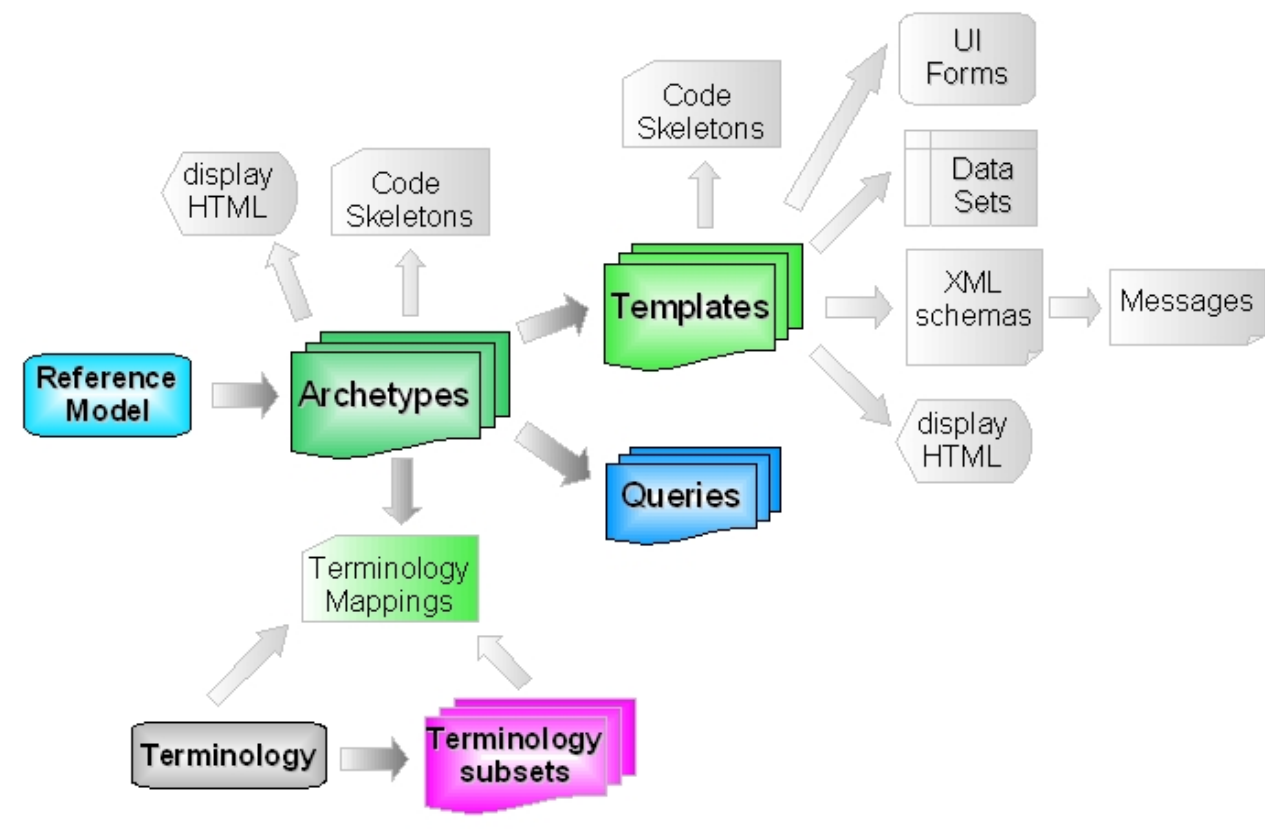

Figure 2.6: The relationship of the formal artefacts of openEHR (adapted from [openEHR, 2007]). 


\subsubsection{Linked2Safety}

Linked2Safety started in 2011 and it is a thirty six month project, promoted to advance clinical practice and accelerate medical research, a project focused on clinical trials and research [Linked2Safety, 2011] . The vision of this project is not only to ensure and empower patients safety, but also support clinical and medical research and improve the quality of healthcare services by providing patients, healthcare professionals and pharmaceutical companies with an innovative interoperability framework [Linked2Safety, 2011]. Linked2Safety built a sustainable business model, as well as a scalable technical infrastructure and platform for the efficient, homogenized access to information, and the effective utilization of the increasing wealth of medical information contained in the EHR and Electronic Data Capture systems [Linked2Safety, 2011]. The 36-month Linked2Safety project, promotes the development of a reference architecture, a data protection framework, a common EHR schema, a lightweight semantic model and an integrated platform that will facilitate the scalable and standardized semantic interlinking, sharing and reuse of heterogeneous EHR repositories. Healthcare professionals, clinical researchers and pharmaceutical companies experts will benefit from a user-friendly, sophisticated, collaborative decision-making environment for:

- Analyzing genetic, environmental and medical data available. Such data exhibit adverse events occurring in the frame of clinical trials, based on the clinical care information existing in the specific patients EHR, leading to the identification of the phenotype and genotype factors that are associated with specific adverse events and thus having direct impact on the patient safety through the early detection of potential patient safety issues; and

- Wide identification and selection of patients for clinical trials, though the seamless and standardized linking with heterogeneous EHR repositories, providing advice on the best design of clinical studies [Linked2Safety, 2011]. 
Indeed Linked2Safety orientation is for a regional and/or national level across Europe, dynamically interconnecting distributed patient data with clinical research efforts, respecting patients anonymity, data ownership and privacy, as well as European and national legislation.

For this project several universities from Europe are involved, such as the University of Manchester, the Gottfried Wilhelm Leibniz Universitat in Hannover and the National University of Ireland, and also institutions and centers from Greece and Cyprus, among others [Linked2Safety, 2011].

From Linked2 Safety global framework several other smaller projects have came to light and are in current implementation. Some of these projects are the EHR $4 C R$, the EU-ADR and the PONTE, which are presented next in detail.

\section{EHR4CR}

EHR $4 C R$, also known as Electronic Health Records for Clinical Research project, aims to design and demonstrate a scalable and cost-effective approach to interoperability between EHR systems and clinical research through initiatives across different therapeutic areas [EHR4CR, 2011]. Expected benefits from academic, pharmaceutical and general healthcare perspectives are [EHR4CR, 2011]:

- Provide tools and services to better plan and conduct academic trials (investigator - initiated trials);

- Facilitate comparative effectiveness research;

- Improve speed and quality of the patient recruitment process and study design by accurate understanding of real patient populations;

- Support to conduct observational and outcomes research studies in real-world settings; 
- Significant facilitation of the reuse of EHR data to allow more efficient management of public health issues; and

- Closer coordination between care providers and patients, resulting in safer and more evidence-based diagnosis and treatment.

Figure 2.7 provides conceptual overview of the project where $E H R 4 C R$ platform will arise in the center and provide a platform for integration and interoperability.

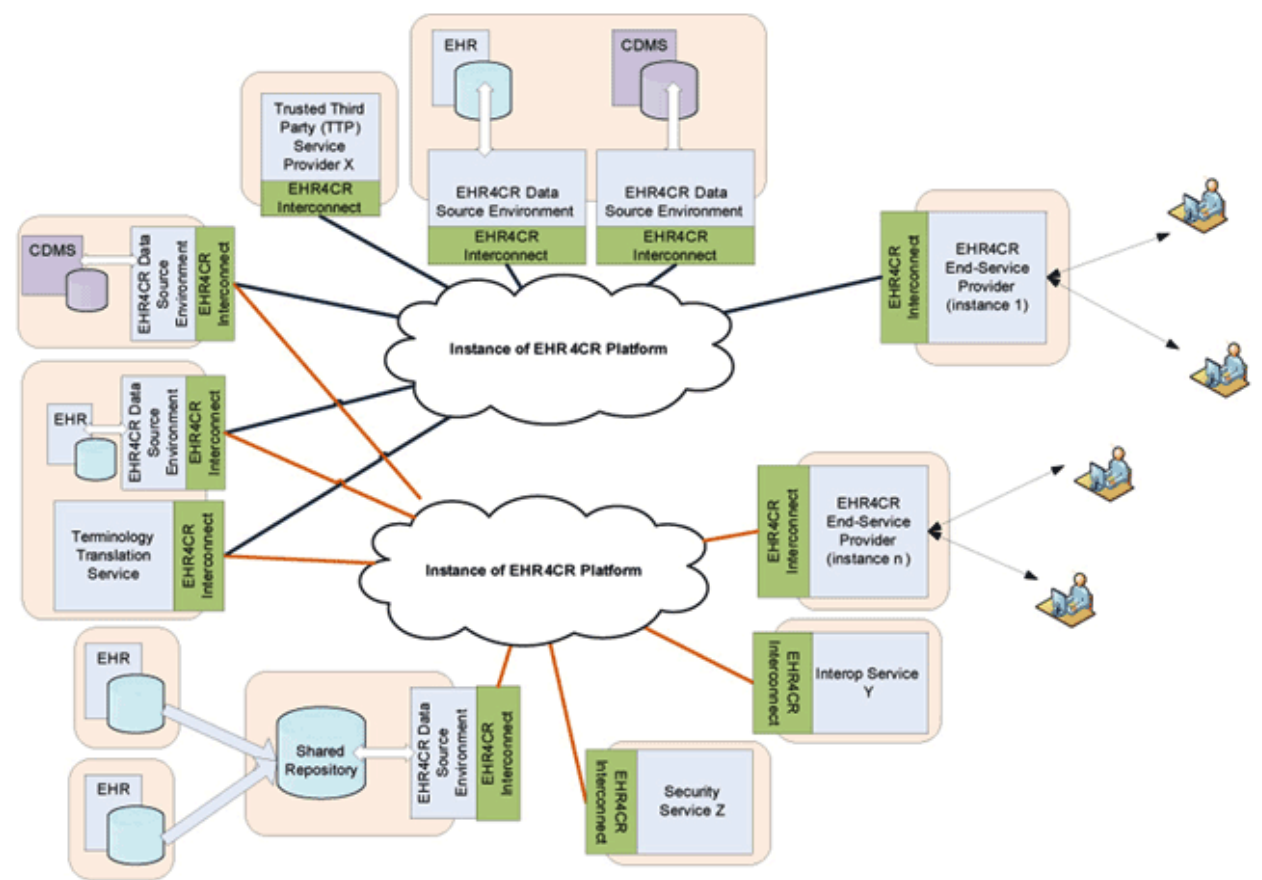

Figure 2.7: EHR4CR conceptual overview (adapted from [EHR4CR, 2011]).

\section{EU-ADR}

The EU-ADR, Exploring and Understanding Adverse Drug Reactions, project aims to develop an innovative computerized system to detect adverse drug reactions (ADRs) by Integrative Mining of Clinical Records and Biomedical Knowledge [EU-ADR, 2008]. EU-ADR is a Research and Development project funded by the Information and Communication Technologies (ICT) Area of the European Commission under the VII Framework Programme [EU-ADR, 2008]. 
The kick-off of this project was in 2008 and from that moment several outputs have become available [EU-ADR, 2012]. For example federated collaborative framework for drug safety studies called the $E U-A D R$ Alliance was developed, which consists of a computer system exploiting data from EHR for the early detection of adverse drug reactions. The system is already mounted for a governance structure and working methods are now in place [EU-ADR, 2012].

\section{Ponte}

PONTE is an European project, that started in 2010 and has an estimate duration of 3 years; it stands for Efficient Patient Recruitment for Innovative Clinical Trials of Existing Drugs to other Indications [PONTE, 2010]. The main goal is to provide a platform following a Service Oriented Architecture (SOA) and Semantic approach. The platform intends to offer automatic intelligent identification of patients eligible to participate within well-specified clinical trials for drug repositioning. It is necessary to focus on mitigating patient safety risks, reducing clinical trial costs and improving clinical trial efficacy [PONTE, 2010].

\subsubsection{MobiGuide}

The MobiGuide project focus on patients with chronic illnesses, and the main aim is to develop an decision-support system that will follow the patients wherever they go, and will help not only them but also their care provider as well, managing their illness, whether they are at home, at work or traveling abroad on holiday or for business [MobiGuide, 2007]. The project started in 2007 and will not finish before 2013 and it is supported under the European Commission Seventh Framework Programme [MobiGuide, 2007].

The patients wear sensors that can monitor biosignals like heart rate, blood pressure. The signals are transmitted to their Smartphone and from there to a pow- 
erful backend computer. The MobiGuide decision-support tools, which have access also to the patient historical clinical data, such as their hospital records, analyse the data, alert the patient about actions that should be taken, ask the patient questions, in the case that additional information is needed, and make recommendations regarding lifestyle changes or contacting care providers. All recommendations regarding therapy are transmitted to the patient care providers. The recommendations are based on evidence-based, state-of-the-art clinical guidelines. During the first years the project focus on the following clinical conditions: atrial fibrillation, gestational diabetes and gestational hypertension [MobiGuide, 2007].

When an Internet connection is not available, the patient's lightweight mobile device can still provide some modicum of support, based on the bodily sensors and on the local mobile device's computational capabilities. Thus, decision support is provided to the patients and to their care providers anytime, anywhere [MobiGuide, 2007].

\subsection{4 epSOS}

epSOS stands for European Patiens Smart Open Services and its main aims are to design, build and evaluate a service infrastructure that demonstrates cross-border interoperability between EHR systems in Europe [epSoS, 2008]. This project started in 2008 and the estimated end date is late in 2013. It is partially funded under the ICT Policy Support Program as part of the Competitiveness and Framework Programm by the European Commission [epSoS, 2008].

This project was born from the opportunity to create and offer seamless healthcare to all European citizens that will have the chance to use cross-border eHealth services when seeking healthcare, whether as tourists, business travelers, commuters or exchange students, in epSOS pilot countries [epSoS, 2008]. Key goals are to improve the quality and safety of healthcare for citizens when traveling to another Eu- 
ropean country. Moreover, epSOS concentrates on developing an eHealth framework that enables secure access to patient health information among different European healthcare systems [epSoS, 2008]. By providing quick access to documentation and reducing medical errors, epSOS framework can make a significant contribution to patient safety [epSoS, 2008]. Another focus of this project is cost reduction providing the medical personnel with life-saving information that could reduce the repetition of diagnostic procedures [epSoS, 2008].

The epSOS architecture is based on a Service-Oriented (SO) paradigm, which services are passive and implemented as Web Services whose interfaces are specified by the Web Service Description Language [W3C, 2010, epSoS, 2008]. Each Participating Nation $(\mathrm{PN})$ provides these services through the National Contact Point that acts as a service provider to other PNs and as a gateway for service consumers. Figure 2.8 provides an overview of the basic architecture of the system.

\section{Basic Architecture}

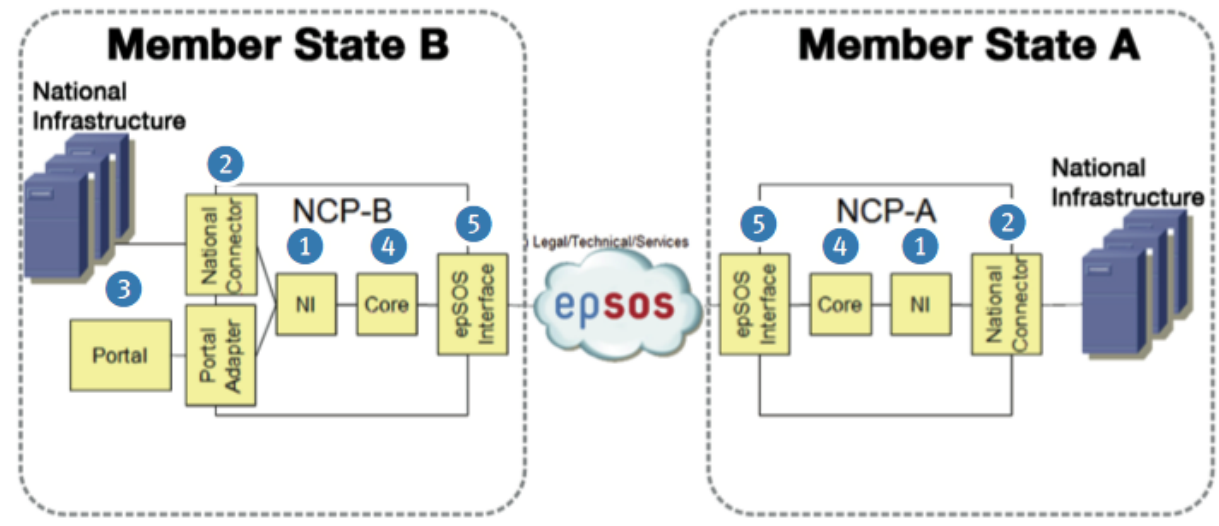

Figure 2.8: epSOS Basic Architecture (adapted from [epSoS, 2012b]).

In Figure 2.8, number 1 represents The Natiomal Interface and number 2 represents The National connector. The National Connector is specific to each country and it is responsible for accessing the national infrastructure and fulfilling the national requirements. Number 3 represents The Portall $\&$ Portal Adapter. The Portal is a Graphical User Interface used by the health professionals when providing epSOS Services (Patient Identification, Patient Summary, ePrescription and eDispensation) 
to patients. The core elements are represented by number 4 . These are the Common Components which were defined within the epSOS project and belong to the business layer in the National Contact Point architecture. They consist of the Security Manager, Policy Manager, Consent Manager, Audit Manager and Repository, the Semantic Transformation Manager, the Terminology Service Access Manager and the component to synchronize National Contact Point configuration and Terminology repository. Finally number 5, The epSoS Interface, which is also a part of the Common Components defined in epSOS initial project and belongs to the epSOS communication layer in the national contact point architecture. It consists of the Inbound Protocol Terminator when acting as the patient country of affiliation and the Outbound Protocol Terminator when acting as the patient country of treatment [epSoS, 2012b].

The epSOS Common Components provide the following end-user services when connected to the national infrastructure of the patient home country:

- Identification Service;

- Patient Service;

- Order Service;

- eDispensation Service; and

- Consent Service.

The National Connect Point encompasses Taxonomy manager and Terminology Service Access Manager for achieving semantic interoperability. In addition, the National Contact Point provides auditing and authentication services [epSoS, 2008].

This project is already implemented and in test phase in several countries all over Europe. Indeed, countries like Spain and France have already their summary for abroad visits available and in Italy for example the first pilot of Integrated electronic 


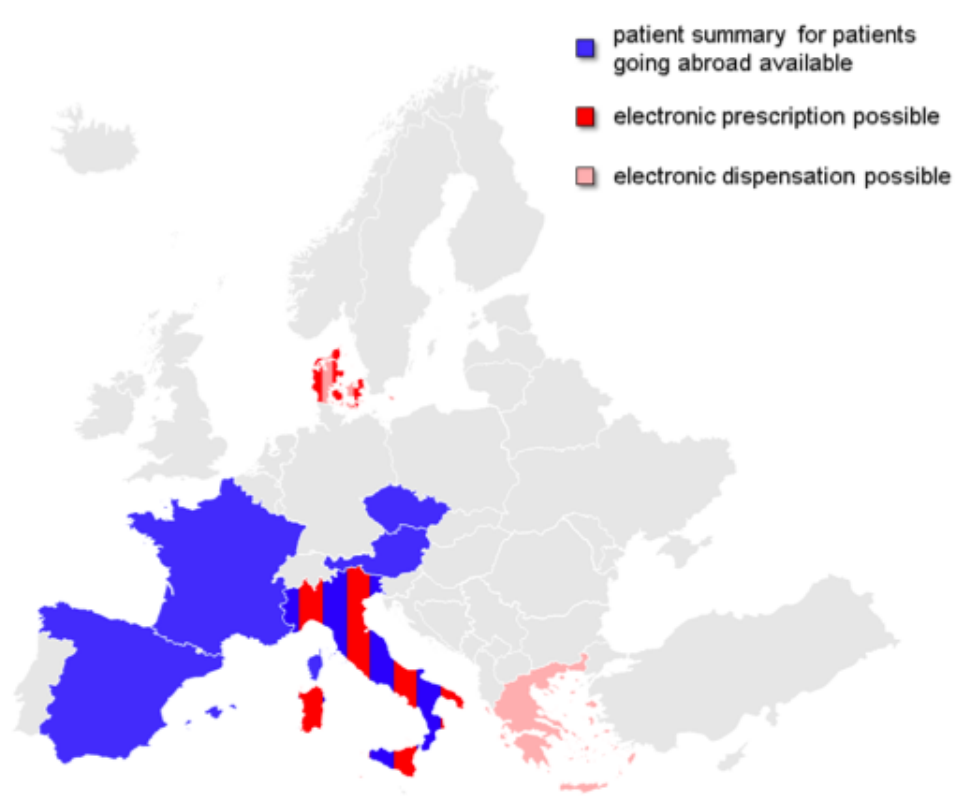

Figure 2.9: European Countries in Pilot phase I (adapted from [epSoS, 2012a]).

prescription is available from April 2012 [epSoS, 2012b]. Figure 2.9 presents the countries already involved in this European initiative.

\subsubsection{SemanticHealthNet}

SemanticHealthNet project is in the very beginning and its main aim is to develop a scalable and sustainable pan-European organizational and governance process for the semantic interoperability of clinical and biomedical knowledge. Its basic infostructure is presented inf Figure 2.10. This SemanticHealthNet will try to help ensure that EHR systems are optimized for patient care, public health and clinical research across healthcare systems and institutions [SemanticHealthNet, 2011]. This project started in 2011 and the estimated end year is 2014. This project is partially funded by the European Commission [SemanticHealthNet, 2011].

The workplan is based in clinical evidences: SemanticHealthNet will try, for example, to capture the needs for evidence-based, patient-centered integrated care and for public health, encapsulating existing European consensus in the management of chronic heart failure and cardiovascular prevention [SemanticHealthNet, 2011]. 


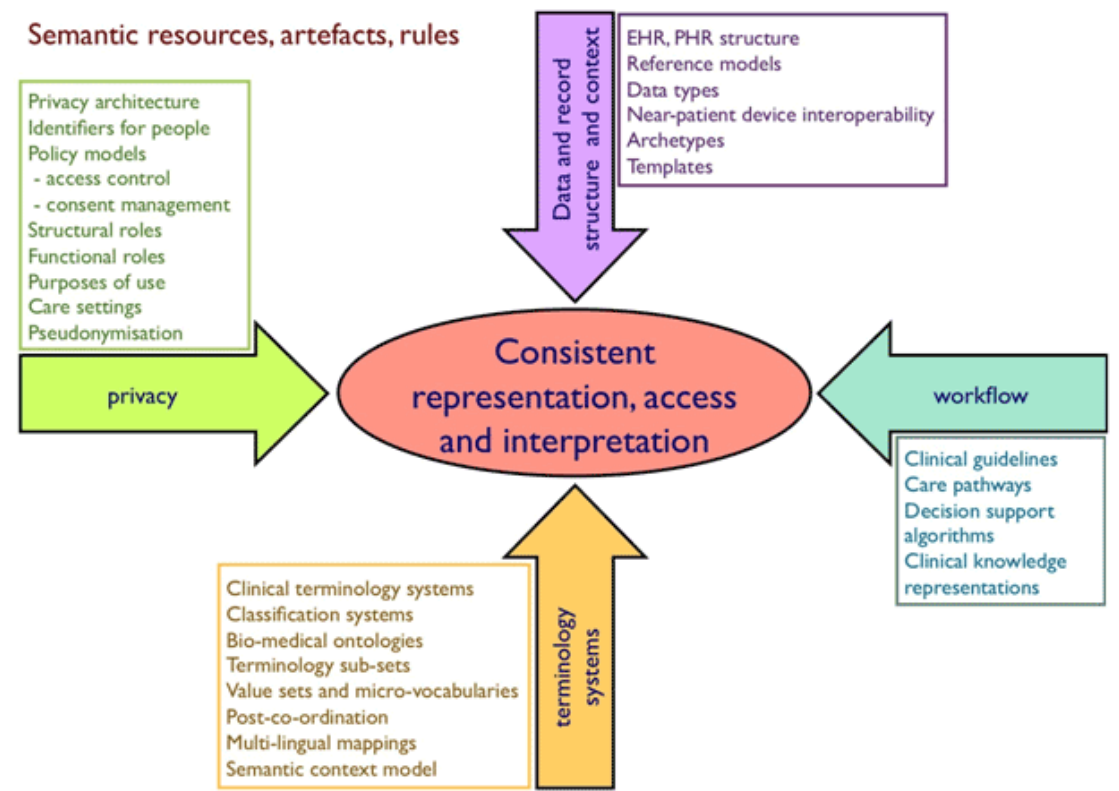

Figure 2.10: Infostructure for semantic interoperability resources (adapted from [SemanticHealthNet, 2011]).

Workplan will include experts in EHR architectures, clinical data structures, terminologies and ontology in order to combine, tailor and pilot their best-of-breed resources in response to the needs articulated by physicians [SemanticHealthNet, 2011].

The project will be divided according to three big Workstreams that will encapsulate nine distinct workplans namely [SemanticHealthNet, 2011]:

\section{- Workstream I:}

- WP1: Patient care exemplar;

- WP2: Public health exemplar; and

- WP3: Stakeholder validation.

\section{- Workstream II:}

- WP4: Harmonized resources;

- WP5: Infostructure and tools; and

- WP6: Industrial engagement. 


\section{- Workstream III:}

- WP7: Adoption and sustainability;

- WP8: European Virtual Organization; and

- WP9: Project management, dissemination, promotion.

In order to become a global project and spread horizons through the world instead of focusing inside Europe the consortium comprises more than 40 internationally recognized experts, including from USA and Canada, ensuring a global impact [SemanticHealthNet, 2011].

\subsubsection{CDA HL7}

The HL7 Clinical Document Architecture (CDA) is based in XML markup standard and intends to specify the encoding, structure and semantics of clinical documents for exchange [CDA, 2000]. CDA is part of the HL7 version 3 standard and was developed using the HL7 development Framework which is based on the HL7 Reference Information Model. CDA documents are persistent in nature. The CDA specifies that the content of the document consists of a mandatory textual part, which ensures human interpretation of the document contents, and optional structured parts for software processing. The structured part relies on coding systems such as from SNOMED and LOINC to represent concepts [CDA, 2000, CT, 2002].

CDA is currently in version 3 and its first version became an American National Standards Institute approved HL7 Standard in November 2000, representing the first specification derived from the Health Level 7 [Dolin et al., 2006].

Figure 2.11 shows the XML structure of the major component of a CDA. The document is wrapped by the tag $<$ ClinicalDocument $>$, which contains both header and body. The header is in between the $<$ ClinicalDocument $>$ and the 


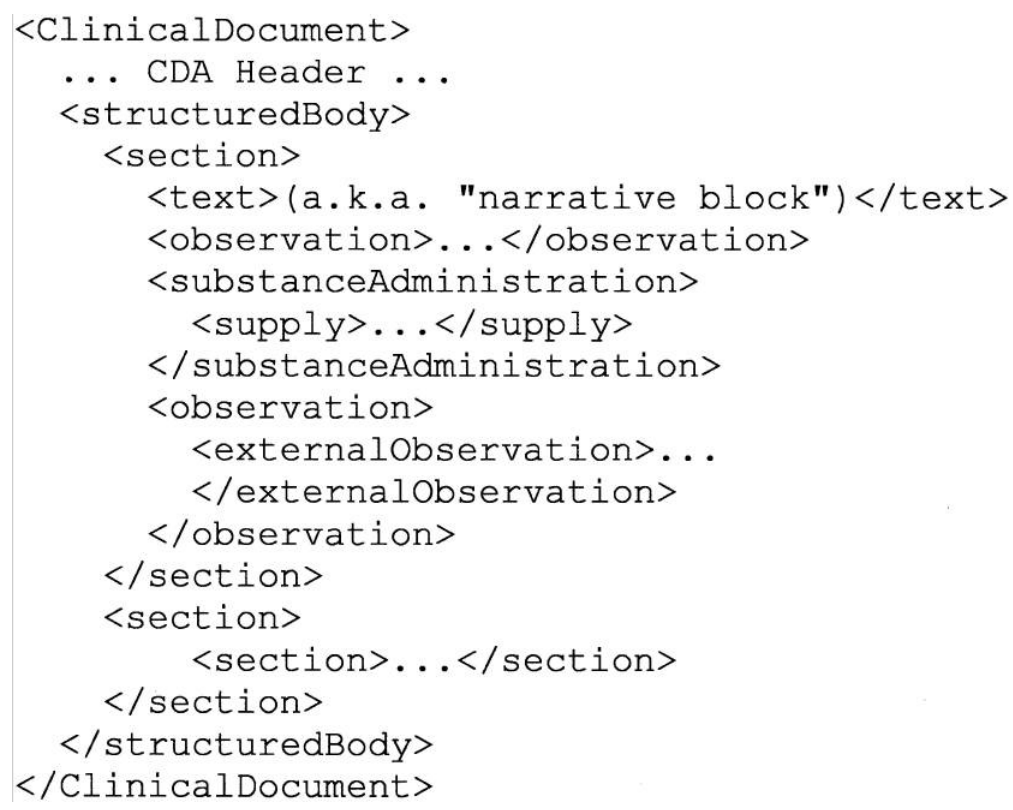

Figure 2.11: Major components of a Clinical Document Architecture document (adapted from [Dolin et al., 2006]).

$<$ structuredBody $>$ elements and identifies and classifies the document and provides information on authentication, the encounter, the patient, and the involved providers [Dolin et al., 2006]. On the other hand, the body contains the clinical report and can be either an unstructured blob or can be comprised of structured markup. The <structuredBody $>$ element is divided up into recursively nestable document sections [Dolin et al., 2006].

A CDA document section is wrapped by the $<$ section $>$ element. Each section can contain a single narrative block and any number of CDA entries and external references. Section $<$ section $>$ contains the tag $<$ text $>$ and also the XML markup that must ensure that the attested portion of the document body is conveyed in narrative blocks such that a recipient, adhering to recipient rendering rules, will correctly render the document. This process ensures human readability and enables a recipient to receive a CDA document from anyone and faithfully render the attested content using a single style sheet [Dolin et al., 2006].

Figure 2.12 shows an example of allergies and adverse reaction document based on CDA structure. Peneicillin, Aspirin and Codein reactions are structured and 
can be understood both by humans and machines providing diagnostic support for physicians directly or by decision support system present in the institution.

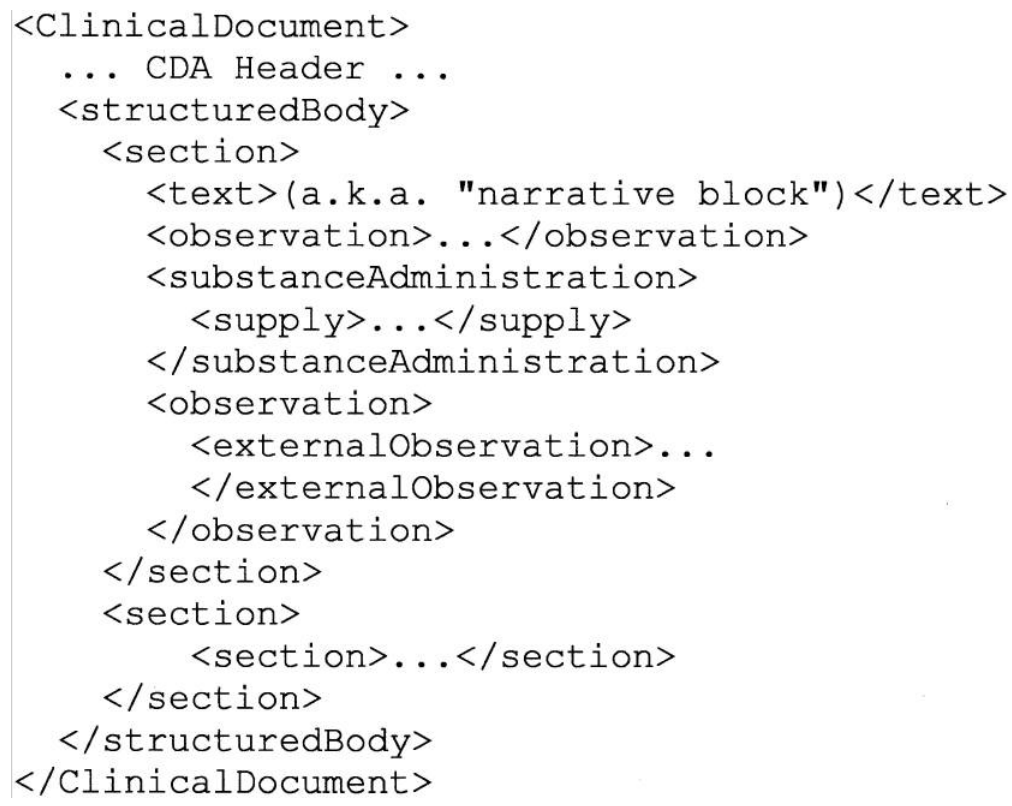

Figure 2.12: CDA - An example of allergies and adverse reaction (adapted from [Dolin et al., 2006]).

CDA, is a normative HL7 specification approved and represents a stable platform for the exchange of clinical documents [Dolin et al., 2006]. The underlying design minimizes the technical barriers to adoption while providing a migration pathway toward progressively richer computer-processable content.

\subsection{Open-Source Software in Healthcare}

Open-source describes practices in production and development that prop up access to the finished source code to users. The basic principles are to provide endusers the code as well as the right to amend it according to the needs. Motivations for using and developing open-source software are mixed, ranging from philosophical and ethical reasons to pure practical issues. Usually, the first perceived advantage of open-source models is the fact that open-source software is made available free or at a low cost. But this characteristic is not exclusive to open-source software, 
and several proprietary software products are made available in similar way. What really distinguishes open-source software from software available without fee is the combination of effects due to the following characteristics [J.M., 2000]:

- The availability of the source code and the right to modify it, which enables the unlimited tuning and improvement of a software product;

- The right to redistribute modifications and improvements to the code, permits all the advantages due to the modifiability of the software to be shared by large communities;

- The right to use the software in any way. This, combined with redistribution rights, ensures a large population of users, which helps in turn to build up a market for support and customization of the software, which can only attract more and more developers to work in a common project.

The combination of competition and cooperation mechanisms is visible in almost any open source project, where every project is in some sense competing with others for resources and market acceptance, while collaborating with the reuse of the same code base. Usually, this mixture of competition and collaboration is not intentional; in short, everybody is forced to compete by exposing the tools (the source code) they are using, and improvements are quick to spread through the competing projects. Competition and collaboration are probably the ultimate cause of the high efficiency, in terms of quality and quantity of software produced with a given set of resources, which open source projects reach.

Open-source models are rapidly being applied in many different fields of endeavor, such as biotechnology and bioinformatics. From a global perspective, healthcare facilities with the same goals and restrictions can improve their Information Systems by sharing source-code and knowledge between them. Besides their abovementioned advantages, open-source applications suffer from several additional barri- 
ers to the general Information Technologies implementation issues. They include the lack of professional knowledge, legal and licensing issues, functional gaps and the lack of a road map for sustainability. Krogh and Hippel in 2006 presented the renewed urgency to adopt health and medical informatics applications and how open-source approaches are gaining attention in the healthcare industry [Krogh and Hippel, 2006].

Open-source software can be characterized by collaboration among individuals and organizations with common interests, shared intellectual property, and a commitment to standards. Information technology in the healthcare industry is evolving from an administrative tool for billing and bookkeeping to a clinical tool for improving the quality and efficiency of healthcare, and the scope of information sharing is expanding beyond the walls of individual institutions. Achieving this level of integration will require that software models overcome a host of technical obstacles, and that they are accessible, affordable, and widely supported.

While not heralding the end of commercial software vendors, conditions are ripe for open-source solutions to take root in healthcare, and that it will likely become the standard for capturing, sharing, and managing patient information to support quality care. It also notes that healthcare businesses have the opportunity to take the lead and drive the shift to this new model [Goulde and Brown, 2006]. The main motivations for using open-source software in healthcare are reduced total costof-ownership, faster delivery of systems, systems being more secure, elimination of vendor lock-in and control over the software (possibility of adapting to local needs).

As Murray describes Information Systems have grown in a structured way and are now considered as being part of good and patient oriented healthcare unities [Murray et al., 2009]. Tools to facilitate the sharing of clinical data are a more recent development in open-source healthcare IT. Healthcare data and interoperability standards, including HL7, CCHIT, and IHE, have all been growing in importance and maturity. Similarly to how standards like HTML, HTTP, and DNS led to the development and adoption of open-source software, a number of open-source soft- 
ware communities have started building tools to implement these healthcare standards. The Mirth project provides an open-source interface engine that can route and transform HL7, NCPDP, and other message formats.

Fundamentally, open-source is about creating a collaborative environment for problem solving. As healthcare technology standards evolve and healthcare IT systems adopt standards-based software technologies that enable greater interoperability, the opportunities for healthcare IT collaboration will only grow [Redhat, 2007]. The compelling economics of open-source and its collaborative development model will continue to improve the affordability of these complex healthcare information systems that are crucial to improving the quality of patient care. 

Chapter 3

\section{Results}



This chapter is divided into four parts called studies, each one representing an article presented to scientific approval whether in conference proceedings or book chapters.

The first article presents the Electronic Semantic Health Record edited by Springer Boston in 2010 [Peixoto et al., 2010]. Systems Interoperability and Electronic Health Records are responsible for an exponential number of visits in electronic repository, either in terms of medical professionals or related staff. This article presentes semantic as a key word which refers to a computational paradigm that allows for interoperability, enabling intelligent ubiquitous computation and communications in order to increase quality of information and decision support [Peixoto et al., 2010].

The next article refers to AASYS, an Appointment Alert System which was presented at the European Simulation and Modeling Conference in Guimarães, Portugal [Peixoto et al., 2012b], which the main aims were to reduce waiting time and improve quality on patient communication. New possibilities upraise with new smart phones and it is up to IT technicians to use them according to national standards and laws. From this work there was an almost $80 \%$ reduction in misses from 2010 to 2011, which is a good indicator of the good performance of the AASYS [Peixoto et al., 2010].

Study number three presents a framework for scheduling preventive actions according to all the needs called ScheduleIT. This study was presented at the International Conference on Health and Social Care Information Systems and Technologies in, Algarve, Portugal in October 2012 [Peixoto et al., 2012a]. Preventive actions management plays a crucial role in clinical applications, not only for those who depend on data to make decisions, but also for those who monitor the operational and financial impact of the systems. This paper presents an open-source platform, named ScheduleIT, capable of managing preventive routines. The platform is based on an estimation model that determines the optimal time interval for interventions, 
according to the criticality of the system and the number of non-programed faults, among others. At this point, the platform covers around $75 \%$ of the healthcare systems and it is fully accepted by its main users as a reliable and effective preventive tool [Peixoto et al., 2012a].

Finally the last study presents AIDA as an Agency for Interoperability, to be presented in the 20th International Symposium on Methodologies for Intelligent Systems, 2012 World Intelligence Congress, Macau (to be published by LNCS Springer) [Peixoto et al., 2012c]. Healthcare systems have to be addressed in terms of a wide variety of heterogeneous, distributed and ubiquitous systems speaking different languages, integrating medical equipments and customized by different entities, which in turn were set by different people aiming at different goals. The main goal of this work is to gathering this information and present it in a readable way to physicians. This work shows how to achieve interoperability in healthcare institutions using AIDA [Peixoto et al., 2012c]. 


\subsection{Study I - Semantic Interoperability and Health Records}

Hugo Peixoto, José Machado, José Neves and António Abelha

E-Health. In Hiroshi Takeda (Ed.), (Vol. 335, pp. 236-237): Springer Boston 2010. 



\subsubsection{Abstract}

Systems Interoperability and Electronic Health Records are responsible for an exponential number of visits in electronic repository, either in terms of medical professionals or related staff. This is paramount for a better and sustainable quality-of-care in clinical assistance and of great potential to medical research. Following these lines of though, we present an agency for the diffusion, integration and archiving of medical information, and show how semantic web can enforce the use of electronic documents in order to envisage free-paper hospitals.

\subsubsection{Introduction}

Healthcare is turning into a science based on information and reputation [I-1]. In the last decade, information systems in healthcare have gained great importance and have grown in quality and in quantity. EHR is a repository of information concerning an individual in an electronic format, stored and transmitted securely and may be accessed by multiple users [I-2]. The main objective is to ensure ubiquity; i.e. information is accessible at anytime and anywhere. Demands of information handling within the healthcare sector range from clinically valuable patient-specific information to a variety of aggregation levels for follow-up and statistical and/or quantifiable reporting. On the other hand, semantic interoperability between healthcare providers is a hard task [I-3].

Researchers in the field of Hospital Information Systems (HIS) have focused special attention to the field of quality of information. A Health Unit is computationally represented by a heterogeneous set of applications that speak different languages and are customized by different customers. So a practical and effective communication platform between information systems is paramount taking into consideration the quality of information [I-3 - I-4]. 
The EHR semantization is one of the latest advances, in the field of internal and external interoperability. With the inclusion of the Semantic Clinical Process it will be possible to guarantee the management of large flows of information while preserving quality, improving clinical practices and guarantying access to information over the paraphernalia of existing applications in the health unity.

\subsubsection{Implementation}

In order to fulfill this goal, it was developed, at University of Minho, an Agency for the Integration, Diffusion, and Archive (AIDA) of medical information, which allows interoperability with different HIS [I-4], and a EHR system.

Integration of the information from the different departments and services within healthcare institutions in order to make it available for the EHR system is also an important requisite for an efficient EHR. The electronic ordering embedded in EHR can be used not only to obtain medical equipment or pharmacological prescriptions, but also for acquiring laboratory and imaging studies outside the service where it is used. Furthermore, it may enable the centralization of exam display, allowing different services to share results concerning the same patient, diminishing costs on unnecessary exams, and above all, improving the quality of service being provided.

\subsubsection{Conclusions}

Semantic, a key word in our work refers to a computational paradigm that allows for interoperability, enabling intelligent ubiquitous computation and communications in order to increase quality of information and decision support. Indeed, doctors gather dissimilar types of information about patients for clinical practices. Different types of tests are visited in a user-friendly, including physical exams, imag- 
ing tests (e.g. XR, CT or MRI), laboratory tests (e.g. blood, urine, fluids or tissues), or pathology and surgical reports, i.e. in Computational Science, the scientific problem must be expressed mathematically, known as the Algorithm. Using semantic web, the algorithm is translated into one or more computer programs and implemented on one or more types of hardware. In our work, the combination of software and hardware is referred to as the Computational Architecture, the AIDA agency referred to above. It is shown that user-friendlier interfaces have a high number of visits, reducing costs and increasing the quality-of-care.

\subsubsection{References}

[I-1] Hersh, W.: Medical Informatics - Improving Health Care Through Information . In: JAMA (2002).

[I-2] Eichelberg, M., Aden, T., Riesmeier, J., Dogac, A. and Laleci, G.: A survey and Analysis of Electronic Healthcare Record Standards. In: ACM Computing Surveys, Vol. V, No. N20YY, Pages 1-47.

[I-3] Hanzlícek, P., Precková, P. and Zvárová, J.: Semantic Interoperability in the Structured Electronic Health Record. In: EuroMISE

[I-4] Machado, J., Abelha, A., Novais, P., Neves, J. and Neves, J.: Quality of Service in Healthcare Units. In: ESM. Universite du Havre, Le Havre, France (2008). 



\subsection{Study II - AASYS - Appointment Alert System}

An open-source-based software to improve show rates in a healthcare unity

Hugo Peixoto, José Machado, António Abelha, José Neves, Manuel Santos and António Correia Novais, P.; Machado, J.; Rodrigues, César; Abelha, A.(ed), Modelling and Simulation 2011, EUROSIS. 



\subsubsection{Abstract}

In this paper we show a practical approach to deal with government impositions correlated with on time appointments in major healthcare facilities in Portugal. Reduce waiting time and improve quality on patient communication are two of the main objectives in this project. Information Systems can improve patient communication with hospitals and build a trust and better patient caregiver relationship. New possibilities upraise with new smart phones and it is up to us to use it according to national standards and laws. We intend to establish a platform named Appointment Alert System (AASYS) that aids healthcare facilities to decrease costs correlated with calls for appointments, which indeed one of the major sources of appointment department costs. Schedule administration is taken in consideration and an user interface web page was also built. At the end we prove that an alert system based on open source software leading to short message service and email can help decrease costs and increase show rates.

\subsubsection{Introduction}

Handel and Hackman in 2010 indicate in their study that Information Communication Technology interventions can improve the efficiency of healthcare services [II-6]. Hospitals could significantly improve in patient appraisal by providing a fast and effective alert and notification system by all means available and with this increase patient attendance. Improve patient assiduity cannot only reduce number of hours spent with doctors with no patients, but also increase cost effectiveness workflows. Schedules can be redesigned to improve attendance times and besides improving appointment times, human resources can be better used to benefit the institution. Studies show that there are distinct reasons for missed appointments [II-3], and several misses are common in Portuguese hospitals [II-12].

Centro Hospitalar do Tâmega e Sousa (CHTS) is a major hospital located in 
the north of Portugal and it covers over 500.000 patients from several regions near Vale do Sousa. Indeed, this population led to 247.003 appointments in 2010 at a pace of almost one thousand every day, over 70 physicians per day as well as 30 administrative helpers. Therefore a rigid schedule plan is taken in consideration to avoid unnecessary losses.

Nowadays Health Information Systems (HIS) capabilities are increasingly exposed and exploited. A Health Unit is computationally represented by a heterogeneous set of applications that speak different languages and are customized by different customers. So a practical and effective communication platform between information systems is paramount taking into consideration the quality of information.

A study published in 2010 by ANACOM, the National Communication Authority in Portugal, reveals that are 15.929 million cell-phones were operating in Portugal for a total of 10 million population size in the last trimester in 2009 [II1]. Adding Internet to this equation is simple to deduce what are the best means to achieve less misses, and they are: Short Message Service (SMS) and e-mail. We present the use of Mirth Connect to empower interoperability and integration [II-11]. The impact of open source in healthcare is still limited due to corporate licenses, although several other areas are now using them [II-13].

Janamanchi and colleagues [II-8] managed to publish a study on the state and profile of open source software projects in health care and medical informatics and they state that more and more healthcare organizations tend to be sponsors of such projects and not only pure users. In this paper we first present Information Systems and how essential they are to healthcare facilities. Next, we show how Integration and Interoperability can be the way to promote communication between information silos within a hospital. Before the workflow, results and conclusion we present how open source and web services can be implemented in healthcare and the best features of these to meet the work goals. 


\subsubsection{Information Systems}

Healthcare is turning into a science based on information [II-7]. In the last decade, HIS have gained great importance and have grown in quality and in quantity. As Sujansky refers the fast growth of Information Systems is due to quick expansion of Biomedical Knowledge, reduction in computing costs and spread of internet access have created an ocean of electronic data and this opens a lot of study opportunities [II-15]. Demands of information handling within the healthcare sector range from clinically valuable patient-specific information to a variety of aggregation levels for followup and statistical and/or quantifiable reporting. HIS have been for some years a very attractive domain for Computer Science (CS) researchers. Even more, such systems have great potential for information integration and automation, and this is an issue of study in which medicine and web service technologies and methodologies for problem solving may overlap [II-7]. Furthermore, healthcare systems have to be addressed in terms of a wide variety of heterogeneous, distributed and ubiquitous systems speaking different languages, integrating medical equipment and customized by different entities, which in turn were set by different people aiming at different goals [II-7].

\section{Integration and Interoperability}

Communication, management and commerce via the Internet became a central focus for businesses, consumers and government. The actual time marks the convergence of the computer and communications industries and their associated services and products [II-14]. A HIS is a set of software applications that often do not interact and create silos of information. Currently, despite the new technological advances, there is still a long way to achieve full interoperability in a healthcare unit. The various sources of information and the unique patient identification were major problems in the project development [II-14]. 
Current implementations still lack information quality and access due to silos of information created by proprietary software and old equipment that doesn't integrate with HIS among other known problems. Despite all the efforts full interoperability is still to come and until that point a lot has to be done and there is still a lot of road to travel. The lack of integration between the different HIS is not only an obstacle for a more effective clinical practice, but it may lead to a suboptimal care for the patient. In this project the main goal was to run into governmental laws and integrate all medical and chirurgical appointments in one single alert system, which reduces costs to the institution and time for administrative tasks. Controlling every appointment implies a huge effort, and several variables should be taken in to consideration. Healthcare Information Systems have become an important helper in these tasks and flawless systems are easy to build, preventing bad procedures and amending potential mistakes.

Figure 3.1 of the integration schemashows the integration model adopted to solve this task. Integration between medical schedules, chirurgical schedules and free spaces is displayed on user friendly web page. A final structured database that results from user interaction with the system is used to feed the main open source software Mirth Connect and alert patients.

The alert system enables one to create, send and retrieve messages online. It

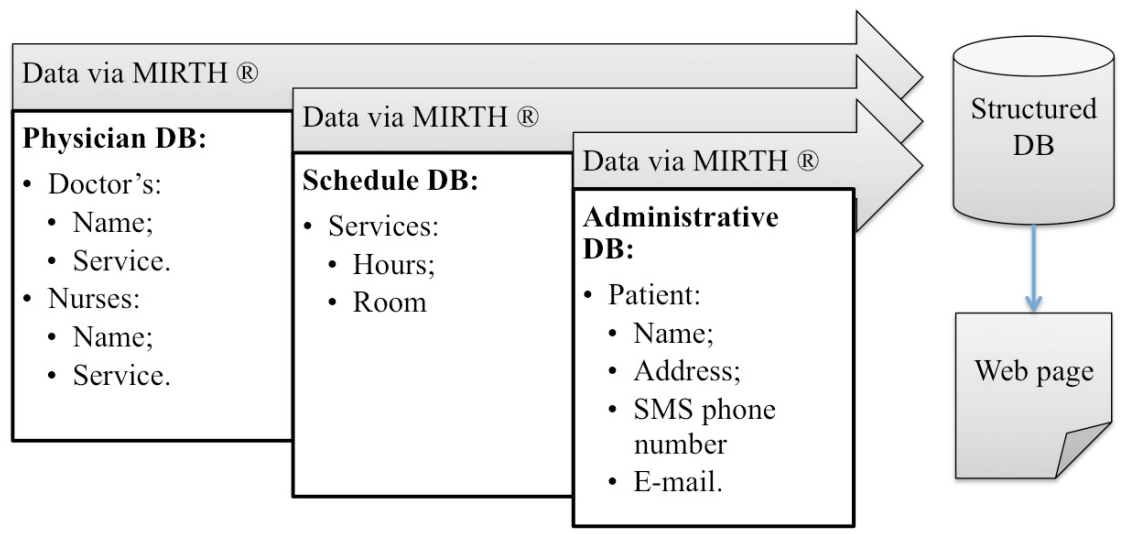

Figure 3.1: Overview of the integration schema. 
may be very useful for handling data, images or even file exchange. Encryption and the right protocols of trading are also paramount [II-10]. Alert systems are extremely important not only for the internal workflow in a healthcare institution, but as well as an essential component for the development of group work [II-16].

\subsubsection{Open Source Software}

Open source software, can be characterized by collaboration among individuals and organizations with common interests, shared intellectual property, and a commitment to standards. The open source model includes the concept of concurrent yet different agendas and differing approaches in production, in contrast with more centralized models of development such as those typically used in commercial software companies. The main principle and practice to development is peer production by bartering and collaboration, with the end-product, source-material, "blue-prints" and documentation available at no cost to the public. This is increasingly being applied in other fields of endeavor, such as biotechnology.

Taken globally several healthcare facilities with the same goals can share information and goals. Open Source applications suffer from several additional barriers to the general Information Technologies implementation issues. They include lack of professional knowledge, as well as, executives lacking knowledge about the benefits of open source. Krogh and Hippel in 2006 presented the renewed urgency to adopt health and medical informatics applications and how open source approaches are gaining attention in the health care industry [II-9].

Information technology in the health care industry is evolving from an administrative tool for billing and bookkeeping to a clinical tool for improving the quality and efficiency of health care, and the scope of information sharing is expanding beyond the walls of individual institutions. Achieving this level of integration will require that software models overcome a host of technical obstacles, and that they 
are accessible, affordable, and widely supported. While not heralding the end of commercial software vendors, conditions are ripe for open source solutions to take root in health care, and that it will likely become the standard for capturing, sharing, and managing patient information to support quality care. It also notes that health care businesses have the opportunity to take the lead and drive the shift to this new model (Goulde and Brown 2006). The main motivations for using Open Source software in healthcare are:

- Reduced total cost-of-ownership;

- Faster delivery of systems;

- Systems being more secure;

- Elimination of vendor lock-in;

- Control over the software (possibility of adapting to local needs).

As Murray describes Information Systems have grown in a structured way and are now considered as being part of good and patient oriented healthcare unities [II-13]. For example, Care2 X, an open source project is one of the several projects ongoing in healthcare. This project is based in four main areas and relies on open source standards. An Electronic Medical Record is under development in Europe and may well be one big substitute to commercial approaches, taking the best of open source standards [II-2].

\subsubsection{AASYS Overview}

One of major tasks to accomplish the desired goal was to collect several phone numbers among the population. New technologies are hard to implement but proximity actions were performed. In order to put this system to work, several public 
collections of correct demographic data were executed. Adding to these actions was instituted internally, that in every single appointment in 2010 the administrative crew had to complete the needed information of the patients or correct information that could lead to future errors in the system.

After this first task was made from a total of numbers 163895 in January 2010 we managed to collect 285560 phone numbers in January 2011. On the other hand, 120739 emails are now correct where in 2010 there were only 80655 correct. A legal issue comes up when providing Short Message Service contact number since every patient should decide whether or not he or she wants to receive this kind of alert. In order to have control of this situation it was necessary to change the basic HIS and provide an extra field in database. This way, patients can provide a different number for SMS service and an emergent contact number when needed. Email was also one of the alert systems to be designed and although Internet is becoming part of everyone's life for elderly people it is still hard to find an email contact.

Every day over 500 letters with appointments calling are issued to the post office meaning costs with paper, envelop and post fees.All this work is just affordable when all appointments are concluded otherwise all the money spent in that call will go to waste and nothing can take it back. Figure - Global Workflowshows the global approach and workflow followed to achieve the final goal. The framework used was Mirth Connect $\mathrm{R}$ open-source software build in JAVA. Mirth Connect was used because is open source and gives correct procedure to all that was needed. Mirth is used, not only, to build information in a structured database to contact patients, but also to contact a commercial Web Service that provides a SMS service.

In Figure 3.2 Global Workflow the first databases are part of the HIS and combine patient demographic information such as SMS phone contact and email, schedule appointments for the day, doctors in scale to give medical care and chirurgical treatment. Having XML message service of Mirth working on the background it is possible to collect all the available data and present it in a user interface friendly 


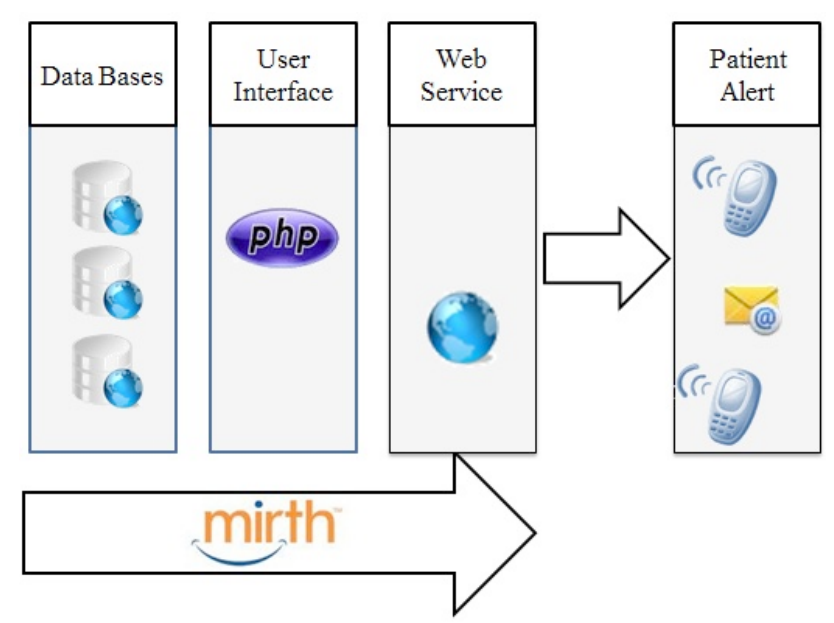

Figure 3.2: Global Workflow.

web page. An administrative team can send in only one step all SMS and email for a specific day or, if wanted or needed, SMS and email can be sent to a certain patient. In the final step, web services provided by a mobile phone company delivers the short message service that alerts the patient. As Dogac stated Web services in healthcare domain brings many advantages such as, providing interoperability of medical information systems through standardizing the access to data through WSDL and SOAP and extend the healthcare enterprises by making their own services available to others [II-4].

To send a SMS to patients the phone company provided us a web service that only needs a few parameterizations to work. The major variables are $\$\{$ user $\}$; $\$\{$ pass $\} ; \$\{$ name $\} ; \$\{$ type $\} ; \$\{$ sms content $\} ; \$\{$ sms number $\}$. On the other hand sending the email requires only an exchange domain, which was already configured in CHTS for internal and external email service to workers. SMTP is contacted providing only the basic email data: $\$$ \{email from $\} ; \$\{$ email to $\} ; \$\{$ email subject $\}$; $\$\{$ email content $\}$. Whether in SMS or email alert a log database is kept and send data and time is saved. With this log database is possible to track potential errors. For this purpose two new agents were built in Mirth Connect. The first agent controls the number of email sent and provides an email and SMS alert to Administrative Chief and to Information System Project Leader. The second agent has the 
same goal but controls the number of SMS sent.

\subsubsection{Results and Discussion}

AASYS was implemented in January 2011 and all the results presented bellow correspond to the first semester of 2011. In order to have some comparison the homologue period of 2010 was used. The total number of appointments scheduled from January until May in 2010 was 107.076, while in 2011 the total of appointments was 111.508.Looking at this number is possible to determine an increase of appointments, meaning the effort made to decrease waiting lists. To evaluate the results of the implemented systems was necessary to determine whether the show rate increased or decreased along the first six months of the year 2011 compared to the same period in 2010. Another important issue that was taken in consideration was if the missed appointments were canceled in time to change to other patient that needed that appointment. Table 3.1 shows the cancellation time of the appointments for the two periods.

Table 3.1: Total of schedule periods

\begin{tabular}{rcc}
\hline Cancelation time & $\mathbf{2 0 1 0}$ & $\mathbf{2 0 1 1}$ \\
\hline Before appointment & 13.908 & 16.565 \\
Same day as appointment & 1.077 & 1.034 \\
After appointment day & 1.068 & 520 \\
\hline
\end{tabular}

As proved by Table 3.1, the number of cancellations before the appointment day has increased from 13.908 to 16.565 . This result lead to new reschedules and helped substantially to reduce waiting lists, since new appointments were scheduled and other patient could take the appointment time instead. Side by side, since no free spaces are available, doctors, nurses and administrative time is monetized leading to better cost control. After appointment day cancellations decreased by $50 \%$ and this can already provide the final predicted results to this work and how well AASYS managed to deal with schedule and show rates problem. In 2010 a total 
of 103.121 appointments were actually performed, while in 2011 the number raised to 109.577 .

Figure 3.3(a) presents the total number of canceled appointments and Figure 3.3(b) presents the total of misses to the appointments. As result shows, there was an almost $80 \%$ reduction in misses from one year to the other, which is a good indicator of the good performance of the AASYS. Besides this good performance, there are several other aspects to be taken into consideration that could significantly affect the expected results. Indeed a better approach to users should be taken in consideration, since elderly population cannot undertake this changes as well as the younger one.

Great effort was taken in the last semester of 2010 to collect as many phone numbers and emails as possible, however for a total of nearly 1.000 appointments per day, the medium number of SMS was 400, and 500 emails. Increasing correct phone numbers and emails is one of the major improvements that can be taken into consideration.

No major problems with the performance of the agents were experienced since MIRTH CONNECT (C) based agents are pretty stable for current use. The major difficulty was to contact the phone company web service since healthcare unities

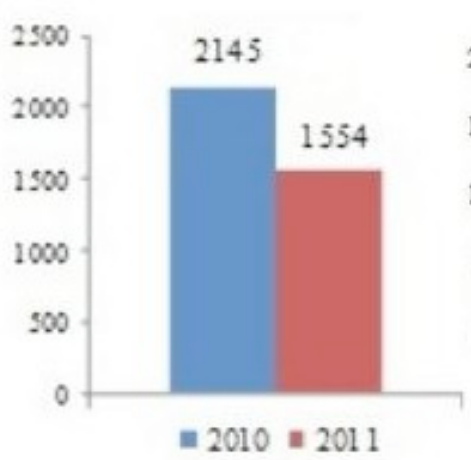

(a) Canceled

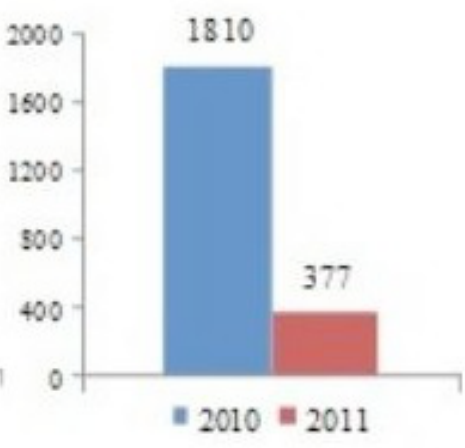

(b) Missed

Figure 3.3: Number of canceled (a) and missed (b) appointments. 
are within a closed LAN. Additionally, AASYS reduce $30 \%$ a day, the number of letters sent to post office to be delivered to patients. From a $0,30 €$ letter cost, just for post office fees, The AASYS platform managed to deliver the same information for patients for just $0,06 €$ per message. Faster, safer, law compatible and cheaper system was achieved when AASYS was installed at CHTS appointment department.

\subsubsection{Conclusions}

In this paper, we present a prototype for Appointment Alert system in a healthcare unity based on integration, interoperability and open source software. The AASYS is one of the objectives of a much more ambitious multidisciplinary effort of Centro Hospitalar do Tâmega e Sousa and University of Minho group of Artificial Intelligence, known as GIA. Such project a seeks to fully integrate and interoperate a healthcare facility using known standards or applying new ones. Although the software presented is still at the initial stages of development it was capable of providing better performance at schedule cancels and cost reduction in CHTS. The current version of the AASYS serves as a basis for future implementation that will focus on end-to-end communication allowing users to contact the care provider via SMS and email.

\subsubsection{References}

[II-1] ANACOM, 2010. ANACOM - Mobile telephone service has 15.9 million users in 2009.

[II-2] Care2x, 2010. Care2x - The open source hospital information system.

[II-3] Defife J.A.; Conklin C.Z.; Smith J.M.; and Poole J., 2010. Psychotherapy Appointment no-shows: Rates and Reasons. Psychotherapy: Theory / Research / Practice / Training, 47, no. 3, 413-417. Doi: 10.1037 / a0021168. 
[II-4] Dogac A.; Laleci G.B.; Kirbas S.; Kabak Y.; Sinir S.S.; Yildiz A.; and Gurcan Y., 2006. Artemis: Deploying semantically enriched Web services in the healthcare domain. Information Systems, 31, no. 4-5, 321-339.Doi: 10.1016 / j.is.2005.02.006.

[II-5] Goulde M. and Brown E., 2006. Open Source Software: A Primer for Health Care Leaders. California Health- care Foundation, ihealthreports.

[II-6] Handel D.A. and Hackman J.L., 2010. Implementing Electronic Health Records in the Emergency Department. The Journal of Emergency Medicine, 38, no. 2, 257-263.Doi: 10.1016 / j.jemermed.2008.01.020.

[II-7] Hersh W.R., 2002. Medical informatics: improving health care through information. JAMA, 288, no. 16, 1955-8.

[II-8] Janamanchi B.; Katsamakas E.; Raghupathi W.; and Gao W., 2009. The State and Profile of Open Source Software Projects in health and medical informatics.International Journal of Medical Informatics, 78, no. 7, 457-472.Doi: 10.1016/j.ijmedinf.2009.02.006.

[II-9] Krogh G.v. and HippelE.v., 2006. The Promise of Research on Open Source Software. Manage Sci, 52, no. 7, 975-983. 1246150.

[II-10] Machado; Abelha A.; Novais P.; and Neves J.; and J. J.N., 2008. Improving Patient Assistance and Medical Practices through Intelligent Agents.

[II-11] MIRTHCOP, 2011.Home - Mirth Corporation.

[II-12] Montalvo A.; Coentro L.; and Cavaco A., 2000. Quem Falta às Consultas? Os Motivos e as Consequências.

[II-13] Murray P.J.; Wright G.; Karopka T.; Betts H.; and Orel A., 2009. Open source and healthcare in Europe time to put leading edge ideas into practice. Stud Health Technol Inform, 150, 963-7. 
[II-14] Peixoto H.; Machado J.; Neves J.; and Abelha A., 2010. Semantic Interoperability and Health Records, Springer Boston, IFIP Advances in Information and Communication Technology, vol. 335. 236-237. Sujansky W., 2001. Heterogeneous database integration in biomedicine.J Biomed Inform, 34, no. 4, 285-98.

[II-15] Sujansky W., 2001. Heterogeneous database integration in biomedicine. J Biomed Inform, 34, no. 4, 285-98.

[II-16] Weed L.L., 1971. The problem oriented record as a basic tool in medical education, patient care and clinical research. Ann Clin Res, 3, no. 3, 131-4. 



\subsection{Study III - ScheduleIT}

Open-Source Preventive Actions Management Platform in Healthcare Information

Systems

Hugo Peixoto, António Abelha, Manuel Santos and José Machado CENTERIS 2012 - Conference on ENTERprise Information Systems / HCIST 2012 International Conference on Health and Social Care Information Systems and Technologies

Healthcare Information Systems, Procedia Technology, Volume 5, Elsevier, 2012. 



\subsubsection{Abstract}

Preventive actions management plays a crucial role in clinical applications, not only for those who depend on data to make decisions, but also for those who monitor the operational and financial impact of the systems. This paper presents an opensource platform, named ScheduleIT, capable of managing preventive routines. The platform is based on an estimation model that determines the optimal time interval for interventions, according to the criticality of the system and the number of nonprogramed faults, among others. ScheduleIT has a web-based interface available to different area end-users, ranging from IT technicians to administrative staff. At this point, the platform covers around $75 \%$ of the healthcare systems and it is full accepted by its main users as a reliable and effective preventive tool.

\subsubsection{Introduction}

Information Communication Technology interventions can effectively improve the efficiency of healthcare services as Handel \& Hackman indicate in their study of 2010 [III-1]. Healthcare organizations could improve patient treatment increasing the uptime of their Information Systems. Improving Hospital Information Systems (HIS) can not only reduce the number of hours spent going through disaster plans, but also increase cost effectiveness in workflows.

HIS make part of day-to-day workflows in healthcare facilities and are used by doctors, nurses and administrative teams. Such systems have become embedded in all processes and it is really hard to imagine few hours without them. Although all the good things HIS bring to users, this reliance only becomes evident in case of failure, and in healthcare failure is even more critical [III-2 - III-4].

Several studies have been taking place during the last years to understand the total impact of HIS failures. In 2001 Anderson Consulting Group Inc. was able to 
determine the total cost per minute of downtime for a Hospital with 1400 beds: the results showed a value of 1000 dollars per minute of downtime [III-3].

Thus, a downtime minute can reveal really expensive within healthcare facilities reality when it comes to reduce costs and improve health treatment.

Another relevant aspect that effects risk management is the current precarious disaster recovery plan, or contingency plan. A study performed in 2002 showed that alternative procedures are often forgotten by the end-users, either if they are based on secondary electronic systems, or on traditional paper records. This kind of actions results in an ineffective, complicated and time-consuming transition from the main to the alternative Information System, which, in most situations, leads to an overload on the trouble requests submitted to the IT professionals, making them to solve secondary problems instead of being focused on answer on time the real problem [III-5].

In order to reduce costs, not only financial but also due to time constraints, and to improve the healthcare services, it is necessary to develop methods for preventive actions that can avoid non-programed stops (corrective maintenance). Thus, to catalog and schedule stops for interventions, such as software cleaning, updates or simple system restarts, is extremely important and can make a difference when it comes to proper system operation. One immediate advantage of a preventive action is that it can be planned and, in fact, can be cheaper when compared to the results of a fault in an operating system [III-6].

Some recent studies present different approaches for preventive actions, but one aspect that seems to be common to all of them is the study of all systems uptime. In a complex Information System, which is the case of HIS, it is necessary a conjoint effort between different directive sectors/units to developed a precise and reliable availability study. Some examples of such studies can be consulted in many reports published in the Information Systems area [III-7 - III-9]. 
This paper presents an open-source-based platform, named ScheduleIT, capable of managing preventive actions within a healthcare facility. The proposed platform will allow reducing non-programed stops, improving the quality of healthcare services and decreasing the number of complaints by the users. In addition, the use of open-source software in healthcare area has intrinsic advantages and has become well establish and accepted among IT professionals.

\subsubsection{Open-Source Software in Healthcare}

Open-source describes practices in production and development that prop up access to the finished source code to users. The basic principles are to provide end-users the code as well as the right to amend it according to the needs.

Motivations for using and developing open-source software are mixed, ranging from philosophical and ethical reasons to pure practical issues. Usually, the first perceived advantage of open-source models is the fact that open-source software is made available gratis or at a low cost. But this characteristic is not exclusive to opensource software, and several proprietary software products are made available in similar way. What really distinguishes open-source software from software available without fee is the combination of effects due to the following characteristics [III-10]:

- The availability of the source code and the right to modify it, which enables the unlimited tuning and improvement of a software product;

- The right to redistribute modifications and improvements to the code, permits all the advantages due to the modifiability of the software to be shared by large communities;

- The right to use the software in any way. This, combined with redistribution rights, ensures a large population of users, which helps in turn to build up a 
market for support and customization of the software, which can only attract more and more developers to work in a common project.

Open-source models are rapidly being applied in many different fields of endeavor, such as biotechnology and bioinformatics. From a global perspective, healthcare facilities with the same goals and restrictions can improve their Information Systems by sharing source-code and knowledge between them. Besides their above mentioned advantages, open-source applications suffer from several additional barriers to the general Information Technologies (IT) implementation issues. They include the lack of professional knowledge, legal and licensing issues, functional gaps and e lack of a road map for sustainability.

Krogh and Hippel [III-11] in 2006 presented the renewed urgency to adopt health and medical informatics applications and how open-source approaches are gaining attention in the healthcare industry.

Open-source software can be characterized by collaboration among individuals and organizations with common interests, shared intellectual property, and a commitment to standards. Information technology in the healthcare industry is evolving from an administrative tool for billing and bookkeeping to a clinical tool for improving the quality and efficiency of healthcare, and the scope of information sharing is expanding beyond the walls of individual institutions. Achieving this level of integration will require that software models overcome a host of technical obstacles, and that they are accessible, affordable, and widely supported.

While not heralding the end of commercial software vendors, conditions are ripe for open-source solutions to take root in healthcare, and that it will likely become the standard for capturing, sharing, and managing patient information to support quality care. It also notes that healthcare businesses have the opportunity to take the lead and drive the shift to this new model [III-12]. The main motivations for using open-source software in healthcare are reduced total cost-of-ownership, 
faster delivery of systems, systems being more secure, elimination of vendor lock-in and control over the software (possibility of adapting to local needs).

As Murray [III-13] describes Information Systems have grown in a structured way and are now considered as being part of good and patient oriented healthcare unities.

For example, Care2 X, an open-source project is one of the several projects undergoing in healthcare. This project is based in four main areas and relies on opensource standards such as Hospital Information System (HIS), practice management, central data server and health exchange protocol. An Electronic Medical Record is under development in Europe and may well be one big substitute to commercial approaches, taking the best of open-source standards [III-14].

\subsubsection{Preventive Actions}

Preventive actions management plays a crucial role in clinical applications, not only for those who depend on data to make decisions, but also for those who monitor the operational and financial impact of systems. In order to build an effective preventive actions management system it is necessary to have knowledge on the hospital information system, hardware infrastructures, workflows and user needs.

The study presented hereby was performed within the Information Systems of the Padre Américo Hospital (HPA), in Penafiel, Portugal. In 2006, this hospital suffered an administrative changed and joined the São Gonalo Hospital, in Amarante, creating a bigger joint healthcare unit named Centro Hospitalar do Tâmega e Sousa (CHTS). This healthcare unit serves now a population of 500 thousand habitants and it generates great amount of clinical and administrative information [III-15].

From that moment, Information Systems became bigger and the user demands started to increase as the technological systems started to grow. New equipment, 
new complementary diagnostic tests or new laboratory forms, result in a higher amount of information that needs to be accessible in a fast, simple and easy-to-use way to a higher number of end-users for a longer period of time.

In order to reduce the number and impact of non-programed stops, new contingency plans were developed by a multidisciplinary team, composed by doctors, nurses, IT professionals, quality technicians and administrative board members. Although these measures/plans are difficult to implement and are often forgotten by the users, as mentioned before, they represent a way to prevent non-programed stops that can introduce high costs to the institution. In addition to that, one can identify two real advantages of preventive actions:

- Lower service downtime, which leads to an increase of the system uptime and availability;

- Controlled operating costs.

\section{Time Interval Estimation Model}

The model proposed in this paper is based in several factors that may alter the time interval between programed interventions. Since this time interval strongly depends on the systems critically level, a characterization of this measure was performed within the healthcare systems by a multidisciplinary team. The critically level of a system is characterized taking in consideration different functional aspects, such as the number of users, the number of requests submitted by the users on the request tracker tool, the age of the hardware and software installation. Additionally, the Recovery Time Objective (RTO) and the Recovery Point Objective (RPO) were identified when the disaster recovery plan was performed.

The Recovery Time Objective is defined as the duration of time and service level within which a business process must be restored after a disaster, in order to 
avoid unacceptable consequences associated with a break in business continuity.

The Recovery Point Objective is defined by business continuity planning. It is the maximum tolerable period in which data might be lost from an IT Service due to a major incident.

Table 3.2 shows the critically levels that can be applied to the systems.

Table 3.2: Criticality level applied to Information Systems.

\begin{tabular}{|c|c|}
\hline Criticality level (Cl) & Description \\
\hline Critical (5) & $\begin{array}{l}\text { Service on which main institution workflows rely on; } \\
\text { Downtime means that patient treatment is immediately } \\
\text { affected. }\end{array}$ \\
\hline Essential $(3-4)$ & $\begin{array}{l}\text { No alternative besides Information Systems. } \\
\text { Backup plan can be applied besides Information Sys- } \\
\text { tems. }\end{array}$ \\
\hline Important (2) & $\begin{array}{l}\text { Service that even without Information Systems can work } \\
\text { on minimal operation. }\end{array}$ \\
\hline Normal (1) & $\begin{array}{l}\text { Any other service that doesn't fit the other three cate- } \\
\text { gories. }\end{array}$ \\
\hline
\end{tabular}

As mentioned above, these levels include the view of experienced professionals on programed and non-programed faults, as well as the input of RTO and RPO. This scale was built according to normative instructions provided by the Quality Department of CHTS and validated together with their staff and directive crew. Table 3.3 presents the different RTO and RPO levels applied to HIS.

Table 3.3: RTO and RPO levels applied to Information Systems.

\begin{tabular}{ccc}
\hline Service Description & RTO (hours) & RPO (hours) \\
\hline Electronic Health Record & 1 & 1. \\
Radiological Information System & 24 & 24 \\
Laboratorial Results & 4 & 1 \\
Emergency Reports & 4 & 1 \\
\hline
\end{tabular}

The optimization model for the time interval between interventions is given by Eq. 3.1. The different variables that influence time interval estimation are based on weighted values according to their importance in the overall objective. The result of this model is a threshold level that will propose the time interval for interventions. 
$\Lambda(t)=(c l \times 0.4)+P(t)-[R T O \times 0.1)+(R T O \times 0.1)]$

where:

- $\Lambda(t)$ - Threshold level;

- $c l$ - Criticality level;

- $t$ - Time interval (weeks);

- $P(t)$ - Fault probability function;

- RTO- Recovery time objective;

- $R P O$ - Recovery point objective.

The fault probability function is given by the following equation (3.2):

$$
P(t)=(n p f(t) \times 0.15)+(r t(t) \times 0.15)+(h a \times 0.05)+(s a \times 0.05)
$$

where:

- $n p f(t)$ - Non-programed faults;

- $r t(t)$ - Fault tickets;

- ha - Hardware age;

- $s a$ - Software age.

Inevitably the factor that most influences the time estimation is the critically level with a weight of $40 \%$ on the overall equation, followed by the system fault probability, which includes the number of non-programed faults (15\%) and the reported problems (15\%). The RTO and the RPO have a weight of $10 \%$ on the model. These weighted values were based on the model proposed by Smith and Dekker [III-16] and took into account the opinions gathered by the multidisciplinary team. 
Using the proposed model, a preventive action is only triggered when a specific threshold is reached. This threshold will then influence the time interval of interventions according to Table 3.4.

Table 3.4: Week interval determination according to threshold level.

\begin{tabular}{cc}
\hline$\lambda(\mathrm{t})$ & Week Interval \\
\hline$\lambda(\mathrm{t})<0$ & 8 \\
$0 \lambda(\mathrm{t})<1$ & 4 \\
$1 \lambda(\mathrm{t})<2$ & 3 \\
$2 \lambda(\mathrm{t})<4$ & 2 \\
$4 \lambda(\mathrm{t})$ & 1 \\
\hline
\end{tabular}

\subsubsection{ScheduleIT}

One of the major goals of this work was to develop a management platform, called ScheduleIT, to ensure the proper workflow within the healthcare facility, not only in HIS, but also related with patient treatment. Therefore, ScheduleIT has many different area end-users as its main target; yet it does not neglects usability to its main users, namely IT technicians [III-17]. ScheduleIT uses the healthcare web portal to alert and inform end-users, as well as emails to clinical directors to notify them of the planned actions taking place in the near future. Having these alerts available, we can reduce the impacts of downtimes, since people are already informed of what is expected during stop time. In order to avoid missing an intervention, and since interventions are not yet automatic, notifications for IT technicians are extremely important; ScheduleIT does this by sending notifications to the request tracker and to the global IT mailing list.

Designed in PHP, this platform allows users to easily set up a new intervention according to the time interval given by the estimation model. Using these time intervals it is easier to present a preventive action calendar for future interventions.From a global point of view, the main features of this platform are:

- Notifications for clinical and administrative teams; 
- Notifications for IT technicians;

- Complete map for Programed Interventions;

- Integration with the IT park software;

- Touch interface compatible;

- History of interventions.

Figure 3.4 shows the main interface of ScheduleIT, in which the most important information is presented to IT user, for the current day. Distinct information is presented to the end-user, at the healthcare web portal, and to the IT technician in the ScheduleIT interface.

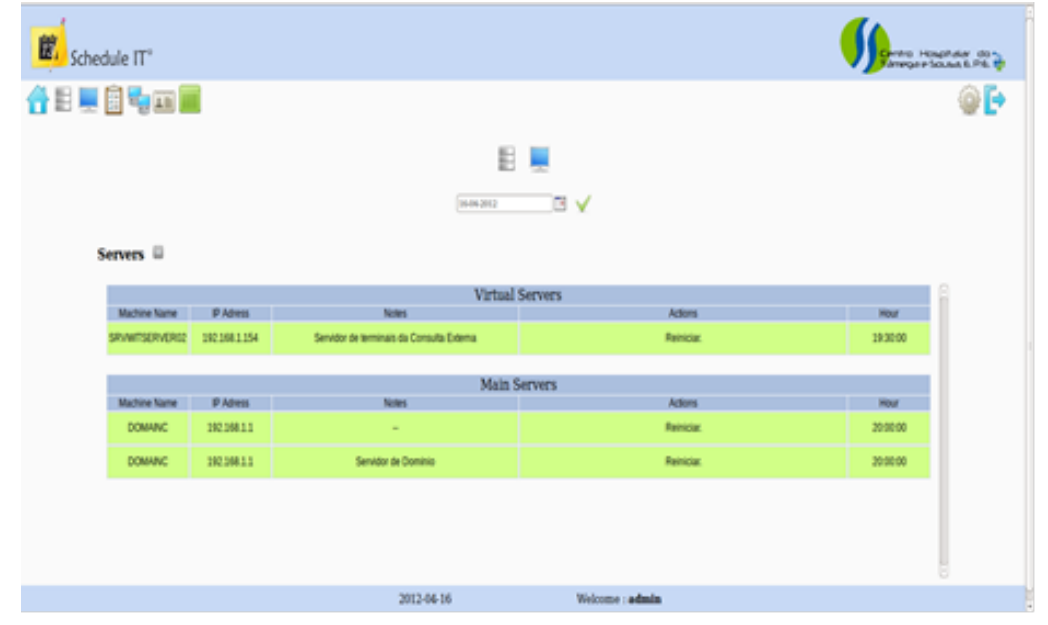

Figure 3.4: ScheduleIT web interface for programed actions for the selected day.

On one hand, the end-user has access to:

- Main services affected;

- Schedule hour;

- Estimated downtime.

On the other hand, IT technician has access to the entire previous mentioned, plus: 
- IP address;

- Machine name;

- Machine group;

- Physical localization of the system;

- Previous intervention notes.

To improve the week interval estimation model, there is a form available to IT technicians in which non-programed interventions are registered. Values collected are presented to initial model and can determine whether changes in week interval are necessary or not. Information provided in Schedule IT forms is always saved and can be used in further studies to increase availability of systems.

At this point, only $75 \%$ of the systems are covered by this model and platform, which means that additional efforts are needed in the future to extend its coverage to all the systems. This must be done not only by IT professionals but also with the cooperation of clinical staff and technicians in a combined effort to determine actuating times and to reduce non-programed stops. There is also an ongoing study that will determine the total impact of using ScheduleIT in Centro Hospitalar Tâmega e Sousa.

\subsubsection{Conclusions}

This paper presents an innovative open-source platform responsible for preventive actions management in a healthcare information system (HIS). Preventive actions are becoming more important in HIS since they can help decreasing the impact, either on costs or operation, of non-programed faults.

The platform proposed hereby is based on a mathematical model that estimates the time interval between programed interventions. This model takes into consider- 
ation factors such as criticality of the system, number of non-programed faults and the Recovery Time Objective (RTO) and Recovery Point Objective (RPO) variables. Currently, ScheduleIT covers around $75 \%$ of all the healthcare facility systems. It has established as a reliable tool of the contingency plan for preventive actions and it is well accepted, not only among IT technicians, but also by the clinical team.

Efforts are now taking place to extend its coverage to the remaining healthcare systems. Additionally, since the platform includes a feedback form from its users, knowledge about non-programed faults and main operation is being gathered to optimize the estimation model.

ScheduleIT platform has, until now, demonstrated to be a useful tool as a preventive actions management software.

\subsubsection{References}

[III-1] Handel, D., Hackman, J.: Implementing Electronic Health Records in the Emergency Department. The Journal of Emergency Medicine 2010. 38:2, 257 263.

[III-2] Valenstein, P., Walsh, M.: Six-year trends in laboratory computer availability. Arch. Pathol. Lab. Med 2003.127:3, 157 - 61.

[III-3] Anderson, M.: The toll of downtime. Healthcare Informatics 2002. 19:4, $27-30$.

[III-4] Kovach, D.: Developing a reliable medical informatics network. Healthc. Financ. Manage 1999. 53:1, 48 - 9.

[III-5] Barnard, A.: Hospital computer crash, a lesson to industry. Boston Globe 2002. 
[III-6] Nakagawa, T.: A replacement policy maximizing MTTF of a system with several spare units. IEEE Transactions on Reliability 1989. 38, 210 - 211.

[III-7] Sherif, Y.S., Smith, M.L.: Optimal maintenance models for systems subject to failure-A review. Naval Research Logistics 1981. 28, 47 - 74.

[III-8] Valdez-Flores, C., Feldman, R.M.: A survey of preventive maintenance models for stochastically deteriorating single-unit systems. Naval Research Logistics 1989. $36,419-446$.

[III-9] Jardine, A.K.S., Buzacott, J.A.: Equipment reliability and maintenance. European Journal of Operational Research 1985.19, 285 - 196.

[III-10] Gonzalez-Barahona, J.M.: Advantages of open source software, http://eu.conecta.it/paper/Advantages_open_source_soft.html

[III-11] Krogh, G., Hippel, E.: The Promise of Research on Open Source Software. Manage. Sci. 2006. 52: 7, 975 - 983.

[III-12] Goulde, M., Brown, E.: Open Source Software: A Primer for Health Care Leaders. California HealthCare Foundation 12006.

[III-13] Murray, J., Wright, G., Karopka, T., Betts, H., Orel, A.: Open source and healthcare in Europe - time to put leading edge ideas into practice. Stud. Health Technol. Inform. 2009. 150, 963 - 967.

[III-14] Care2 X, http://www.care2x.org/

[III-15] Peixoto, H., Machado, J., Abelha, A., Neves, J., Correia, A., Santos, M.: AASYS - Appointment Alert System: An open-source-based software to improve show rates in a healthcare unit. In European Simulation and Modelling Conference 2011. 1-10.

[III-16] Smith, M.A.J., Dekker, R.: Preventive maintenance in a 1 out of n systems: The uptime, downtime and costs. European Journal of Operational 
Research 1997. 99, 565-583.

[III-17] Kushniruk, A.: Evaluation in the design of health information systems: application of approaches emerging from usability engineering. Computers in Biology and Medicine 2002.32:3, 141-149. 


\subsection{Study IV - Intelligence in Interoperability with AIDA}

Hugo Peixoto, José Machado, António Abelha and Manuel Santos, 20th International Symposium on Methodologies for Intelligent Systems, 2012 World Intelligence Congress, Macau (to be published by LNCS Springer). 



\subsubsection{Abstract}

Healthcare systems have to be addressed in terms of a wide variety of heterogeneous, distributed and ubiquitous systems speaking different languages, integrating medical equipments and customized by different entities, which in turn were set by different people aiming at dif- ferent goals. Demands of information within the healthcare sector range from clinically valuable patient-specific information to a variety of aggregation levels for follow-up and statistical and/or quantifiable reporting. The main goal is to gathering this information and present it in a readable way to physicians. In this work we show how to achieve interoperability in healthcare institutions using AIDA, an interoperability platform developed by researchers from the University of Minho and being used in some major Portuguese hospitals.

\section{Keywords}

Semantic Interoperability, Ambient Intelligence, Electronic Health Record

\subsubsection{Introduction}

Healthcare systems have been for some years a very attractive domain for Computer Science (CS) researchers. Even more, such systems have great potential for information integration and automation, and this is an issue of study in which medicine and agent-based technologies and methodologies for problem solving may overlap. Furthermore, healthcare systems have to be addressed in terms of a wide variety of heterogeneous, distributed and ubiquitous systems speaking different languages, integrating medical equipment and customized by different entities, which in turn were set by different people aiming at different goals [IV-1].

Demands of information within the healthcare sector range from clinically valuable patient-specific information to a variety of aggregation levels for follow-up and 
statistical and/or quantifiable reporting. Gathering this information and present it in a readable way to physicians it is an interesting task. This lead us to consider the solution to a particular problem, to be part of an integration process of different sources of information, using rather different protocols, in terms of an Agency for the Integration, Diffusion and Archive (AIDA) of Medical Information, bringing to the healthcare arena new methodologies for problem solving and knowledge representation, computational models, technologies and tools, which will enable ambient intelligence or ubiquitous computing based practices at the healthcare facilities [IV-2]. With access granted to clinical and historical databases, agent technology may provide answers to those who give assistance to patients in time and medical evidence [IV-3].

Every day new applications are developed to assist physicians on their work and healthcare is turning into a science based on information and reputation. We want to find out how usability is maintained in this new landscape of social and ubiquitous computing, when applied to healthcare units, a domain that presents the strongest social focus, and in this way offering the biggest challenge for socially aware software systems design [IV-4].

Nowadays, the exchange and share of clinical knowledge among medical information systems is an important feature to improve healthcare systems, quality of the diagnosis, but mainly, to improve quality in patient treatment.

Semantic Interoperability and Ambient intelligence are seen in this work as the key to solve this problem. Electronic Semantic Health Record (ESHR) will provide the base for this work. The guarantee of a homogeneous information system in a health care unity will produce enormous benefits to the institution. Reduction in diagnosis and appointments time since information about a patient is available at one time in the same place would give doctors more time to treat patients better. Less medical errors would be expected due to better quality of information [IV-5]. 


\subsubsection{Interoperability}

Nowadays information technologies (ITs) in medicine and healthcare are facing a scenario in which a variety of healthcare providers have introduced ITs in their everyday workflows with a certain degree of independence. This independence may be the cause of difficulty in interoperability between information systems [IV5]. The overload of information systems within an healthcare facility may lead to problems in accessing the total information needed, since it is hard for a physician to access all information sources in an acceptable period of time. In the last decade, Health Information Systems (HIS) have gained great importance and have grown in quality and in quantity. With this information overload, it is necessary to infer what information is relevant to be registered in the EHR and decision support systems must allow for reasoning on incomplete, ambiguous and uncertain knowledge. Demands of information handling within the healthcare sector range from clinically valuable patient-specific information to a variety of aggregation levels for follow-up and statistical and/or quantifiable reporting.

Researchers in the field of Hospital Information Systems have focused special attention to the field of quality of information. A Health Unit is computationally represented by a heterogeneous set of applications that speak different languages and are customized by different customers. So a practical and effective communication platform between information systems is paramount taking into consideration the quality of information [IV-5].

Each service has small database management systems where specific patient data are registered depending on pathologies or specific interests. This computational tissue generates development problems. However, these applications are used by people with good satisfaction despite they do not allow a transversal vision of the patient data along different services or specialties, they can not grow easily and sometimes they do not attend secure and confident procedures. Running applica- 
tions in distributed environment is a huge problem when applications have not been developed to share knowledge and actions.

Information Systems capabilities are increasingly exposed and exploited, however, software developers and users must lead with new challenges. The EHR is already a topic widely discussed and explored that has brought innovations and advances every day. However the new requirements are to manage all information that is produced in health facilities to ensure quality and easy exchange between HI. It is necessary to use new emerging technologies.

Interoperability has been rather confined within the realms of IT and technology. Although IT plays a key role in making businesses interact seamlessly, such an information exchange infrastructure is meaningless if the other core aspects of business collaborations are not interoperable. Hence, the concept of Business Interoperability goes beyond IT, into organizational aspects of businesses, and includes the level of people-to-people interactions. Smoother workflows also mean that business processes originating in one organization can seamlessly flow into a collaborating partner organization without getting caught up in bureaucratic red tape. Systems for conflict resolution and Intellectual Property Management can further ensure Business Interoperability.

In the last years many projects have pursued the interoperability of EHR information systems. The different approaches have proposed solutions based on specific standards and technologies in order to satisfy the needs of a particular scenario, but no global interoperability frameworks have been provided so far. Some countries are already planning a unified medical language to ensure that the information is stored according to the same syntax and semantic. The Unified Medical Language System (UMLS) is a project of the US National Library of Medicine (NLM) and provides a conceptual framework for concept categorization. Information access is simple and effective, providing to users information with quality [IV-5]. 
There are some research groups around the world working on semantic web, including the clinical area. Jentzsch and some colleagues developed a system to support the pharmaceutical area that allows the connection between drugs, treatments, cures and laboratory tests via semantic web. This system shows how to search for a Chinese medicinal herb that met the requirements for patient administration [IV-6]. Jentzsch and his staff show how to build decision support systems in clinical activity. These technologies will be of great interest, requiring only some adaptation in HIS and hospital software providers [IV-6].

\subsubsection{Semantic Interoperability}

The information to be transferred must be standardized and normalized in order avoid different structures and misinterpretations. We must also take into account the data semantics, so information can be understood by different systems. In addition, the use of standards ensures the best communication between health professionals and interoperability between systems, allowing some automation in the hospital recording. The standards used in EHR are divided into three different purposes:

- Standards for representing clinical information;

- Communication standards; and

- Image standards.

International Classification of Diseases, Ninth Revision, Clinical Modification (ICD-9-CM), Systematized Nomenclature of Medicine-Clinical Terminology (SNOMED-CT) and International Classification for Nursing Practice (ICNP) are standards for classification of diseases and therapeutic clinics, where each therapy or disease is associated with a code recognized anywhere in the world. The use 
of these standards ensures that the EHR can be readable by any clinician in the world, allowing machines to interpret symptoms and assisting the clinicians in making a diagnosis and treatment plan decision [IV-7]. As communication standards, the AIDA-PCE adopts the Health Level Seven (HL7) as a protocol for exchanging messages, and web architectures and Service-Oriented Architectures (SOA).

There are a high number of benefits of semantic web but there are also some disadvantages. One negative factor is the complexity of implementation and the specific domain of the medical field.

\subsection{Ambient Intelligence}

Ambient intelligence is related with an atmosphere where rational and emotional intelligence is omnipresent $[\mathrm{IV}-2]$. In an ambient intelligent environment, people are surrounded with networks of embedded intelligent devices to gather and diffuse information around physical places, forming a ubiquitous network around an integrated global middleware accepting specific requests and data from heterogeneous sources, and providing ubiquitous information, communication and services. Intelligent devices are available whenever needed, enabled by simple or effortless interactions, attuned to senses, adaptive to users and contexts, and acting autonomously. High quality information and content may therefore be available to any user, anywhere, at any time, and on any device. Users are aware of their presence and context and digital environments are sensitive, adaptive, and responsive to needs, habits, gestures and emotions [IV-2]. In virtual health care environments, they can not be separated from medical informatics, biomedical informatics or bioinformatics, aggregating electronic health records, decision support, telemedicine, knowledge representation and reasoning, knowledge discovery and computational biology. Radiological films, pathology slides and laboratory reports can be viewed in remote places. Remote robotics is used in surgery and telemedicine is becoming 
popular. However applications are used for discrete clinical and medical activities in specific areas and services, in particular diagnostics and pathologies.

Ambient Intelligence benefited from an exponential growth of Internet use on the last few years. New rapid web advancements are emerging, transferring technology benefits sometimes without a solid theoretic underpinning [IV-2]. Although web browsers support many features that facilitate the development of user-friendly applications and allow users to run application anywhere without installing flat software packages in order to run remote applications. Storage and information access over the web encourages the information and knowledge reuse and the offer of global information and resources. The vitality of a web-based system lies in its integration potential, in supporting communities of virtual entities and in the gathering, organization and diffusion of information. Operating on the web means the use of documents or programs that contain images, audios, videos and interactive tools in addition to text. Scripting languages are used to build high level programs improving distribution, as well as information and knowledge sharing, increasing quality software and reducing costs $[\mathrm{IV}-2]$.

\subsection{Implementation}

\subsubsection{AIDA framework}

To build systems for real healthcare environments, the infrastructure must meet a range of basic requirements with respect to security, reliability and scaling. With access granted to Clinical and Historical Databases, agent technology may provide answers to those who give assistance to patients with a maximum of quality and medical evidence [IV-8]. Communications are sometimes limited by old infrastructures and new projects collide with financial restrictions and bureaucratic delays. The homogeneity of clinical, medical and administrative systems is not pos- 
sible due to financial and technical restrictions, as well as functional needs. The solution is to integrate, diffuse and archive this information under a dynamic framework, in order to share this knowledge with every information system that needs it. Indeed, to build systems for real healthcare environments, the infrastructure must meet a range of basic requirements with respect to security, reliability and scaling. With access granted to Clinical and Historical Databases, agent technology may provide answers to those who give assistance to patients with a maximum of quality and medical evidence [IV-9]. Figure 1 shows the schematic representation of AIDA framework. In this schema, it is possible to understand the workflow of information, as well as integration and interoperability.

AIDA is an agency that provides intelligent electronic workers, here called proactive agents and in charge of tasks such as communicating with the heterogeneous systems, sends and receives information (e.g., medical or clinical reports, images, collections of data, prescriptions), managing and saving the information and answering to requests, with the necessary resources to their correct and an on time accomplishment [IV-9].

AIDA also supports web-based services to facilitate the direct access to the information and communication facilities set by th1ird parties, i.e., AIDA construction follows the acceptance of simplicity, the conference of the achievement of common goals and the addressing of responsibilities. The main goal is to integrate, diffuse and archive large sets of information from heterogeneous sources (i.e., departments, services, units, computers, medical equipments); AIDA also provides tools in order to implement communication with human beings based on web-based services. Under these presuppositions, a healthcare information system (HIS) will be addressed in terms of Figure 3.5:

- Administrative Information System (AIS), which intends to represent, manage and archive the administrative information during the episode. Being an 
episode a collection of all the operations assigned to the patient since the beginning of the treatment until the end;

- The Medical Support Information System (MIS), which intends to represent, manage and archive the clinical information during the episode;

- The Nursing Support Information System (NIS), which intends to represent, manage and archive the nursing information during the episode; and

- The Electronic Medical Record Information System (EMR); and

- The Information Systems (DIS) of all the departments or services, in particular of the laboratories (Labs), Radiological Information System (RIS) and Medical Imaging (PACS - Picture Archive and Communication System), which deals with images in a standard format, the DICOM one.

The architecture presented (Figure 3.5) was envisaged to support medical applications in terms of AIDA and EHR, a form of web spider of an intelligent information processing system, its major subsystems, their functional roles, and the ow of information and control among them, with adjustable autonomy.

Healthcare staff acquires this information and its value is automatically stored and distributed to where it is needed. Every document created within a specialized service respect this rules, making different and individualized departments closer. The coding and ordering features are very useful to link different data to one specific problem, as coded data is much easier to access and it is recommended for decision support using Artificial Intelligence. The electronic ordering embedded in EHR can be used not only to obtain medical equipment or pharmacological prescriptions, but also for acquiring laboratory and imaging studies outside the service where it is used. Furthermore, it may enable the centralization of exam display, allowing 


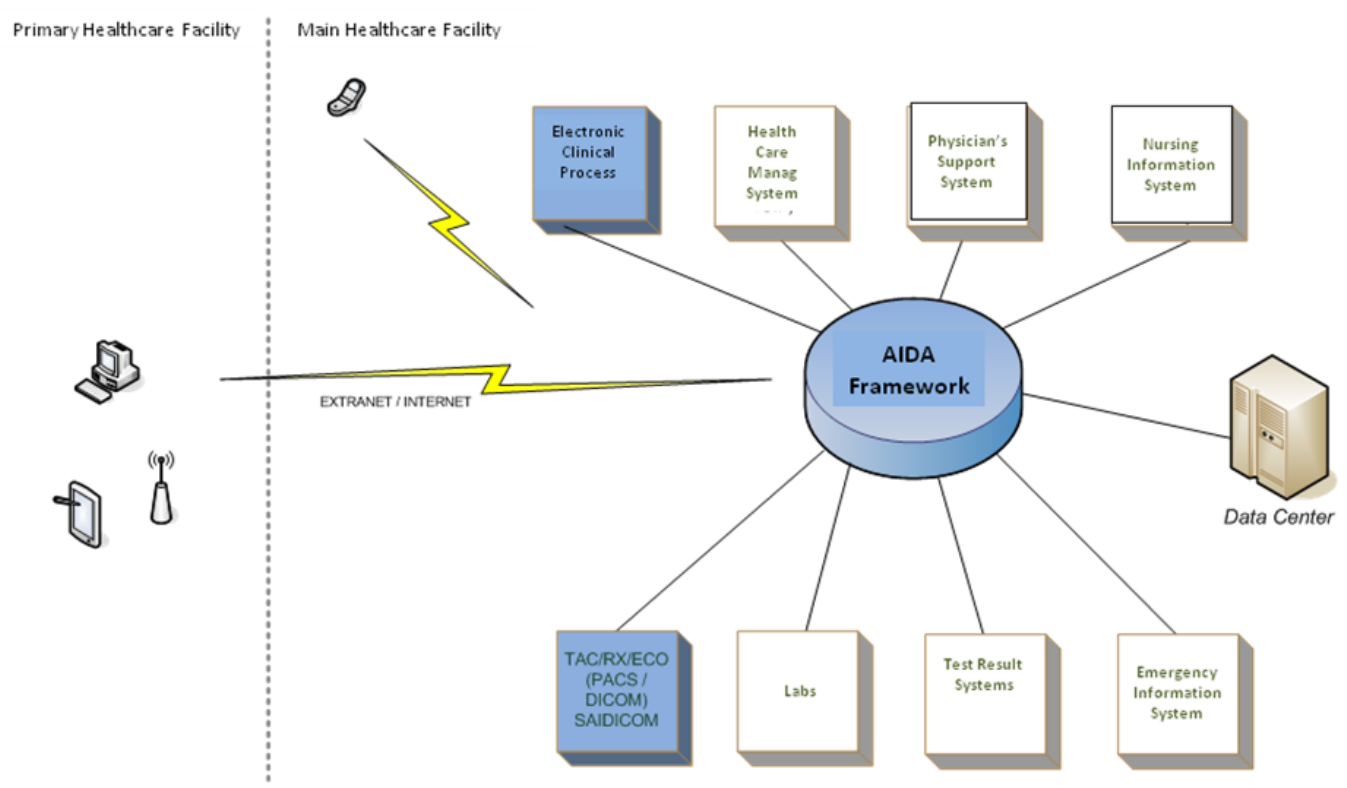

Figure 3.5: AIDA- Agency for Integration Diffusion and Archive.

different services to share results concerning the same patient, diminishing costs on unnecessary exams, and above all, improving the quality of service being provided $[\mathrm{IV}-9]$.

There are also different access permissions when dealing with medical data. Although it can only be viewed by the authorized personnel from any terminal inside the healthcare facility or even on its own laptop or PDA, the access must be flexible in order to enable the professionals to access it when needed. In other words, the access to the medical information of the patient is as important in terms of privacy as in terms of significance for medical situations. On the other hand, interfaces must be intuitive and easy to use. Messaging enables one to create, send and retrieve messages online. It may be very useful for handling data, images or even file exchange. Encryption and the right protocols of trading are also paramount. Messaging systems are extremely important not only for the internal workflow in a healthcare institution, but as well as an essential component for the development of group work, namely in the area of diagnostic that is supported by decision support systems. 


\subsubsection{Electronic Semantic Health Record}

Adoption of Electronic Health Record (EHR) is well known in several countries all over the world. Canada, Australia, England and United States have already started their own way to achieve an infrastructure for national Health Information Systems [IV-10]. All of these projects share the main elements and focus on the same important subject, interoperability and integration of HIS in spite of interoperability between healthcare providers being a hard task [8]. Unfortunately, information emerges from an assortment of sources, from informatics applications, medical equipments and physicians knowledge introduced in the Electronic Health Record. Decision support systems are enhanced by quality of information and that can only be achieved with good collection of all the data from the patient. With this information overload, it is necessary to infer what information is relevant to be registered in the EHR and decision support systems must allow for reasoning on incomplete, ambiguous and uncertain knowledge.

Demands of information handling within the healthcare sector range from clinically valuable patient-specific information to a variety of aggregation levels for follow-up and statistical and/or quantifiable reporting.

EHR is a repository of information concerning an individual in an electronic format. It is stored and transmitted securely and may be accessed by multiple users [IV-11]. The main objective is to ensure ubiquity, i.e. information is accessible at anytime and anywhere. The lack of integration between the different HIS is not only an obstacle for a more effective clinical practice, but it may lead to a suboptimal care for the patient. Although, this is an accepted definition Hayrinen proved that different researches describe in distinct ways the same thing, and EHR definition is one example [IV-12].

Hayrinen published, in the International Journal of Medical Informatics, an exploratory approach to review the impact of use of the HER as well all the definitions 
associated with EHR. Hayrinen tries to understand the ongoing studies on several countries and evaluate the possibility of current technologies and underlying architectures and on exploring the health care registers as a source for evidence-based medicine. Automated search was used by the author in several known databases such as PubMed, Cinalh and Cochrane to find recent published works on the area.

In Europe various organizational, institutional, governmental and private initiatives are in course, having the some common main proposes: the standardization, the definition of functional models, minimal data sets and interoperability. EHR depends on three areas:

- Terminology;

- Structure; and

- Interoperability in Communication [IV-13].

Semantic Web has been the subject of much debate and several studies in recent years by the scientific community and the main issue is whether he can fill some gaps in the information systems of health units and perhaps bring an additional quality. W3C consortium is one of the world leading task forces where several research teams gather their work and present it to scientific community in seek for approval and newer approaches for improvements [IV-14].

Several papers come out from this consortium presenting state of the work and tasks executed between publications. Paper derive from explanatory to exploratory and descriptive but the main investigation query and theme is how to use semantic as a mean to achieve full interoperability between systems under the main theme of healthcare. 
Jentzsch and colleagues presents the use of semantic as linked data to drugs systems and enabling integration with other web based systems for studies and result retrieving. Their main efforts go to provide the correct drug for the treatment of the patient and study whether their system meets the desired requirements. For the big test for their system they apply it to the search of Chinese herbs that may help in certain diseases. The final results prove that their system is able to provide extended studies for retrieving the correct herb, such as gene study of the patient, side effects expected and how active ingredients can interfere with patient health [IV-6]. As well as Jentzsch, Clark followed a case study for presenting his work in the Semantic Web in Health Care and Life Sciences Interest Group (HCLS) and the goal is to develop cures for highly complex diseases, such as neurodegenerative disorders, even thought it requires extensive interdisciplinary collaboration and exchange of biomedical information in context. This research team presents the process of integration of semantic ontology in SWAN Alzheimer Knowledge Base. The description provides the user knowledge of ontology that can improve search and connection between systems for extraction of information in easier queries. This project is fully integrated in the Massachusetts General Hospital and provides better access to information relevant for better diagnosis and scientific studies of Alzheimer disease [IV-15].

These studies prove that semantic can promote better results for decision support systems since quality of information is preserved during all processes and correct data is accessed when certain query is performed. Making usage of such technology and combining it with AIDA work methodology an Electronic Semantic Health Record improves quality of information accessed inside the institution. Making a semantic approach to current health records is possible to enhance communication between health care facilities and information can be shared without any lost in quality since queries are most accurate and specific. Semantic enhances linked data and provides the tools to compare data that is most of the time separate but that 
can together provide accurate information and most important quality information for users. Our main goal is to take semantic advantages and pull out graphical interactions from disperse data.

\subsubsection{Conclusions}

This paper presents an innovative intelligent framework responsible for interoperability in healthcare units. The homogeneity of clinical, medical and administrative systems was not possible due to financial and technical restrictions, as well as functional needs. The solution was to integrate, diffuse and archive this information under a dynamic framework, in order to share this knowledge with every information system that needs it.

AIDA platform has, until now, demonstrate to be an useful tool in order to interoperate in a healthcare facility, being used in several portuguese hospitals in Elvas, Portalegre, Guimarães, Penafiel, Amarante and Porto. Starting from AIDA, projects in the area of Business Intelligence are now at an ending point. AIDA has shown to be very useful in the process of extracting, loading and transforming info rmation in order to extract knowledge.

\section{Acknowledgments.}

We are thankful to the Centro Hospitalar do Tâmega e Sousa (CHTS), in Penafiel, Portugal, for their help in implementing and testing of the above referred Electronic Health Record, which is now being largely used in their premises.

\subsubsection{References}

[IV-1] J. Machado, A. Abelha, P. Novais, J. Neves and J. Neves, Quality of service in healthcare units, Int. J. Computer Aided Engineering and Technology, 
Vol. 2, No. 4, 2010.

[IV-2] J. Machado, A. Abelha, J. Neves and M. Santos, Ambient intelligence in medicine, Proceedings of the IEEE-Biocas, Biomedical Circuits and Systems Conference, Healthcare Technology, Imperial College, London, UK: 2006.

[IV-3] P. Maes, Modeling adaptive autonomous agents, Artificial Intelligence Magazine.

[IV-4] G. Marreiros, R. Santos, C. Ramos, J. Neves and J. Bulas-Cruz, ABS4GD:a multi-agent system that simulates group decision processes considering emotional and argumentative aspects, AAAI Spring Symposium Series, Stanford University, 2008.

[IV-5] H. Peixoto, J. Machado, J. Neves and A. Abelha, Semantic Interoperability and Health Records, E-Health. In Hiroshi Takeda (Ed.), Vol. 335, pp. 236-237, Springer Boston, 2010.

[IV-6] A. Jentzsch, J. Zhao, O. Hassanzadeh, K. Cheung, M. Samwald and B. Andersson, Linking Open Drug Data, iTriplification Challenge, 2009.

[IV-7] J. Duarte, C.F. Portela, A. Abelha, J. Machado and M. Santos, Electronic Health Record in Dermatology Service, ENTERprise Information Systems, Communications in Computer and Information Science, Volume 221, p. 156-164, 2011.

[IV-8] H. Rigor, J. Machado, A. Abelha, J. Neves and C. Alberto, A Webbased system to reduce the nosocomial infection impact in healthcare units, Webist. Madeira: 2008.

[IV-9] A. Abelha, J. Machado, M. Santos, S. Allegro, F. Rua, M. Paiva and J. Neves, Agency for Integration, Diffusion and Archive of Medical Information, Proceedings of the Third IASTED International Conference - Artificial Intelligence and Applications, ISBN 0-88986-390-3, Benalmadena, Spain: 2002. 
[IV-10] W. Sujansky, Heterogeneous Database Integration in Biomedicine, Journal of Biomedical Informatics, 2001.

[IV-11] M. Eichelberg, T. Aden, J. Riesmeier, A. Dogac and G. Laleci, A survey and Analysis of Electronic Healthcare Record Standards, ACM Computing Surveys, Vol. V, No. N 20YY, Pages 1-47, 2005.

[IV-12] K. Häyrinen, K. Saranto and P. Nykänen, Defenition, structure, content, use and impacts of electronic health records: A review of research literature, International Journal of Medical Informatics 77, p. 291-304, 2008.

[IV-13] J. Neves, M. Santos, J. Machado, A. Abelha, S. Allegro, M. Salazar, Electronic Health Records and Decision Support - Local and Global Perspectives, WSEAS Transactions on Biology and Biomedicine, Issue 8, Volume 5, pp. 189-198, ISSN 1109-9518, 2008.

[IV-14] W3C - World Wide Web Consortium, www.w3C.org.

[IV-15] T. Clark, and M. Ocana, Semantic Web Applications in Neuromedicine (SWAN) Ontology, http://www.w3.org/TR/hcls-swan/ , 2009. 
Chapter 4

\title{
Discussion, Conclusions and
}

\author{
Future Work
}





\subsection{Discussion}

One of the main objectives of this work is to demonstrate how Information Systems can provide continuous improvements, not only for healthcare institutions, but also and mainly for the patients. In order to intervene in key areas inside the healthcare institution under study, four practical studies were implemented and analyzed. These studies were submitted to peer review processes and accepted by the scientific community as valuable research work that represented significant advances when compared with current implementations. The focus of the studies were to give overall answers for the questions raised at the beginning of this thesis work, taking into account the improvements needed for a better financial, economic and personal management at a healthcare unit such as the Centro Hospitalar Tâmega e Sousa, E.P.E.

The quality of the Information Systems department at the CHTS was improved, as well as the relation between the patient and the healthcare facility. In addition, it was noted a better access and quality of the information provided to the users.

The next paragraphs intend to give an overall discussion concerning each study at the CHTS, pointing out the main challenges and difficulties that arise during the implementation, as well as the major outcomes.

The first study focused on Semantic Interoperability and Health Records. A diffusion and archive agency was presented that empowered the integration and semantic interoperation of data information present at the healthcare unit. The possibility of exchange information in a structured manner, that can also be recognized and interpreted by machines, will allow in the future for scientific studies, extended researches or even decision support systems which can be based on more and more reliable information. 
One of the main conclusions of this study is that semantic is an inescapable paradigm that plays, and will continue playing, a fundamental role in research in Health Records. In fact, as demonstrated in Chapter 2, Section 4, several international projects have been following the lines that are essential for a common final goal, which is totally interoperable systems working and communicating in consonance, despite heterogeneous development sources, in order to improve the patient treatment and well-being. All the projects converge in Semantic Health Records, in which the information is available anywhere and anytime, whether for decision support when diagnosing patients, monitoring their treatment, or for consulting in future appointments.

When facing the question Can Electronic Semantic Health Record overwhelm the current Electronic Health Record?, the answer comes demystified: Semantic is indeed the future of Information Systems and can no longer be ignored when dealing with clinical data that arises from heterogeneous data sources with no apparent connection.

The second study was based in a more practical approach that dealt with patient appointment management. A new platform, named AASYS - Appointment Alert System, was developed in order to narrow the link between patients and healthcare units. By creating an alert system that deals with appointment scheduling, it was possible to act in two important and specific areas of the health system: first, cost reduction due to a decreasing number of missed appointments; and second, a significant improvement in the relation between the patient and the hospital.

This study revealed how a simple text message, SMS, or electronic mail was able to improve the appointments management, not only for the hospital but also for the patient itself. On one hand, an alert for the patient could avoid him to miss an appointment that might have taken several months to schedule, depending on the waiting list. On the other hand, by having knowledge about the patient's intention to attend the appointment or not, the hospital can avoid several inconveniences and 
try to re-schedule a new appointment taking into consideration its own needs and workflow. Thus, the hospital can benefit from an improved management of both staff and physical space. The clinicians can fulfill their work schedule without any blank spaces or interruptions, which allows for a better use of resources that are essential in a healthcare system.

In this manner, by providing a new communication link between the hospital and the patient, Information Systems allow to create a solid relationship between the two entities based on trust. Given the increasing number of cellphones and use of electronic mail in the population, this becomes practically a mandatory procedure within healthcare units. It is then clear that simple and effective procedures conducted by Healthcare Information Systems can in fact help redefine the unit/patient dynamics. The usage of Open Source software enables not only the reduction of the total cost-of-ownership, but also increases the security and eliminates the vendor lock-in of systems. Following the guidelines of Open Source software presented in Chapter 2, AASYS provided a new level of interoperability to CHTS and this was achieved having in mind not only the costs of implementation but also patient needs.

Study III presented a management and maintenance tool for preventive actions of servers and clients inside the healthcare unit. As mentioned before, the access to information is a crucial aspect and IT experts must paid special attention when dealing with information integrity and availability. A starting point is to make sure that the information is in fact available at any time, everywhere and to any user that needs and has permissions to see it. This is usually guaranteed by systems with high availability, i.e., ensure that information access is not compromised, which can be done by improving uptimes and reducing the number of interventions or nonprogrammed stops of servers.

ScheduleIT is a systems management tool that allows to program preventive actions through an alert interface, available not only for the IT specialists, but also for further users that will be informed about the programmed stops that will take 
place in specific time intervals. Due to high number of users that will be affected by the stop time of a given server, it is necessary to carefully schedule these programmed stops. It is required to estimate the best time of the day, the best day of the week and the best interval to execute preventive actions on servers in order to guaranteed their optimal performance. The platform presented in this study is based on a mathematical model that accounts for all the aspects mentioned before and estimates the optimal week interval to perform servers restart. Parameters such as the criticality of the system, number of non-programmed faults and Recovery Time Objective (RTO) or Recovery Point Objective (RPO), are all taken into consideration when estimating these time intervals. Another key point of this platform is that it is based on open-source software which allows for a significant reduction of implementation costs. In addition, in the future this platform can also be used in other healthcare units that share the same necessities.

ScheduleIT already covers more than $75 \%$ of the servers inside CHTS and its usage has been extremely important for the institution, with good results in reducing the number of non-programmed stops. By providing mechanisms that deal with sensitive and complex areas of Information Systems in healthcare and that are aware of IT specialists and user needs, the ScheduleIT platform not only is an effective management tool, but also promotes a self-reliance environment among the existing systems. ScheduleIT is an example of an application module that can be added to AIDA. Showing the scalability, manageability and performance of AIDA, which is maintained when addind application modules.

Finally, the last study presents the recent advances introduced in the platform AIDA - Agency for Integration, Diffusion and Archive. The main focus was the necessity for data share and exchange procedures with improved quality. As the need for more information grows it becomes imperative that new implementations are developed, especially in healthcare area.

Basically, AIDA intends to serve the main necessities and requirements pre- 
sented along this thesis. Unlike the previous studies, it does not focus on one single aspect of actuation, but instead it provides formulation of standards and workflows essential to build a healthcare unit with quality and financially viable and sustainable.

The AIDA platform revealed excellent results when dealing and managing the information from different sources, ranging from laboratory results to medical images and even when integrating results from external providers. One of the main challenges was to provide to the clinicians the requested information to help them to decide at the exact moment they need. To do this, the platform uses intelligent agents that deal with requests and ensure the information is provided to the right user, with integrity and when it is asked. This allows reducing the waiting times for results, either when diagnosing or during an appointment, since the information that once was dispersed is now integrated and managed by the platform.

Although the concept and principles behind the platform functioning seem trivial, its implementation is in fact more complex, especially when working within a healthcare unit environment. It is necessary to formulate new definitions, introduce user permissions, adequate services so that the global system workflow is not compromised.

Through artificial intelligence and web-services it is possible to present the requested information using a web user interface, parameterized, friendly and easyto-use that allows data visualization as quick as possible.

AIDA is a central part of this work. Without AIDA, it will be impossible to have a testing and working platform to enhance this work. AIDA has proved its strength to solve interoperability problems in real world environment and this paper is the most important description of AIDA, being edited by Springer under the well known series of Lectures Notes in Computer Science. 


\subsection{Conclusions}

A research work must be seen above all as an important tool to discover new methodologies and techniques to reach pre-determined objectives and to truly bring innovation to improve a service or procedure. Nonetheless, during this journey new questions arise and sometimes it can lead to the definition of new paths for research and new states of knowledge that could reveal to be extremely relevant for future work.

Throughout this thesis, four main questions revealed fundamental as guiding lines for the proposed work, which are related with Health Information Systems and its implementation costs, the strategies to achieve interoperability among systems and finally the strengthener of the relation between the patient and the healthcare unit. The exhaustive research on existing projects inside and outside the European Community allowed to better understand the current strategies and methodologies applied at healthcare units to overcome some of the difficulties presented every day. All these projects were supervised by either the European Commission or governmental institutions and indicated that Health Information Systems, Quality of Information, Interoperability and Electronic Health Records are major concerns for world leaders, and that patients and physicians have their needs more exposed than ever.

To give answers to the questions mentioned above, four studies were conducted at the Centro Hospitalar Tâmega e Sousa, E.P.E. (CHTS), and posteriorly submitted to peer reviewed conferences with good impact.

The first study, focused on the Electronic Semantic Health Record, showed that semantic is indeed the path to be adopted since it plays a fundamental role for the continuous improvement on Health Information Systems. Semantic is a computational paradigm that allows the interoperability, computing and intelligent communication between systems in order to improve the quality of the information 
available to the users. By promoting a global and intuitive view of the information sources to the user, without the need to skip between applications, the waiting times and the quality of the patient diagnosis can become significantly improved.

A better patient-hospital relationship was enhanced by the AASYS system. This system is an alert appointment system based on open-source software that sends to the patients text messages and electronic mails. AASYS allowed to improve show rates at CHTS, promoting a more effective scheduling of appointments and a better use of human and physical resources, and consequently a reduction of costs for the CHTS. Although it is still on an initial phase of implementation, this system has means to evolve to an end-to-end communication allowing patients to contact the care provider via text message or electronic mail.

The third study presented an open-source platform for preventive actions management, called ScheduleIT. Preventive actions promote more reliable systems and increase the confidence that users have on the systems that they use every day. In addition, by using open-source software not only the implementation costs are diminished as also the platform can be used by other institutions promoting the sharing and continuously improvement of the software itself. ScheduleIT has proved to be an important tool to prevent non-programmed stops.

Finally, a platform that manages and integrates the information that emerges from heterogeneous sources inside the hospital was presented. This platform was named AIDA and, as the name says, it is an Agency of Integration, Diffusion and Archive of information that provides the users all the data they need to perform their clinical practice. It is today one of the main tools inside a healthcare unit regarding systems interoperability, artificial and ambient intelligence and intelligent agents.

All the implementations mentioned above contribute to turn CHTS one of the leading Portuguese hospitals in the area of interoperability and healthcare with 
quality of services.

\subsection{Summary of Thesis Achievements}

The following list comprehends the main achievements accomplished during the execution of this thesis:

- Improvement of quality of information available to the physician using an ESHR, provided by AIDA;

- Improvement of quality of care through a simple and user-friendly ESHR;

- Use of Semantic as a tool to ensure interoperability and intelligent communication between systems;

- Improvement of patient-hospital relationship by the Health Information Systems;

- Improvement of show rates to appointments by implementing an Alert Appointment System;

- Reduction of costs related to appointments misses, such as service interruptions and wrong allocation of human resources and physical spaces;

- Reduction in the number of non-programmed stops of the systems, by providing a preventive actions management tool;

- Systems interoperability through the platform AIDA; and

- Implementation of tools based on open-source software, promoting a collaborative environment and at the same time avoiding high implementation costs. 


\subsection{Future Work}

Every research work has the intention to stimulate new ideas and to propose new challenges, not only for those who develop the investigation but also for those who will eventually lie across with the research in the future. After the conclusion of this thesis work, the feeling remains that there is still a long way to scout before reaching a complete interoperability of Health Information Systems. New methodologies and procedures arise every day, but it urges the formulation of standards so that the investigation does not diverge to less important areas for both users and patients. In this manner, and taking into account the country where this investigation took place, Portugal, it is urgent to adopt new measures, whether by the government authorities or by the healthcare units them self, working together or individually, in order to pursue solutions for the problems arising every day. HIS specialist should promote the contact between new software tools and the users that will benefit from them. The reality shows that existing procedures are many times confuse or simply inaccessible to the users; it is necessary to create tools, such as websites with forums and blogs or simple white papers distribution, that can stimulate this communion and that boost the pursuit of a healthcare system with higher quality.

A simple task that needs to be performed is the elaboration of a document that clearly identifies, resumes and explains the standards followed by healthcare units in agreement with their external partners. In that way, it would be possible to create a national platform that managed standards according to the principles established by the European Union, so that an interaction and cooperation between the healthcare units among the European members could be promoted. The implementation of such a platform could be done in phases, with an increasing number of participating healthcare units. 



\section{Bibliography}

[Abelha, 2004] Abelha, A. (2004). Multi-Agent Systems to Support Cooperative Work in Health Care Units. PhD thesis.

[Abelha et al., 2002] Abelha, A., Machado, J., Santos, M., Allegro, S., Paiva, M., and Neves, J. (2002). Agency for integration, diffusion and archive of medical information. In Proceedings of the Third IASTED International Conference Artificial Intelligence and Applications.

[Aguilar, 2005] Aguilar, A. (2005). Semantic interoperability in the context of ehealth.

[AKMI, 2011] AKMI (2011). Working group medical informatics. URL: http://iig.umit.at/akmi/akmi.htm.

[AMI, 1968] AMI (1968). Ami - association pour les applications de 1 informatique en medecine. URL: http://france-aim.org.

[APAMI, 1993] APAMI (1993). Apami - asia pacific association for medical informatics. URL: http://www.apami.org/.

[Bakker and Leguit, 1999] Bakker, A. R. and Leguit, F. A. (1999). Evolution of an integrated his in the netherlands. International Journal of Medical Informatics, 54(3):209-224. 
[Berger and Ciotti, 1993] Berger, H. S. and Ciotti, G. V. (1993). His (healthcare information systems) consultants: when are they necessary, and why? Healthc Financ Manage, 47:44-49.

[Bodenreider, 1998] Bodenreider, O. (1998). Evolution of the unified medical language system as a medical knowledge source. Journal of the American Medical lnformatics Association., pages 76-87.

[Campos, 2002] Campos, C. H. S. (2002). Tecnologia aplicada a saude a servico do cidadao.

[CDA, 2000] CDA (2000). Cda - clinical data architecture by interoperable ehr. URL: http://iehr.eu/.

[Chen et al., 2010] Chen, Y. N., Latour, T., Guedria, W., and David (2010). Towards a systemic formalisation of interoperability. Computers in Industry, 61:176185.

[CHI, 2001] CHI (2001). Canada health infoway. URL: https://www.infowayinforoute.ca.

[CHI, 2010] CHI (2010). National impact of generation 2 drug information systems technical report.

[Clark and Ocana, 2009] Clark, T. and Ocana, M. (2009). Semantic web applications in neuromedicine (swan) ontology. URL: http://www.w3.org/TR/hclsswan/.

[Collen, 1988] Collen, M. (1988). HIS concepts, goals and objectives, pages 3-9. North-Holland, Amsterdam.

[CPSA, 2004] CPSA, College of Physicians, S. o. A. (2004). Transition to electronic medical records - cpsa guideline. 
[CT, 2002] CT, S. (2002). International health terminology standards development organization. URL: http://www.ihtsdo.org/snomed-ct/.

[Currie and Procter, 2002] Currie, G. and Procter, S. (2002). Impact of mis/it upon middle managers: some evidence from the nhs. New Tech. work Emp., 17:102-118.

[DCMI, 1995] DCMI (1995). Dcmi - dublin core metadata initiative. URL: http://www.dublincore.org/.

[Delone and Mclean, 2003] Delone, W. H. and Mclean, E. R. (2003). The delone and mclean model of information systems success: A ten-year update. Journal of Management Information Systems, 19:9-30.

[Dick and Steen, 1991] Dick, R. and Steen, E. (1991). The computer-based patient record - an essential technology for health care.

[Dolin et al., 2006] Dolin, R. H., Alschuler, L., Boyer, S., Beebe, C., Behlen, F. M., Biron, P. V., and Shabo, A. (2006). Hl7 clinical document architecture, release 2. Jornal of the American Medical Informatics Association, 13:30-39.

[Duarte, 2008] Duarte, J. (2008). Qualidade e Normalizacao do Registo no Processo Clinico Electronico. PhD thesis.

[EFMI, 1976] EFMI (1976). Efmi - european federation for medical informatics. URL: http://www.helmholtz-muenchen.de/ibmi/efmi/.

[EHR4CR, 2011] EHR4CR (2011). Ehr4cr - electronic health records for clinical research. URL: http://www.ehr4cr.eu.

[epSoS, 2008] epSoS (2008). European patiens - smart open services. URL: www.epsos.eu.

[epSoS, 2012a] epSoS (2012a). epsos news: epsos on its way to pilot cross-border ehealth services.

[epSoS, 2012b] epSoS (2012b). Technical aspects. 
[Erstad, 2003] Erstad, T. (2003). Analyzing computer based patient records: A review of literature. Journal of Healthcare Information Management, 17:51-57.

[EU-ADR, 2008] EU-ADR (2008). Eu-adr - exploring understanding adverse drug reactions. URL: http://www.euadr-project.org/.

[EU-ADR, 2012] EU-ADR (2012). Exploring and understanding adverse drug reactions by integrative mining of clinical records and biomedical knowledge.

[Fedele, 1995] Fedele, F. (1995). Healthcare and Distributed Systems Technology.

[Ferrand and Lay, 1994] Ferrand, D. and Lay, C. (1994). Diagnosing strategic performance of the hospital information systems planning cycle.

[Figueiredo, 2002] Figueiredo, J. (2002). Criacao de comunidades medicas virtuais baseadas no uso de tecnologias wireless.

[GMDS, 2006] GMDS (2006). Gmds - german society for medical computer science, biometry and epidemiology. URL: http://www.gmds.de/.

[Goulde and Brown, 2006] Goulde, M. and Brown, E. (2006). Open Source Software: A Primer for Health Care Leaders. California Healthcare Foundation.

[Graybeal, 2009] Graybeal, J. (2009.). Achieving semantic interoperability.

[Gurley, 2004] Gurley, L. (2004). Advantages and disadvantages of the electronic medical record. American Academy of Medical Administrators.

[Hayrinen et al., 2008] Hayrinen, K., Saranto, K., and Nykanen, P. (2008). Definition, structure, content, use and impacts of electronic health records: A review of the research literature. International Journal of Medical Informatics, 77:291-304.

[Helfenbein, 1987] Helfenbein, S. (1987). Technologies for management information systems in primary health care. 
[Hersh, 2002] Hersh, W. R. (2002). Medical informatics: improving health care through information. JAMA, 288(16):1955-8.

[HIMSS, 2005] HIMSS (2005). Interoperability definition and background.

[HITECH, 2004] HITECH (2004). Office of the national coordinator for health information technology. URL: http://healthit.hhs.gov/portal/server.pt/.

[HL7, 2010] HL7 (2010). Hl7, health level seven international. URL: http://www.hl\%.org/.

[Hurtubise, 1984] Hurtubise, R. (1984). Managing information systems: concepts and tools. Technical report.

[IEEE, 1991] IEEE (1991). Ieee standard computer dictionary. a compilation of ieee standard computer glossaries.

[ISO, 2004] ISO (2004). Health informatics health informatics profiling framework.

[Jentzsch et al., 2009] Jentzsch, A., Zhao, J., Hassanzadeh, O., Cheung, K., Samwald, M., and Andersson, B. (2009). Linking open drug data. iTriplification Challenge.

[J.M., 2000] J.M., G.-B. (2000). Advantages of open source software.

[Kalva, 2002] Kalva, P. R. (2002). Diminuindo a ocorrencia de interacoes medicamentosas com o sistema alianca.

[Kivinen and Lammintakanen, 2012] Kivinen, T. and Lammintakanen, J. (2012). The success of a management information system in health care - a case study from finland. International Journal of Medical Informatics.

[Kongstvedt et al., 2000] Kongstvedt, P. R., Plocher, D. W., and Stanford, J. C. (2000). Integrated Health Care Delivery Systems. Aspen Publication. 
[Krogh and Hippel, 2006] Krogh, G. v. and Hippel, E. v. (2006). The promise of research on open source software. Manage. Sci., 52(7):975-983. 1246150.

[Kukafka et al., 2007] Kukafka, R., Ancker, J., Chelico, J., Khan, S., Mortoti, S., Natarajan, K., Presley, K., and K., S. (2007). Redesigning electronic health record systems to support public health.

[Langefors and Sundgren, 1975] Langefors, B. and Sundgren, B. (1975). Information systems architecture.

[Linked2Safety, 2011] Linked2Safety (2011). Linked2safety. URL: http://www.linked2safety-project.eu.

[Lopes, 2002a] Lopes, H. (2002a). Computacao movel em telemedicina: Aplicacao ao ensino de cirurgia oncologica pediatrica.

[Lopes, 2002b] Lopes, M. U. (2002b). Sistema de controle de interacao medicamentosa.

[Mahmud, 2002] Mahmud, S. D. (2002). Aplicacao de sistemas de informatica para o uso racional e seguro de medicamentos no hospital de clinicas de porto alegre.

[Marques et al., 2010] Marques, A., Correia, A., Cerqueira, L., Machado, J., and Neves, J. (2010). Archetype-based semantic interoperability in healthcare. pages $305-308$

[MeSH, 1987] MeSH (1987). Medical subject headings - health information systems. URL: http://www.ncbi.nlm.nih.gov/mesh/68006751.

[Middleton, 2004] Middleton, B. (2004). The value of healthcare information exchange and interoperability. In HIMSS, editor, HIMSS Annual Conference.

[MIM, 1974] MIM (1974). Mim - belgian society for medical informatics. URL: http://www.bmia.be/portal.php?p=Introduction.html. 
[Miranda et al., 2009] Miranda, M., Duarte, J., Abelha, A., Machado, J., and Neves, J. (2009). Interoperability and healthcare. In European Simulation and Modelling Conference, pages 205-212. EUROSIS.

[MobiGuide, 2007] MobiGuide (2007). Mobiguide. URL: http://www.mobiguideproject.eu.

[Murray et al., 2009] Murray, P. J., Wright, G., Karopka, T., Betts, H., and Orel, A. (2009). Open source and healthcare in europe - time to put leading edge ideas into practice. Stud Health Technol Inform, 150:963-7.

[Mykkanen and Tuomainen, 2008] Mykkanen, J. and Tuomainen, M. (2008). An evaluation and selection framework for interoperability standards.

[Neves et al., 1999] Neves, J., Alves, V., Nelas, L., Romeu, A., and Basto, S. (1999). An information system that supports? knowledge discovery and data mining in medical imaging.

[openEHR, 2007] openEHR (2007). openehr - openehr foundation. URL: http://www.openehr.org/.

[Orgun and Vu, 2006] Orgun, B. and Vu, J. (2006). Hl7 ontology and mobile agents for interoperability in heterogeneous medical informations. Computers in Biology and Medicine, 36:817-836.

[Ovretveit et al., 2007] Ovretveit, J., Scott, T., Rundall, T., Shortell, S., and Brommels, M. (2007). Implementation of electronic medical records in hospitals: two case studies. Health Policy, 84:181-190.

[Peixoto et al., 2012a] Peixoto, H., Abelha, A., Machado, J., Duarte, J., and Santos, M. F. (2012a). Scheduleit - open-source preventive actions management platform in healthcare information systems information systems. In CENTERIS 2012 Conference on ENTERprise Information Systems / HCIST 2012 - International Conference on Health and Social Care Information Systems and Technologies. 
[Peixoto et al., 2012b] Peixoto, H., Machado, J., Abelha, A., Neves, J., Correia, A., and Santos, M. (2012b). Aasys : Appointment alert system : an open-sourcebased software to improve show rates in a health care unity. In ESM, editor, Proceedings of the European Simulation and Modelling Conference.

[Peixoto et al., 2012c] Peixoto, H., Machado, J., Abelha, A., and Santos, M. (2012c). Intelligence in interoperability with aida. In The 20th International Symposium on Methodologies for Intelligent Systems. Springer.

[Peixoto et al., 2010] Peixoto, H., Machado, J., Neves, J., and Abelha, A. (2010). Semantic Interoperability and Health Records., volume 335 of IFIP Advances in Information and Communication Technology, pages 236-237. Springer Boston.

[Pereira, 2003] Pereira, A. (2003). Registos clinicos electronicos - apontamentos da disciplina de introducao a informatica medica.

[Pires, 2002] Pires, F. A. (2002). Sistema baseado em regras para processamento do faturamento hospitalar - sifh.

[PONTE, 2010] PONTE (2010). Ponte - efficient patient recruitment for innovative clinical trials of existing drugs to other indications. URL: http://www.ponteproject.eu/.

[Ralyte et al., 2008] Ralyte, J., Jeusfeld, M. A., Backlund, P., Kuhn, H., and ArniBloch, N. (2008). A knowledge-based approach to manage information systems interoperability. Information Systems, 33:754-784.

[Redhat, 2007] Redhat (2007). Open source and healthcare it. URL: http://www.redhat.com/f/pdf/OSHealthcareWhitepaper_web.pdf.

[Santos, 2002] Santos, M. d. (2002). Chat para diagnostico clinico.

[Seals, 2000] Seals, M. (2000). The use of xml in healthcare information management. 
[SemanticHealthNet, 2011] SemanticHealthNet (2011). Semantichealthnet - the semantichealthnet project. URL: http://www.semantichealthnet.eu.

[SHARPS, 2010] SHARPS (2010). Strategic health it advanced research projects. URL: www.sharps.org.

[Silverstein, 1999] Silverstein, S. (1999). What is medical informatics, and why is it an important specialty? URL: http://www.ischool.drexel.edu/faculty/ssilverstein/informaticsmd/infordef1.htm.

[S.M. and Moore, 2003] S.M., C. C. and Moore (2003). Ihe: a model for driving adoption of standards. Computerized Medical Imaging and Graphics, 27:137-146.

[Sujansky, 2001] Sujansky, W. (2001). Heterogeneous database integration in biomedicine. J Biomed Inform, 34(4):285-98.

[Sullivan, 2009] Sullivan, F. (2009). Overview of global economy.

[W3C, 2010] W3C (2010). W3c - world wide web consortium. URL: http://www.w3.org/.

[WHO, 1988] WHO (1988). The challenge of implementation: district health systems for primary care. Technical report.

[WHO, 2010] WHO (2010). Capacity of the health system in kazakhstan for crisis management. Technical report, WHO.

[Wolfram, 1995] Wolfram, D. A. (1995). An appraisal of internist-i. Artificial Intelligence in Medicine, 7:93-116.

[Yu, 2003] Yu, L. (2003). Medical informatics association ubc. 



\section{Appendix A}

\section{Interoperability and the Semantic}

\section{Health Record (in Portuguese)}

Interoperabilidade e o Processo Clínico Semântico

Hugo Peixoto, José Machado e António Abelha

First European Workshop on Computing and ICT Professionalism (EWCIP), Santiago de Compostela, Spain, in ISI Web of Science, 2010 



\section{A.1 Abstract (in Portuguese)}

Este artigo vem mostrar que a interoperabilidade e a semântica são dois pilares essenciais na construção e na implementação do processo clínico electrónico. Dessa forma, é possível construir um sistema capaz de desenvolver a investigação clínica e apoiar os profissionais de saúde na resolução dos problemas dos pacientes, com qualidade. Velocidade e custos baixos.

\section{A.2 Keywords (in Portuguese)}

Processo Clínico Electrónico, Registo Clínico Electrónico, Interoperabilidade, Semântica.

\section{A.3 Introduction (in Portuguese)}

A prestação de cuidados de saúde é uma ciência baseada em informação [A I]. Nos últimos anos, os Sistemas de Informação em unidades de saúde têm vindo a ganhar uma enorme relevância e têm crescido em qualidade e quantidade. Com este crescendo de informação, torna-se necessário discernir o que é informação relevante e o que não é, ou seja o que deve fazer parte do processo clínico e o que não deve. Assim garantir que apenas informação com qualidade é consultada é um problema para o qual os investigadores na área dos Sistemas de Informação na saúde têm voltado as suas atenções. Uma unidade de Saúde é constituída por uma grande quantidade de aplicações que falam linguagens diferentes, que são costumizadas de maneira distinta pelos seus criadores e é essencial uma comunicação concreta e eficaz entre sistemas para que não se perca informação nem se passe a informação errada $[\mathrm{A}-\mathrm{II}, \mathrm{III}]$. 
O Processo Clínico Electrónico é definido como um repositório de informação referente a um indivíduo em formato electrónico, passível de ser armazenado e transmitido em segurança e acessível a múltiplos utilizadores [A - IV]. O principal objectivo é garantir que a informação está acessível em qualquer momento, independentemente do local e que a mesma tem qualidade e responde exactamente ao que foi solicitado. A tecnologia que vem sendo proposta para solucionar este problema é a Semântica.

Nos dias que correm, os Sistemas de Informação têm capacidades cada vez mais expostas e exploradas, contudo e como em qualquer área, quanto maior for a oferta maior se torna a necessidade e maior é a margem de evolução que permite conseguir atingir novos objectivos. O processo clínico electrónico é já um tema amplamente discutido e explorado, que vem trazendo novidades e avanços a cada dia. No entanto as novas necessidades passam por gerir toda a informação que é produzida nas unidades de saúde, garantir a qualidade e a fácil troca da mesma. É necessário recorrer a essas novas tecnologias emergentes para fazer face às exigências.

A semantização do Processo Clínico Electrónico é um dos avanços mais recentes e facilita a interoperabilidade não só dentro da organização como também entre organizações. Com a inclusão do denominado Processo Clínico Semântico nos Sistemas de Informação do Hospital é possível garantir a gestão de grandes fluxos de informação, preservando a qualidade necessária e indispensável à prática clínica e garantido, acima de tudo, a acessibilidade à informação espalhada pela quantidade de aplicações existentes dentro da Unidade de Saúde. A criação de ontologias associadas à prática clínica e aos registos de informação médica no processo clínico semântico tem vindo a ser igualmente discutida apesar de na actualidade cada sistema ter a sua representação e linguagem própria $[\mathrm{A}-\mathrm{V}]$.

Inicialmente foi estudada a nova vaga de semantização da Web e a sua aplicabilidade à área clínica. A metodologia usada é explicada recorrendo a diagramas de fluxo que permitem visualizar o percurso da informação e o seu caminho até ser 
acedida pelos utilizadores.

\section{A.4 Semantic Web vs Medical Semantic (in Por- tuguese)}

Estamos numa era em que a internet está no nosso quotidiano e é indispensável para tudo aquilo que fazemos. As evoluções da internet reflectir-se-ão na sociedade e a investigação científica caminha lado a lado com as suas evoluções.

O consórcio W3C [A - VI] tem vindo a efectuar diversos estudos e a publicar diversas linhas orientadoras de semantização Web que permitirão uma interoperabilidade mais eficaz. A interoperabilidade é garantida porque os utilizadores conseguem compreender a informação que lhes é disponibilizada, assim como os computadores. Em traços gerais é assim definida a Semântica Web, isto é, estabelecimento de princípios e regras que são seguidos de forma concisa e disciplinada, que permite a ligação entre sistemas de forma correcta e inequívoca. O acesso à informação é efectuado de forma simples e eficaz garantindo aos utilizadores a qualidade na informação.

Existe já um conjunto de grupos de investigação em busca da semantização nas mais diversas áreas e a área clínica não foge à regra. Jentzsch e colaboradores desenvolveram um sistema de apoio à área farmacêutica que permite a ligação entre medicamentos, tratamentos, curas e testes laboratoriais via semântica Web. O sistema apresentado mostrava como procurar uma erva medicinal chinesa que cumprisse os requisitos para ser administrada a um determinado paciente [A - VII]. Como Jentzsch e os seus colaboradores mostram, é possível a construção de sistemas de apoio à decisão na actividade clínica recorrendo a tecnologias usadas na Web. Estas tecnologias serão tanto melhor comportadas pelas unidades de saúde quanto maior for a capacidade dos fornecedores de sistemas de informação adequarem os seus 
produtos e será um processo tanto mais rápido quanto mais célere for a adaptação de tais ferramentas.

As vantagens da semantização são enormes mas, como em qualquer tecnologia, existem desvantagens. Neste processo, o factor negativo será a complexidade de execução e o grau de exigência que é aplicado à área médica. É necessário construir sistemas que dêem garantias de eficiência e sucesso, mas tudo passará pela capacidade de evolução e adaptação das unidades de saúde.

\section{A.5 Health Record (in Portuguese)}

Em termos gerais, o Processo Clínico (PC) consiste num registo clínico, elaborado pelos profissionais de saúde, que corresponde a um acompanhamento geral de cada paciente. $\mathrm{O}$ PC é formado por um conjunto ordenado de documentos normalizados, que contêm toda a informação referente ao estado clínico de um determinado individuo [A - VIII]. O PC tem de incluir todos os problemas de saúde, a sua gestão e a resposta de um certo individuo à mesma, de forma a assistir aos cuidados de saúde sempre que necessário [A - IX]. Este processo deve incluir todos os dados de interesse clínico do paciente, desde um histórico clínico até aos exames laboratoriais. A informação existente num registo clínico corresponde a informação maioritariamente alfanumérica, ou seja, informação que pode ser representada por caracteres ou dígitos. A restante informação não textual, fundamentalmente oriunda dos meios complementares de diagnóstico, como sinal ou imagem, habitualmente não está disponível juntamente com o processo clínico (ex: imagens das endoscopias só são visualizadas quando explicitamente solicitadas), não ficando toda a informação clínica de um determinado doente disponível como um todo [A - X]. Os dados deste tipo de registo clínico são normalmente organizados em três grupos distintos, dados de carácter administrativo, dados médicos físicos e outros dados médicos. Os dados administrativos são caracterizados como dados de identificação administra- 
tiva do doente. Por sua vez, os dados médicos físicos dizem respeito a ocorrências singulares do doente. Finalmente, os outros dados médicos são classificados como ocorrências múltiplas de dados ou dados temporais $[\mathrm{A}$ - X, XI]. Em meio hospitalar, o PC tem de cumprir diferentes funções, atendendo a etapas de registo formais ou informais. Este deve-se corporizar como uma área de trabalho onde se atinge um consenso clínico, constitui-se ideias, observações e registos durante o período em que um determinado individuo seja sujeito a cuidados médicos, ao longo de um ou mais episódios [A - XII].

\section{A.6 Electronic Health Record (in Portuguese)}

Existem várias definições de PCE, mas na generalidade, este pode ser definido como o registo informático de dados clínicos do paciente, ou seja, de toda a informação desde dados demográficos, antecedentes médicos, dados laboratoriais, etc. Estes dados estão inseridos num sistema electrónico que permite a captura, a manutenção, a transmissão e o armazenamento de informação clínica, a qual é essencial, não só para o correcto acompanhamento do estado de saúde de cada paciente, mas também para outros efeitos como por exemplo para propósitos de gestão de custos [A - VIII, XI, XIII]. Historicamente, os primeiros SIH apareceram nos anos 60, dando o primeiro impulso do PCE na história, embora estes sistemas primitivos ainda não se centravam especificamente na parte clínica [A - VIII].

\section{A.6.1 EHR features (in Portuguese)}

Com o objectivo de facilitar e melhorar os cuidados prestados nos estabelecimentos de saúde, o PCE desempenha determinadas funcionalidades, algumas das quais semelhantes com o tradicional Processo Clínico em Papel (PCP). Das funcionalidades destacam-se: manter a história clínica de cada paciente, servindo como 
suporte à assistência do mesmo, para efeitos de apoio à decisão ou mesmo como fonte de informação para todos os profissionais clínicos envolvidos; baixar a frequência de perda de registos ou dados de registo, assim como reduzindo a ocorrência de erros médicos; suportar a comunicação entre fontes externas de informação médica; a gestão e o planeamento de recursos, assim como a melhoria dos procedimentos de avaliação de custos. A grande diferença do modo de funcionamento do PCE e do PCP está relacionada com a interacção existente entre os dois tipos de registo clínico e as fontes de informação, que permitem a realização do mesmo. A ligação estabelecida entre as fontes de informação e o PCE é bidireccional, ou seja, existe feedback, isto não existia relativamente ao PCP. Desta forma, um registo electrónico para além de conter a informação referida, ainda permite a partilha de informação entre os diferentes utilizadores, assim como a interacção entre as fontes de informação [A $-\mathrm{X}]$.

\section{A.6.2 EHR requirements (in Portuguese)}

O sucesso da implementação de um PCE depende de um conjunto de requisitos que esta terá de seguir. Para além das características comuns do PCE com o PCP, o PCE deve ser rápido na resposta, fiável, íntegro, seguro e acessível $24 \mathrm{~h}$ por dia. A estruturação do PCE deve possibilitar a integração total com os sistemas de informação hospitalares existentes, promovendo a ubiquidade de registos entre diferentes especialidades e serviços e possibilitando o acesso a mecanismos de monitorização, alarme e apoio à decisão. O registo electrónico terá de possibilitar a geração de documentos e relatórios personalizados para fins específicos, facilitando ainda a configuração de interfaces de registo, entre outros. A informação nele contida terá de ser normalizada e uniforme e os profissionais de saúde terão de ser alvo de formação específica [A - VIII, XIV, XV]. 


\section{A.6.3 EHR advantages (in Portuguese)}

\section{Physical advantages (in Portuguese)}

Comparando com o PCP, a grande vantagem do PCE é o pequeno espaço que ocupa um dispositivo capaz de armazenar uma enorme quantidade de informação. Esta vantagem ainda pode acentuar-se mais com o desenvolvimento das ciências computacionais [A - VIII, XVI]. Outro ponto positivo é a duplicação e a partilha de informação, esta tarefa torna-se mais simples e imediata. Esta vantagem possibilita a partilha do PC por diferentes tarefas síncronas, a implementação de arquivos clínicos para backup de informação e salvaguardada a hipótese de perda e/ou dano $[\mathrm{A}-\mathrm{VIII}, \mathrm{XVI}]$.

\section{Structural advantages (in Portuguese)}

O registo electrónico suporta a personalização da interface do utilizador, permitindo o uso de diferentes layouts de inserção e visualização de informação, aspecto bastante útil dada a existência de modalidades específicas em ambiente hospitalar. O PCE assegura a legibilidade dos dados, o que não acontece com o PCP, já que os dados são introduzidos manualmente e a legibilidade dos mesmos depende da caligrafia dos profissionais de saúde. Outra vantagem importante é o facto de o PCE realizar o processamento de dados em contínuo, facilitando a detecção de erros e a emissão de alarmes correspondentes a situações de eventual anomalia patológica. Finalmente, o PCE possibilita a recolha automatizada de parâmetros clínicos a partir de monitores, aparelhos de imagiologia, análises químicas, entre outros [A - VIII, $\mathrm{XVI}]$. 


\section{A.7 Agency for Integration, Diffusion and Archive (in Portuguese)}

A AIDA (Agência para Integração, Difusão e Arquivo da Informação Médica) é uma plataforma que consiste num Sistema Multi-Agente (SMA) e surge devido às dificuldades em alcançar a homogeneidade dos sistemas clínicos, médicos e administrativos bem como complexidade das diferentes fontes de informação [A - XVII]. A AIDA foi implementada no Centro Hospitalar do Porto (CPO). É uma agência que fornece funcionários electrónicos dotados de inteligência, os agentes. Esta plataforma apresenta um comportamento pró-activo em que as principais funções são comunicação entre sistemas heterogéneos, gestão e armazenamento de informação, resposta a pedidos em tempo útil e envio e recepção de informação (relatórios médicos, imagens, prescrições, etc.). Desta forma a AIDA assume papel principal e central no SIH, como demonstra a Figura A.1 [A - XVIII, XIX]. Verifica-se na Figura A.1 que a AIDA possui um fácil acesso, permitindo a gestão da informação clínica em qualquer ponto do hospital, desde que este permita acesso à rede. Para além disto, a plataforma permite o envio de mensagens via telemóvel ou correio electrónico [A - XIX].

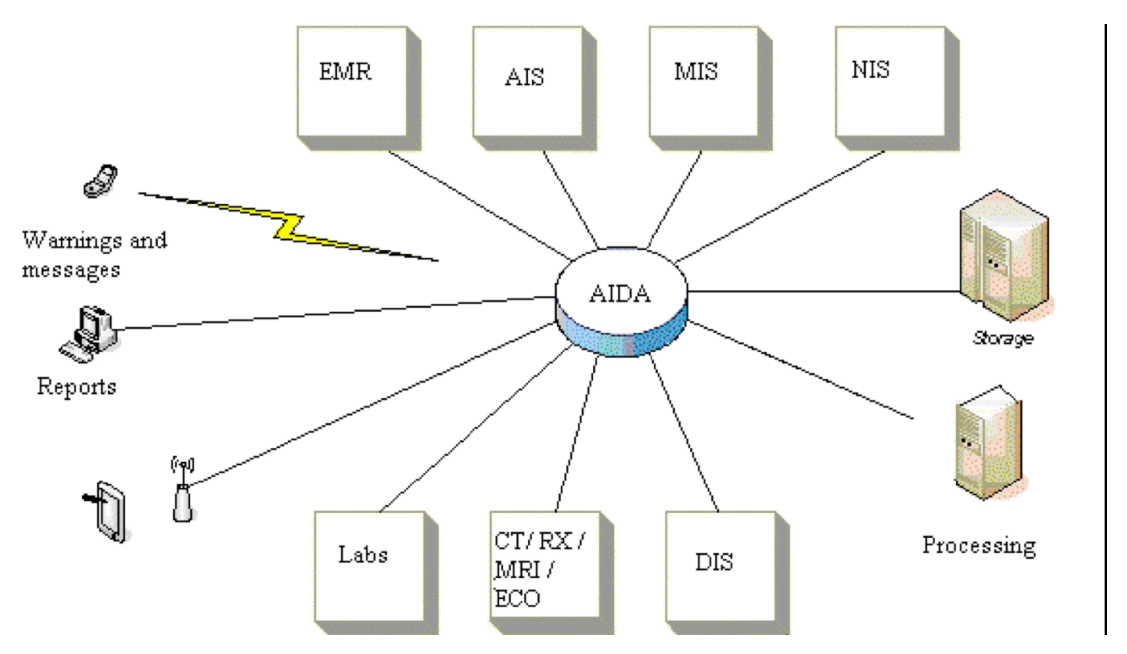

Figure A.1: AIDA. 


\section{A.7.1 AIDA-PCE (in Portuguese)}

O AIDA-PCE é um PCE e foi implementado no CPO como um subsistema do SIH nesta instituição. O AIDA-PCE segue uma organização orientada ao problema sugerida pelo Lawrence Weed na década de 60. Este modo de organização da informação ficou conhecido como Registo Médico Orientado ao Problema (ProblemOriented Medical Record, POMR) e permitiu que o registo clínico se tornasse num documento científico. Neste tipo de organização toda a informação clínica (anotações, terapêuticas, diagnósticos) deveria ser registada por problema específico, criando uma lista de problemas organizada numa estrutura em árvore, em que cada novo problema derivaria do ramo principal [A - VII, X, XIX]. De referir que os problemas podem ser classificados como activos ou inactivos, em que problemas activos são aqueles em que a doença ainda está activa ou quando ainda é necessária a intervenção imediata, e por outro lado, problemas inactivos são aqueles que não requerem nenhuma acção urgente.

No AIDA-PCE os problemas activos são acompanhados e registados diariamente segundo uma estrutura SOAP. Deste modo, cada registo possui os sintomas do paciente, uma observação do médico, uma análise de diagnóstico e um plano terapêutico a que o paciente é sujeito [A - VIII, XX]. O AIDA-PCE utiliza uns interfaces acessíveis e perceptíveis aos profissionais de saúde. Destacam-se, na página principal do processo de um qualquer paciente, a lista de problemas, que aparece centralizada na página, o fácil acesso aos últimos Meios Complementares de Diagnóstico e Terapêutica (MCDT) realizados e a visualização de todo o PC organizada em árvore. 


\section{A.8 Goals (in Portuguese)}

O Processo Clínico Semântico é a disponibilização de informação relativa a um indivíduo, informação passível de ser interpretada pelos utilizadores e por computadores. Este documento apresenta as bases para um sistema de apoio à decisão e procura mostrar o trabalho inicial que está a ser desenvolvido para cimentar o caminho para o objectivo final. Assim o principal objectivo deste documento é mostrar a semantização dentro de uma unidade de Saúde e as iterações necessárias para atingir esse objectivo.

Disponibilizar informação aos utilizadores e, por conseguinte, permitir que possam processar essa informação computacionalmente é fulcral para uma prática clínica de qualidade. Garantido a interoperabilidade entre sistemas garante-se o acesso a toda a informação disponível para o doente e com o acréscimo da informação do doente poder ser usada para confrontar situações similares. Casos clínicos idênticos, prescrições similares e dados demográficos aproximados são situações recorrentes que podem fazer a diferença entre um correcto diagnóstico ou uma correcta prática clínica e um mau diagnóstico ou uma prática clínica inadequada. É preciso garantir que os sistemas de informação trabalham em cooperação com os utilizadores e são uma mais-valia de qualidade em todo este processo.

Este artigo procura explorar as complicações encontradas ao longo do trabalho bem como mostrar os caminhos traçados e as tarefas desenvolvidas para atingir os objectivos finais. 


\section{A.9 Methodologies (in Portuguese)}

\section{A.9.1 XML construction (in Portuguese)}

Como referido anteriormente, uma unidade de saúde corresponde a um aglomerado de softwares que muitas das vezes não interagem entre si criando silos de informação. Actualmente, e apesar das novas tecnologias e os sistemas terem a capacidade de interagir, há ainda um longo caminho a percorrer para atingir a completa interoperabilidade numa Unidade de Saúde. As diversas fontes de informação e a identificação única do paciente foram alguns dos principais problemas encontrados no desenvolvimento deste projecto.

Apesar de todos os esforços e da aposta na tecnologia, a completa interoperabilidade em algumas unidades de saúde a total interoperabilidade é ainda uma miragem, ainda que não tão distante daquilo que se possa pensar. No sentido de tirar partido de toda a informação existente e espalhada pela estrutura dos sistemas de informação foi criada uma ferramenta de integração que constrói uma interface gráfica apresentada ao utilizador, que tem por base uma estrutura em XML de acordo com as referências do consórcio W3C. Esta estrutura XML construída em semântica permite, recorrendo ao software existente na internet, produzir uma escala temporal pela qual o utilizador pode navegar, consultando a informação relativa ao doente.

A Figura A.2 mostra um exemplo de um XML que proporciona a construção da timeline de interface com o utilizador. São armazenados em conformidade com W3C os dados mais relevantes como resultados clínicos, relatórios de MCDTs (Meios Complementares de Diagnóstico), dados demográficos, diagnósticos. Toda esta informação esta organizada por episódio e é apresentada ao utilizador final por ordem cronológica permitindo uma rápida navegação pela informação e um acesso intuitivo aos dados mais relevantes para acesso imediato. 


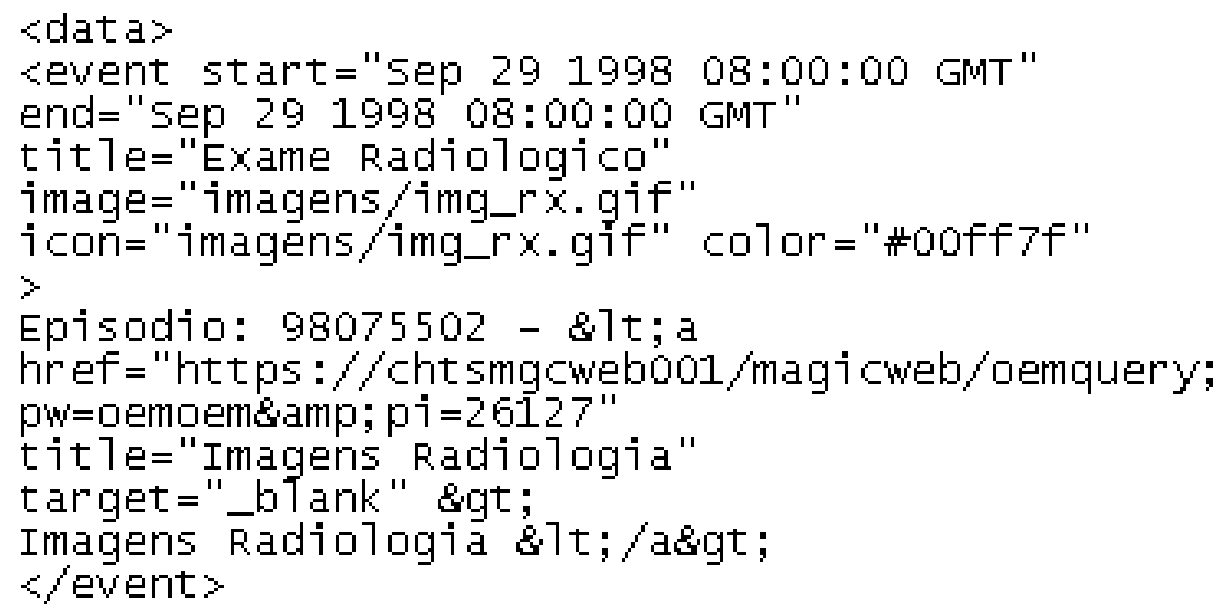

Figure A.2: Ficheiro XML.

A Figura A.3 apresenta um esquema identificativo do fluxo da informação até à apresentação final ao utilizador.

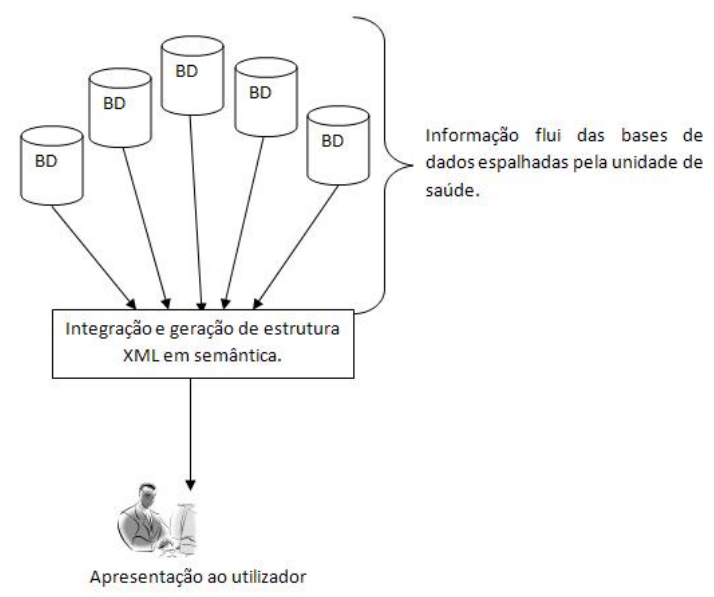

Figure A.3: Workflow.

Como se pode verificar pela Figura A.2 a informação flui de diversos pontos e é concentrada num único processo de conversão e geração da estrutura em XML. Foi necessário um vasto trabalho no sentido de garantir os acessos às mais diversas aplicações e conseguir extrair a informação necessária de cada uma, o que permitirá construir o processo clínico semântico com diversidade de informação. Com esta estrutura, é possível garantir a transformação de dados em informação disponível para o utilizador.

Para além de disponibilizar a informação para o utilizador a mesma fica ar- 
mazenada em semântica e pode ser acedida das mais diversas formas pelos mais diversos utilizadores, quer estejam no ambiente hospitalar quer em casa, efectuando estudos científicos e recorrendo a informação totalmente anonimizada e para extracção do conhecimento e aprendizagem. Da mesma forma que um utilizador acede à informação, também uma máquina a consegue processar, devido ao facto de estar em semântica e utilizar a mesma para relacionamentos e sistemas de apoio à decisão.

\section{A.9.2 Semantic Health Record (in Portuguese)}

São inúmeras as vantagens que se podem associar a um Processo Clínico Electrónico, relativamente ao processo clínico baseado em papel, vantagens estas que vão desde um melhor acesso, segurança, apoio à tomada de decisão, à partilha célere dos dados entre instituições, i.e., a uma melhoria dos cuidados de saúde prestados.

A prática clínica envolve, entre outros, um processo de colheita de dados cujo objectivo se traduz em coligir e sistematizar informação referente ao doente e ao seu estado de saúde, bem como às razões que motivaram o seu contacto com a unidade prestadora de cuidados de saúde. A par desta colheita de dados, desenrola-se um processo de registo de dados clínicos, de uma forma estruturada, que potencia a sua automatização, com recurso às Tecnologias da Informação. Desta forma pode construir-se um repositório de informação para sustentar a prática e investigação clínica, permitindo:

- Registar de uma forma segura, consistente, eficiente, clara e estruturada todos os dados colhidos sobre o paciente, a patologia e a terapia recomendada;

- Mimetizar e complementar os processos em papel de registo de informação, assim como prover ao intercâmbio de informação entre os profissionais de saúde que tratam ou trataram o mesmo paciente; 
- Assegurar o registo de dados clínicos no contexto do PCE;

- Implementar de uma forma segura e eficiente o protocolo de utilização do PCE;

- Associar os profissionais de saúde ao registo de dados clínicos (logs).

Outro passo importante para este trabalho foi a escolha da interface de apresentação para o utilizador, isto é, qual o aspecto que deve ter o Processo Clínico Semântico para o utilizador final e qual é ga melhor forma para ser acedido. A Figura A.4 mostra o aspecto final do Processo Clínico Semântico, ou seja, a interpretação da estrutura XML previamente construída.

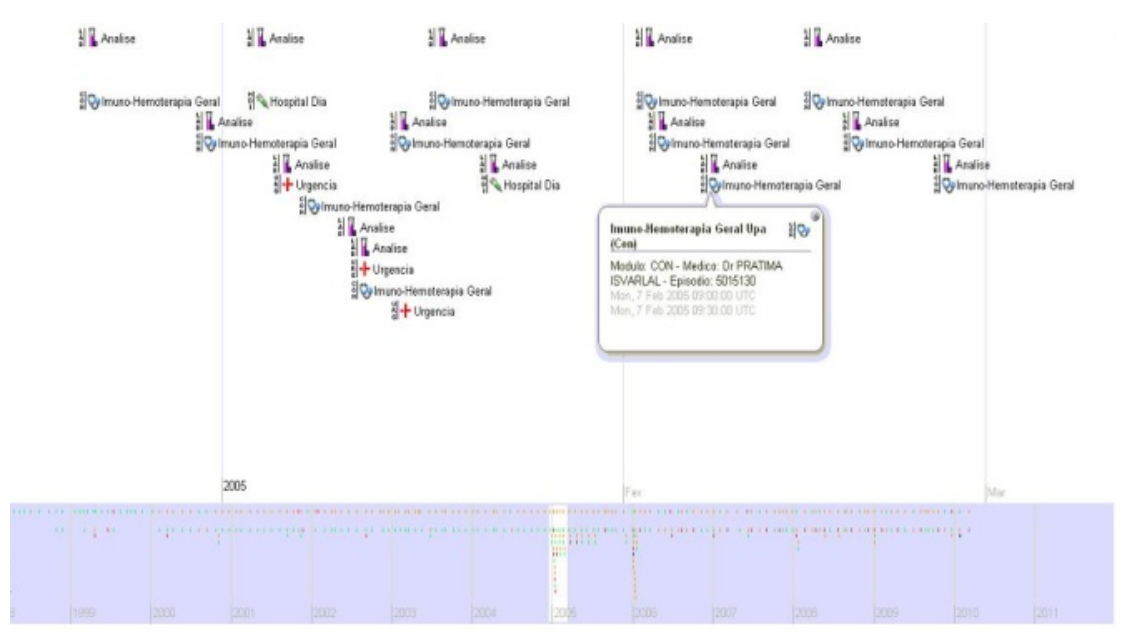

Figure A.4: Processo Clínico Semântico.

O conceito apresentado foi absorvido por pesquisa na internet e é disponibilizado pela SMILE [A - XXI]. É um software opensource e satisfaz as principais necessidades para a implementação deste projecto. A timeline permite uma rápida navegação por todos os episódios do doente e um acesso eficaz e simples à informação. Assim, para além de uma interface intuitiva, é garantido que os utilizadores acedem apenas à informação importante num único local e apenas do utente em causa. A iconografia apresentada permite que o utilizador se foque no essencial e encontre facilmente a informação que necessita. Uma das principais vantagens da estrutura apresentada é que pode ser facilmente parametrizada e a apresentação pode ser 
mudada em apenas alguns passos sem que alterações estruturais ao processo sejam necessárias.

\section{A.10 Results (in Portuguese)}

Com o projecto apresentado foi possível construir uma interface amigável que permite ao utilizador um acesso intuitivo e rápido aos episódios registados na instituição. Aliado aos dados identificativos de cada episódio estão também os endereços para os respectivos resultados de análises, MCDTs, prescrições e demais registos efectuados em cada episódio.

Após a introdução da solução na unidade de saúde foi verificado um aumento dos acessos aos relatórios. Em média cada relatório de MCDTs era acedido 3,4 vezes, sempre pelo médico que havia solicitado o respectivo exame no seguimento do acompanhamento feito ao doente em âmbito de consulta. Os acessos aumentaram, uma vez que quer em consulta quer em âmbito de internamento os relatórios são acedidos de forma mais intuitiva aumentando a média de acessos para 4,2 vezes. Pode perceber-se pela análise da Tabela A.1 que a implementação deste método, ainda que ligeiramente, aumentou o número de acessos aos relatórios elaborados para MCDTs.

Table A.1: Acesso a relatórios.

\begin{tabular}{|c|c|c|c|}
\hline Mês & Relatórios & Acessos & Acessos por exame \\
\hline Outubro & 3514 & 12018 & 3,42 \\
\hline Novembro & 3244 & 10803 & 3,33 \\
\hline Dezembro & 2918 & 10476 & 3,59 \\
\hline Janeiro & $\mathbf{3 7 9 0}$ & $\mathbf{1 5 9 1 8}$ & $\mathbf{4 , 2}$ \\
\hline
\end{tabular}

A possibilidade de facilmente saltar para um episódio anterior referente ao mesmo doente permite aos utilizadores consultarem rapidamente as diferentes fontes de informação e reunir todo o material necessário para efectuar um diagnóstico ou concretizar uma prescrição. Para além de acessos a relatórios, os resultados de 
análises foram consultados em maior número e resultados que por vezes não eram consultados passaram em formato electrónico a sê-lo.

O presente trabalho, para além de garantir um processo de interoperabilidade entre os sistemas de informação existentes na unidade hospitalar, pretende mostrar que é possível utilizar a informação produzida, não só para disponibilização directa ao utilizador, como também reutilizada em outras situações.

\section{A.11 Conclusions (in Portuguese)}

Os sistemas de apoio à decisão são fundamentais nas áreas clínicas e médicas, na medida em que podem ajudar os profissionais de saúde a tomar decisões mais certas, mais rápidas e mais baratas. São conjugadas dessa forma três características essências nos sistemas de informação do presente em que qualidade, velocidade e custo são atributos essências na avaliação dos sistemas. Por outro lado esses sistemas podem ser constituídos por agentes inteligentes dotados de autonomia, proactividade e perícia. Dessa forma é importante desenvolver mecanismos e comunicações intra e inter-organizacionais que garantam a interoperabilidade, permitindo dessa forma um processo clínico mais eficaz, mais orientado à investigação clínica e mais compreensível. Este artigo vem mostrar que a semantização e a interoperabilidade são os dois pilares do Processo Clínico Electrónico.

\section{A.12 Acknowledgements (in Portuguese)}

Gostaríamos de agradecer aos profissionais do Centro Hospitalar do Tâmega e Sousa o apoio demonstrado na realização deste projecto. 


\section{A.13 References (in Portuguese)}

[A-1] Hersh, W.: Medical Informatics - Improving Health Care Through Information . In: JAMA. 2002.

[A - II] Rigor, H., Machado, J., Abelha, A., Neves, J. and Alberto, C.: A Web-based system to reduce the nosocomial infection impact in healthcare units. In: Webist. Valência, 2008.

[A - III] Machado, J., Abelha, A., Novais, P., Neves, J. and Neves, J.: Quality of Service in Healthcare Units. In: ESM. Universite du Havre, Le Havre, France, 2008.

[A - IV] Hanzlícek, P., Precková, P. and Zvárová, J.: Semantic Interoperability in the Structured Electronic Health Record. In: EuroMISE.

[A - V] Bicer, V., Kilic, O., Dogac, A., Laleci, G.: Archetype-Based Semantic Interoperability of web service messages in the HealthCare Domain. International Journal on Semantic Web \& Information Systems. 2005.

[A - VI] W3C consortium. http://w3c.org .

[A - VII] Jentzsch, A., Zhao, J., Hassanzadeh, O., Cheung, K., Samwald, M. and Andersson, B.: Linking Open Drug Data. In: iTriplification Challenge 2009.

[A - VIII] Abelha, A.: Multi-Agent Systems to Support Cooperative Work in Health Care Units - PhD Thesis. Departamento de Informática, Universidade do Minho, Braga, Portugal, 2004.

[A - IX] Slee, V., Slee, D., Schmidt, J.: The Endangered Medical Record: Ensuring Its Integrity in the Age of Informatics. Tringa Press k Maxwell, A Treatise on Electricity and Magnetism, 3rd ed., vol. 2. Oxford: Clarendon, 1892, pp.6873, 2000 . 
[A - X] Pereira, A.: Registos Clínicos Electrónicos - Apontamentos da Disciplina de Introdução à Informática Médica. Faculdade de Medicina, Universidade do Porto, 2003.

[A - XI] Dick, R. \& Steen, E.: The Computer-based Patient Record - An Essential Technology for Health Care. Washington, DC: National Academy Press, 1991.

[A - XII] Kay, S. \& Purves, I.: Medical Records and Other Stories: A Narrational Framework. Methods of Information in Medicine. 35:72-87, 1996.

[A - XIII] Elberg, P.B.:Electronic patient records and innovation in health care services. International Journal of Medical Informatics 64:201205, 2001.

[A - XIV] International Organization for Standardization. Requirements for an Electronic Health Record Reference Architecture - ISO 18308. Geneva: International Organization for Standardization.

[A - XV] Häyrinen K, Saranto K, Nykänen P.: Definition, structure, content, use and impacts of electronic health records: A review of the research literature (Review). International Journal of Medical Informatics, 77:291304, 2008.

[A - XVI] Coiera, E.: Guide to Health Informatics (2nd ed). London: Hodder Arnold, 2003.

[A - XVII] Abelha, A., Machado, J., Santos, M., Allegro, S., Rua, F., Paiva, M. \& Neves, J.: Agency for Integration, Diffusion and Archive of Medical Information. Proceedings of the Third IASTED International Conference - Artificial Intelligence and Applications (ISBN 0-88986-390-3), Malaga, Spain, 2002.

[A - XVIII] Abelha, A., Santos, M., Machado, J. \& Neves, J.: Auditing Agents in the Context of a Telemedical Information Society. Proceedings of the 2nd International Conference on Knowledge Engineering and Decision Support, Knowledge 
and Decision Technologies. Vale, Z., Ramos, C. \& Faria, L. (eds), Lisbon, Portugal (ISBN: 972-8688-39-3), 2006.

[A - XIX] Machado J., Abelha A., Novais P., Neves J., Neves J.: Improving Patient Assistance and Medical Practices through Intelligent Agents, 5th Workshop on Agents Applied in Health Care, in the Seventh International Conference on Autonomous Agents and Multiagent Systems (AAMAS 08), Cascais, Portugal, 2008.

[A - XX] Bossen, C.: Evaluation of a computerized problem-oriented medical record in a hospital department: Does it support daily clinical practice?. International Journal of Medical Informatics. 76:592600, 2007.

[A - XXI] http://simile-widgets.org/. 



\section{Appendix B}

\section{Modelling intelligent behaviours in multi-agent based HL7 services}

Miguel Miranda, Gabriel Pontes, Pedro Gonçalves, Hugo Peixoto, Manuel Santos, António Abelha and José Machado

Computer and Information Science. In Roger Lee (Ed.), (Vol. 317, pp. 95-106):

Springer Berlin / Heidelberg, Studies in Computational Intelligence, 2010. 



\section{B.1 Abstract}

With the dissemination of Health Information Systems and the greater relevance of interoperability towards the quality of the information available to the clinical personnel, distinct architectures and methodologies have been devised in order to improve the existing platforms in the healthcare environment. However, most of them are based on HL7, an international standard for healthcare interoperability, which depending on the implementation as any technology has its advantages and limitations. This paper details the architecture and methodologies of a multi-agent based HL7 interoperation service. The mentioned system is incorporated in an integration platform, which is implemented in several healthcare institutions and uses Multi-Agent Systems to control and enable the ow of data and information within them. The log registry and extracted statistics of several years of interoperation in one institution are used to analyse the development of prediction models to imbue intelligent behaviour in the existing platform. The resulting models are studied and embedded into a validation HL7 server agent.

\section{B.2 Introduction}

The healthcare environment congures a paradigm of intricate information technology architectures, in which distinct solutions must share data and information. The exchange of data and information is of the essence towards the optimisation of existing resources and the improvement of the decision making process through the increase of the quality of information.

Numerous architectural solutions have been developed towards interoperability in healthcare, depending of the objectives, context and methodological approaches. At this architectural level, one can enumerate distinct and relevant abstract interoperability approaches, such as end-to-end, hub-and-spoke, distributed multi-agent 
or service oriented. Properties such as modularity, availability, scalability or delay timespan are associated to the interaction of different systems comprised in the devised architecture.

Within the healthcare environment the integration of all otherwise secluded applications is of the essence for the development of a scalable and functional Health Information System (HIS). A HIS can be dened as an abstract global information system for the processing of data, information and knowledge within the healthcare institution. It is therefore the consorted and integrated effort of the different heterogeneous solutions within the healthcare institution to collect, process, report and use information and knowledge relatated to its unique environment to inuence the existing management policies, health programs, training, research and medical practice within this institution [B - VII].

Considering the denition of an HIS, its essence is the architectural model composed of a group of integrated and interoperable solutions within the healthcare institution. In contrast with the usage of a centralised solution, which is unthinkable considering the specicities of each areas of a healthcare unit, it aims to maintain all distinct services and solutions. It is henceforth essential to imbue the HIS architecture with the capacity to allow communication among different and otherwise secluded systems, avoiding their centralization and dissemination of End-to-End connections, which restrict the growth of all the infrastructure associated to the HIS. The non-modularity of services adds complexity to alterations and improvements, increasing the global costs of the information systems [B - I]. Therefore, it is understandable the present concern demonstrated by distinct international institutions, responsible for nancing and regulating the purchase and development projects for new HIS, with matters of exibility, interoperation and integration of heterogeneous systems [B - II] [B - XIII].

Congruently with these concerns, present tendencies regarding research and industry in interoperability applied to healthcare information systems, indicate the 
potential of agent oriented architecture [B - 5]. Asides from modularity, scalability and adaptability these systems have also the potential to imbue new features associated to intelligent agents which may address the existing problems and solve important limitations otherwise difcult to tackle. Although healthcare standards like HL7 are completely distinct from agent communication standards, HL7 services can be also implemented under the agent paradigm. These agent based HL7 services can communicate with services that follow distinct paradigms and communicate with other agents using either HL7 or agent communication standards. Although the HL7 standard can be implemented using other architectures, agent based solutions enjoy of a vast interoperability capability, being capable to be embedded with the most particular behaviours. These behaviours can become increasingly effective if they use machine learning and other articial intelligence techniques in order to adapt to the existing environment and being able to prevent and correct the ow of information and extraction of knowledge within the institution.

Henceforth, the beginning of this paper details the architecture and methodologies of a multi-agent based HL7 interoperation service. This system is part of an integration platform, which is implemented in several healthcare institutions and uses Multi-Agent Systems (MAS) to control and enable the ow of data and information within them. The log registry and extracted statistics of several years of interoperation are used to analyze the development of prediction models to imbue intelligent behaviour to the existing platform.

\section{B.3 Health Level Seven Protocol}

Health Level Seven (HL7) started as a mainly syntactic healthcare oriented communication protocol at the application layer, the seventh layer of the Open System Interconnection (OSI) communication model. This protocol dened the message structure to be exchanged by loosely connected healthcare applications by classify- 
ing the different types of messages involved in this environment with the aggregation of standardized segments.

The structuring and design of this standard, dening which artefacts of data should be transferred by a certain message, enabled and potentiated the application of HL7 in client-server architectures [B - XII]. The most common implementation of this architecture using HL7 is based on distinct socket communication clients and servers, in which the client sends an HL7 structured message to the server, that upon processing sends an acknowledgement HL7 standardized message. The HL7 standard is not bound to this architecture, but it is the most widely used in healthcare interoperability.

Although the initial standard was uniquely syntactic, the current version 3 is opening the HL7 scope towards semantic interoperability including the appropriate use of exchanged information in the sense of the communicating applications behaviour. The Message Development Framework (MDF) is currently moving towards the HL7 Development Framework (HDF), by that way shifting the HL7 paradigm from message to architecture. Newer HL7 developments such as the EHR-S Functional Model and the SOA Project Group activities have been pushing this move [B - VIII].

\section{B.4 AIDA Platform and HL7 Services}

The AIDA (an Agency for the Integration, Diffusion and Archive of Information) platform was developed by the Articial Intelligence Group of the University of Minho, in Portugal, in order to support the diffusion and integration of information generated in the healthcare environment. This platform imbues many different integration paradigms, using mainly Service Oriented Architectures (SOA) and MAS to implement interoperation in a distributed, specic and standardised manner with all 
the service providers within an healthcare institution. Using this synergy it is maintained the independence and modularity of SOA and the intelligence and autonomy associated to MAS and Articial Intelligence [B - IX] [B - X].

Being MAS a eld of research in Distributed Articial Intelligence, this technology is intrinsically relates with distributed problem solving, while being distinct in the intrinsic denition of an agent versus the properties of the general middlewares of the architecture called in its support [B - XIV]. Indeed, under this approach a MAS subsumes a distributed architecture.

The MAS is able to manage through the agent life cycle the availability of the modules of the healthcare system and the HIS as a whole, while keeping all the agents that constitute the MAS freely distributed. In fact, new agents with the same characteristics and objectives can be created on-demand by the MAS, according to the necessities of the system they belong to. The structuring of these agents and of the MAS can be developed according to the services they provide and the logical functionality of the systems they interoperate with, allowing conceptually to take advantages of the SOA paradigm.

The core of SOA has as a key principle the division of large and complex problems into simpler and modular ones. However, contrary to the common methodologies to address a great number of complex problems, this architecture aims for the services of the smaller conceptual units to be achieved through complete independence. This methodology searches distinct areas of logic automation in order to unitarily make available a service that is part of a vaster and more complex service. It is ensured that in this way each of these units can be replaced by any other unit which performs the same service without concern. These base units can provide a service in a distributed way, independently and disassociated of the underlaying global services structure [B - IV]. Although, at rst glance, it may be extremely similar to the MAS paradigm, SOA is a concept not bound to one specic technology, it can be based on web-services, agents or any other technology following these basic 
rules.

Through the SOA paradigm, a system will not be dependent of its core units. It means that services can be easily replaced and updated, enabling modularity, scalability and independence [B - VI]. These are the properties the AIDA platform associates the MAS and SOA paradigm in interoperability systems. Henceforth, the agencys top layer of abstraction conceptually consists of 7 (seven) multi-agent based subsystems:

- AIDA-RIS - Radiological Information System;

- AIDA-MEIS - Medical Exams Information System;

- AIDA-LIS - Laboratories Information System;

- AIDA-ISM - Information System for Monitoring (e.g., vital signals monitoring);

- AIDA-PRM - Patient Relationship Management (including communication using SMS);

- AIDA-OWM - Organisation and Work Management (Including agenda, scheduling, planning and resource management; and

- AIDA-EHR- Electronic Health Records.

AIDA devised architecture supports intelligent agents that acting as distributed entities on a healthcare environment, gather all the data, transform the underlying information, correct information incoherence and disseminate it thought the HIS. The introduction of data validation allows to improve the overall quality of information extracted and avoids the spread of inconsistencies over all involved systems. The quality of the gathered information is important to guarantee that the decisions made in these environments are based on sound principles and are not led astray by incoherent or inexistent information. 
This platform was engineered under the perspective of a centralised repository for all the signicant data in a healthcare institution. Under this happening, the underlying information must be retrieved from and disseminated towards the different service providers in the healthcare institution. Henceforth, the gathered information must be processed and corrected, validating the execution of existing workows and ensuring the Quality-of-Information (QoI) disseminated to other systems. The presence of a global information and knowledge repository that is oriented towards the whole of the healthcare institution, that has the extensibility to adapt to the heterogeneity within its environment, is an important tool for information validation and knowledge discovery. For this purpose the AIDA platform uses an ORACLE RAC database, structuring most of its clinical and management information in highly compact but well structured XML syntax. The use of XML grants the necessary malleability to adapt the repository conguration to the needs of a specic institution, service or external provider. Clinical reports and other information gathered by the platform are therefore structured and processed in this repository and validated against existing knowledge or information.

Intelligent behaviours are essential to predict and validate, both semantically and syntactically, the data and information gathered according to the knowledge representation and reasoning techniques used in each middleware agent responsible for systems interoperability. Each of the agents is embedded with the explicit particular behaviours congruently with the particularities of the service provided in order to guarantee good quality of the information exchanged among any particular agent it is meant to interoperate with. The scalability and modularity of this architecture is essential not only to the selection of new solutions but specially when developing Decision Support Systems (DSS). The multitude and intricacy of services that must be performed by DSS or Group Decision Support (GDSS), require such a platform or otherwise would be inefciently intertwined with other essential solutions such as the Electronic Health Record (EHR) [B - XI] [B - III]. 
Within its several MAS modules, the AIDA platform contains a proprietary communication system which implements service communication via HL7 standardised messages. This service is one of the core dissemination methods for medical information within the healthcare institutions and as mentioned before is oriented towards a service oriented paradigm. Each agent works either as client or server for a specic service within the healthcare institution. These agents reactively receive or send information for their specic system and have no other interaction with these external systems. Any of the described top layers of abstraction, can communicate with HL7 specialised client agents that exist within their MAS to exchange information with other MAS or external information systems.

\section{B.5 HL7 Activity study}

From the previous activity recorded by the AIDA HL7 services, behavioural patterns of the integrated systems may be extracted in order to increase the reliability and performance of interoperation. The initial models are essentially directed towards the analysis of current load over the existing architecture and prediction of existing bottlenecks. However, with the existing data further information can be extracted in order to develop models which can be embedded in order to overcome limitations and problems of these systems.

Bearing in mind the implemented architecture of HL7 and the underlying nature of service oriented paradigm, the study of such systems should be oriented towards a specic case and context. The model created for a specic service most surely will not express the functional behaviour of another, which inherent properties are usually distinct from each other. Besides, adaptive models must also be dynamically updatable and be able to learn changes in the environment they interact with. The inuence of time of day over a service behaviour is understandable, as services which require human interaction are more active during regular work time due to 
scheduled external consultation, while automated services regarding monitoring are more regular throughout the day. As an example, in Figure B.1 one can notice that the peak of the messages sent to the radiological information system (RIS) service coincides with the working day hours of the healthcare institution. On the other hand the automated chemical analysis service (WAP), as demonstrated in the Figure B.2 has a continuous activity thought the day. Models directed towards the analysis and prediction of communication behaviour must adapt to this constraints in order to provide contextualized information and handle the regarded data.

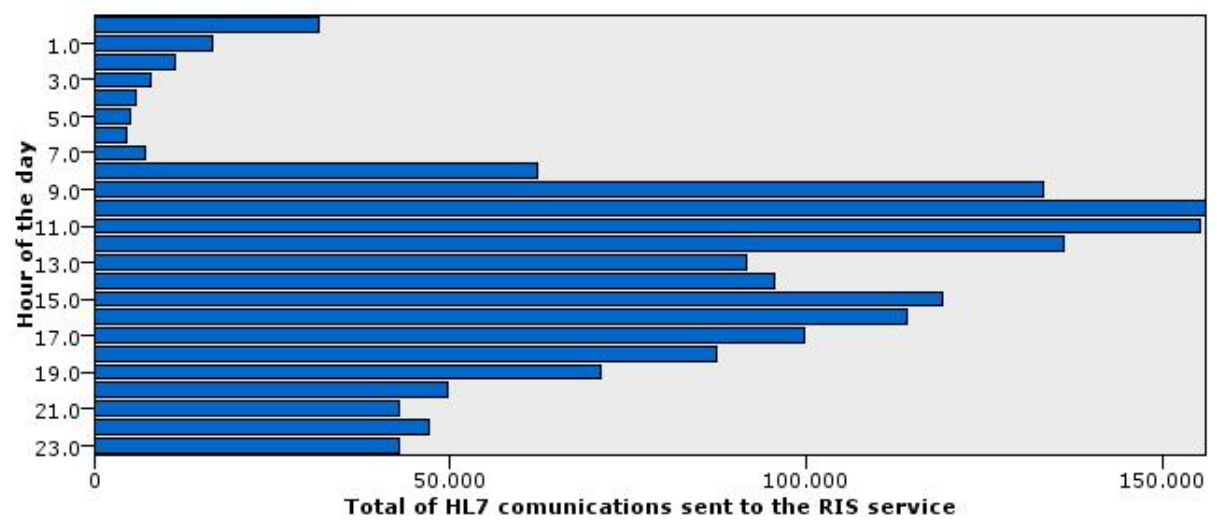

Figure B.1: Study of HL7 communications sent to the RIS service depending the time of the day.

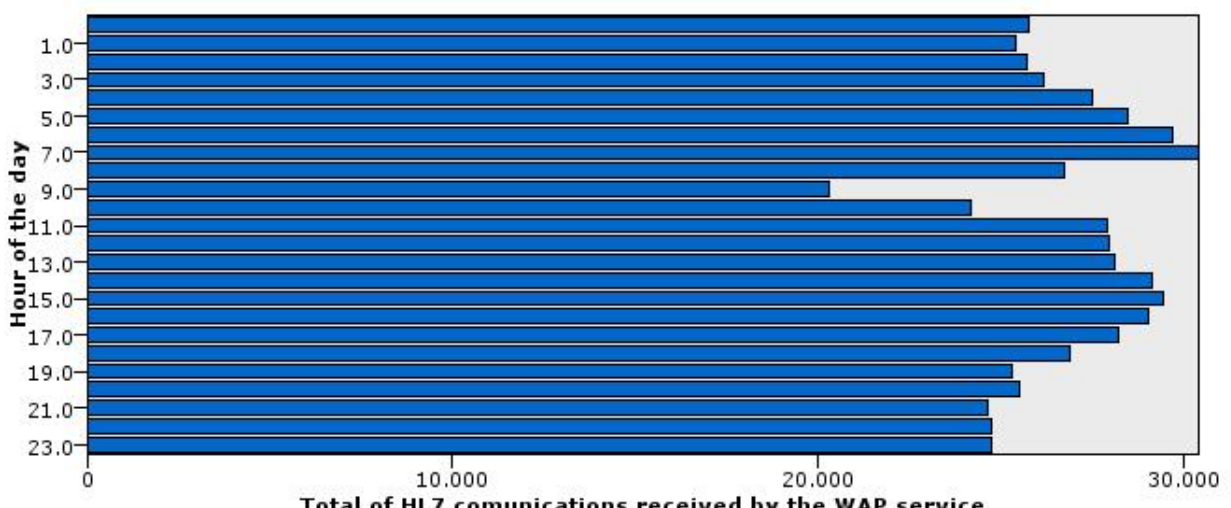

Figure B.2: Study of HL7 communications received by the WAP service depending the time of the day.

Henceforth, the learning approach to interoperation agents can or can not be 
segmented into daily periods of time depending on the usage of the specic service, this segmentation however is of the essence for the proper classication and prediction of bottlenecks or systematic failure.

\section{B.6 Modelling approaches}

The selected approaches are dictated by the objectives and associated problems of the matter in study. One of the main concerns in the healthcare environment, combined with the need to increase services availability and reliability, is the instant response to errors and failure. One of the problems, which can be modelled, seems to be the regular need to reset HL7 server connections due to the loss of communication and incapability of these systems to detect and react to correct any faults.

To understand the implications and complexity of the detection of these events consider the case of the communication between a RIS and the medical emergency software. Regardless of the requesting method implemented, if the performed exam information is being disseminated through HL7, the failure to communicate the radiological complementary diagnosis method requested is hard to detect even with heuristic methods. Systems with no intelligence can not determine by themselves wether or not the fact that an exam for example is not available is due to a loss of systems communication. This will require additional effort by the physicians and technicians to access the exam stored at the Picture Archive Communication System (PACS) using the Radiological Information System (RIS) as there is no information of its existence. In different words, it will be far more probable that the end user will be the rst in detecting the failure in the information workow via HL7. More than just radiological exams information is increasingly performed by HL7, medication, analysis and other services in the healthcare area are now integrated using HL7. In these cases more than revenue is at stake, the quality of the provided healthcare service may be harmed by this limitation. 
Table B.1: K-Means Clustering Centres - RIS Timespan Between HL7 Messages Study A.

\begin{tabular}{|c||c||c||c||c|}
\hline Cluster 1 & Cluster 2 & Cluster 3 & Cluster 4 & Cluster 5 \\
\hline 37,29 & 2766038,00 & 10103,55 & 64661,00 & 3254,04 \\
\hline
\end{tabular}

To predict the loss of communication and errors in the HL7 server service it is proposed to analyse the time between HL7 messages of each service. Although this study is limited to the proposal of approaches and methodologies, it will be validated against existing data of one of the most active services in an healthcare institution, the RIS. Regarding the time of study, it will concern two years of interoperation communication via HL7. In light of the objective aimed with this analysis and the previous knowledge of each services specicity, data must be segmented into services and time of day.

Considering the volume and attributes to analyse, from the available techniques to mine the existing data and extract patterns that might enable the induction of anomalous situations, clustering seemed to provide the most adequate set of tools. The objective was henceforth to create clusters of timespans between messages, which might allow the detection of values beyond the expected for a specic service on a give time. With this knowledge interoperation service agents could predict the loss of communication, warning system administrators and prevent the existence of incoherent information among supposedly integrated systems.

A rst study (Study A) was performed using the overall clustering of timespan data with the K-Means algorithm and 5 centroids. The resulting clustering information displayed in Table B.1 and Table B.2 showed that over 99\% of the cases were inside a single cluster with a rather low centroid. The maximum value within the mentioned Cluster 1 was of 1767 seconds, meaning that the maximum time between messages within this cluster was approximately under 30 minutes. The remaining cases could be considered as exceptional events with really high and high volume of them conciliated with the existing socket reset logs of the agent system. This 
Table B.2: Number of Cases in each Cluster - Study A

\begin{tabular}{|c||c|}
\hline Cluster 1 & 1590327 \\
\hline Cluster 2 & 1 \\
\hline Cluster 3 & 404 \\
\hline Cluster 4 & 1 \\
\hline Cluster 5 & 3391 \\
\hline Valid Cases & 1594124 \\
\hline
\end{tabular}

Table B.3: K-Means Clustering Centres - RIS Timespan Between HL7 Messages Between 8 A.M. and 8 P.M - Study B

\begin{tabular}{|c||c||c||c||c|}
\hline Cluster 1 & Cluster 2 & Cluster 3 & Cluster 4 & Cluster 5 \\
\hline 24,75 & 15382 & 620,29 & 2766038 & 64661 \\
\hline
\end{tabular}

indicates that this cases should be managed by the agent system as system failure and loss of communication.

However, considering the functional activity of the service being analysed, it is inferable by the study of the existing data that most of the activity is found within a limited daily time-frame. A comparative clustering study (Study B and Study C) using segmented data further displays this effect by the difference found in the rst and lowest timespan between messages centroid. Over $86 \%$ of the overall activity in this service was performed during the time frame of Study B, as on the Study C the activity of this service is limited to emergency or internment occurrences. This causes that the rst centroid has far lower value in the Study B than in the Study C.

Withdrawing conclusion over the values of the other centroids is rather hypothetical, however they are connected with the need of server reset or other complications to the ow of information. The one simultaneous fact considering the performance of an HL7 server and the workow of an healthcare service is the exis-

Table B.4: Number of Cases in each Cluster - Study B

\begin{tabular}{|c||c|}
\hline Cluster 1 & 1360928 \\
\hline Cluster 2 & 2 \\
\hline Cluster 3 & 10297 \\
\hline Cluster 4 & 1 \\
\hline Cluster 5 & 1 \\
\hline Valid Cases & 1371229 \\
\hline
\end{tabular}


Table B.5: K-Means Clustering Centres - RIS Timespan Between HL7 Messages Between 21 P.M. and 7 A.M - Study C

\begin{tabular}{|c||c||c||c||c|}
\hline Cluster 1 & Cluster 2 & Cluster 3 & Cluster 4 & Cluster 5 \\
\hline 82.40 & 2489.31 & 30637 & 6788.74 & 12779.25 \\
\hline
\end{tabular}

Table B.6: Number of Cases in each Cluster - Study C

\begin{tabular}{|c||c|}
\hline Cluster 1 & 218164 \\
\hline Cluster 2 & 3879 \\
\hline Cluster 3 & 3 \\
\hline Cluster 4 & 711 \\
\hline Cluster 5 & 711 \\
\hline Valid Cases & 222895 \\
\hline
\end{tabular}

tence of a distinct cluster of regular expected values that depends on the regularity of the ow of information. The cases within this cluster are with an high degree of certainty examples of regular performance within the service. Henceforth as the time between HL7 messages falls outside the limits of this cluster it indicates the existence of an error with the ow of information within this system. Further studies variating the number of clusters would still create a cluster with impressively higher concentration of cases and lower timespan.

\section{B.7 Embedding adaptive learning behaviours}

With the resulting model indicating that regular cases within the system interoperation process usually create a stable concentrated cluster, such concept can be embedded into the multi-agent system in order to evaluate the current behaviour of the service. On regular distant intervals the agent evaluates the distribution of the information ow determining wether the service has lower activity intervals. The segmentation of these intervals as demonstrated before is important to add more sensibility and accurate knowledge to the agent. Depending on this analysis it segments or not the data into different datasets running the clustering algorithm and extracting the centroids and boundaries expected to each cluster in each segmented 
dataset.

The HL7 server agents were imbedded within this knowledge and as the timespan between messages approximates the upper boundary of the lowest centroid it generates warnings to the system administrators. However, when the server agent detects that it has left the upper boundary for this cluster it runs incrementally networking and thread reset/cleaning procedures.

\section{B.8 Conclusion}

With the massive introduction of information systems within healthcare institutions the relevance of the quality of the information they provide and the reliability in their performance became an essential requirement. As secluded systems ultimately work as hidden repositories of information the process of interoperation between all systems is an important directive in HIS management policies. However, as interoperation becomes a regular process the breakdown of these processes greatly diminishes the quality of information available. For this reason, embedding intelligent behaviours in order to enable to predict, prevent and correct such complications is an opportunity to both study the boundaries of intelligent agents and to improve the quality of service within healthcare interoperability.

The study of past interoperability processes indicates clustering the corresponding data, when the system is in full working production environment, a main cluster with the regular time between information exchange. This fact is understandable considering that a stable and working HL7 server will process this messages in regular intervals and will rarely loose socket connections, although that will eventually happen resulting in abnormal timespans between messages until the end user or system administrator notice and correct this factor.

This model that was embedded into the agent based HL7 server is a simple 
example how unsupervised learning capabilities when properly explored can be of use to improve the quality of existing software and add new perspectives on how to address important limitations. The introduction of such models adds both an ability to the agent to adapt and possibly improve their actuation over the environment they are inserted in, but also add a certain degree of unpredictability that on other areas of healthcare could result in complex issues. Although most of these virtual agents are still rather limited in learning, adaptation and autonomy, displaying solely reactance to predicted or programmed events, current research methodologies for embedding further intelligence as the proposed open for learning virtual entities. As virtual entities intervene in decision making processes with moral weight, a justied doubt and concern regarding the impact of actions performed by these entities arises. From the numerous scenarios where they can interact with their surrounding environment, some carry moral consequences and describe ethically intricate actions from a human point of view.

Although the main objective was to add a new tool to agent based systems directed towards interoperability, the resulting knowledge isnt only important to these agent based systems. The resulting models reveal tendencies of interoperability procedures within the distinct services and the importance of the distribution of work, which are the cornerstone to understand the usual behaviour of personnel and the ow of information within the information system. Knowledge regarding these subjects is vital to evaluate and improve existing procedures, as well a to detect bottlenecks that undermine the response of the HIS.

Due to this study, the response time of the HL7 services based on multi-agent paradigms and their results were proven to be considerably low. Although no direct comparison can be established, the introduction of intelligent behaviours associated to a good response time demonstrate the potential of this technology towards system interoperability. Furthermore, the recent evolution of HL7 from a syntactic to a semantic paradigm adapts with the perspective of agent-communication paradigm 
and are an interesting area of current research.

Further techniques must be studied and embedded in current production systems in order to validate their usefulness and the potential to result in agents with the capability to adapt to changes in their environment, perceiving data in a different perspective from human agents. In fact, with the implemented model agents can adapt to changes in the existing environment with far more condence that system administrators can predict the behaviour of the HIS.

\section{B.9 Acknowledgements}

This research was performed with the support of the Portuguese Foundation for Science and Technology, with the grant SFRH/BD/65023/2009.

\section{B.10 References}

[B - I]. Aier, S., Schonherr, M.: Evaluating integration architectures a scenario - based evaluation of integration technologies. Trends in Enterprise Application Architecture pp. 214 (2006).

[B - II]. Berg, M.: Health Information Management: Integrating Information Technology in Health Care Work. Routledge (2004).

[B - III]. Duarte, J., Miranda, M.F.M., Abelha, A., Santos, M., Machado, J., Neves, J., Alberto, C., Salazar, M., Quintas, C., Ferreira, A.M.S.F., Neves, J.: Agent-based group decision support in medicine. In: H.R. Arabnia, D. de la Fuente, J.A. Olivas (eds.) IC-AI, pp. 115121. CSREA Press (2009).

[B - IV]. Erl, T.: Service-Oriented Architecture: Concepts, Technology, and Design. Prentice Hall PTR (2005). 
[B - V]. Isern, D., Sanchez, D., Moreno, A.: Agents applied in health care: A review. International Journal of Medical Informatics 79(3), 145166 (2010).

[B - VI]. Juric, M.B., Loganathan, R., Sarang, P., Jennings, F.: SOA Approach to Integration - XML, Web services, ESB, and BPEL in real-world SOA projects. PACKT Publishing (2007).

[B - VII]. Kirsh, W. (ed.): Encyclopedia of Public Health, vol. 1. Springer Science (2008).

[B - VIII]. Lopez, D.M., Blobel, B.G.: A development framework for semantically interoperable health information systems. International Journal of Medical Informatics 78(2), 83103 (2009). DOI DOI: 10.1016/j.ijmedinf.2008.05.009

[B - IX]. Machado, J., Abelha, A., Novais, P., Neves, J.: Quality of service in healthcare units. European Simulation and Modelling Conference 2008 pp. 291298 (2008). Bertelle, C Ayesh, A European Simulation and Modelling Conference OCT 27-29, 2008 European Technol Inst, Havre, FRANCE.

[B - X]. Machado, J., Alves, V., Abelha, A., Neves, J.: Ambient intelligence via multiagent systems in the medical arena. Engineering Intelligent Systems for Electrical Engineering and Communications 15(3), 151157 (2007).

[B - XI]. Miranda, M.F.M., Abelha, A., Santos, M., Machado, J., Neves, J.: A group decision support system for staging of cancer. In: D. Weerasinghe (ed.) eHealth, Lecture Notes of the Institute for Computer Sciences, Social Informatics and Telecommunications Engineering, vol. 1, pp.114121. Springer (2008).

[B - XII]. Ohe, K., Kaihara, S.: Implementation of hl7 to client-server hospital information system (his) in the university of tokyo hospital. Journal of Medical Systems 20(4), 197205 (1996).

[B - XIII]. PHII: Guiding principles for effective health information systems. Public Health Informatics Institute, Decatur Institute, GA (2004). 
[B - XIV]. Weiss (ed.): Multiagent Systems A Modern Approach to Distributed Modern Approach to Articial Intelligence. MIT Press, Cambridge, Massachusetts - London, England (1999). 